\title{
JONAS TAKADA
}

Contribuição da drenagem ecoguiada à paliação endoscópica da obstrução biliar maligna

Tese apresentada à Faculdade de Medicina da Universidade de São Paulo para obtenção do título de Doutor em Ciências

Programa de: Clínica Cirúrgica

Orientador: Prof. Dr. Everson Luiz de Almeida Artifon 
Dados Internacionais de Catalogação na Publicação (CIP)

Preparada pela Biblioteca da

Faculdade de Medicina da Universidade de São Paulo

Creprodução autorizada pelo autor

\section{Takada, Jonas}

Contribuição da drenagem ecoguiada à paliação endoscópica da obstrução biliar maligna / Jonas Takada. -- São Paulo, 2012.

Tese(doutorado)--Faculdade de Medicina da Universidade de São Paulo.

Programa de Clínica Cirúrgica.

Orientador: Everson Luiz de Almeida Artifon.

Descritores: 1.Ecoendoscopia 2.Neoplasias do sistema biliar 3.Obstrução das vias biliares 4.Drenagem 5.Cuidados paliativos

USP/FM/DBD-258/12 


\section{DEDICATÓRIA}

Aos meus pais, Torao Takada e Elisa Midori Kajiwara Takada.

Às minhas irmãs, Sheilla, Nanci e Cintia.

À minha parceira querida, Lucimara Salvalagio. 


\section{AGRADECIMENTOS}

Ao Prof. Dr. Everson Luiz de Almeida Artifon, orientador incansável, perseverante, que sempre me incentivou. Pelos inúmeros ensinamentos na minha formação como endoscopista e pessoa, por ter acreditado em minha capacidade desde o início desse trabalho.

Ao Prof. Dr. Paulo Sakai, por estar sempre presente nas atividades do serviço, pelos inúmeros ensinamentos repassados durante a minha formação e pela grande personalidade que lhe é peculiar.

Ao Prof. Dr. Eduardo Guimarães Hourneaux de Moura, pelo incansável empenho no aperfeiçoamento de todos que passam pelo Serviço de Endoscopia, pela colaboração e estímulo nas diferentes etapas de realização deste trabalho.

Ao Prof. Dr. Samir Rasslan, Chefe do Departamento de Clínica Cirúrgica, pelo incentivo, colaboração e permissão na elaboração deste trabalho.

Ao Prof. Dr. Luiz Francisco Poli-de-Figueiredo (in memoriam), pela honra de ter sido meu orientador inicial e de quem recebemos o aprendizado de compartilhar sempre a amizade e respeito no meio acadêmico, pessoal e profissional. 
Aos Profs. Drs. Rolf Gemperli e Edna Frasson Montero, pela oportunidade de realizar a Pós-Graduação no Departamento de Cirurgia da Faculdade de Medicina da Universidade de São Paulo.

Aos médicos assistentes do Serviço de Endoscopia Digestiva do Hospital das Clínicas da Faculdade de Medicina da Universidade de São Paulo, pela qualidade dos ensinamentos prático-científicos, pela grande amizade e oportunidades tão importantes em minha formação como pessoa e profissional.

Aos funcionários da secretaria e enfermagem do Serviço de Endoscopia do Hospital das Clínicas da Faculdade de Medicina da Universidade de São Paulo, pelo apoio e prestação de importantes serviços aos pacientes e ao meu trabalho.

As secretárias Eliane e Márcia, do Programa de Pós-Graduação da Clínica Cirúrgica do Departamento de Cirurgia da Faculdade de Medicina da Universidade de São Paulo, pela orientação e ajuda tão importantes para a condução e realização desta tese.

Aos meus amigos Flávio Ferreira e Luciano Okawa, pela ajuda e participação imprescindíveis na elaboração deste trabalho.

Aos pacientes, pelo depósito de sua confiança e credibilidade em minha capacidade. 
Esta tese está de acordo com as seguintes normas, em vigor no momento desta publicação:

Referencias: adaptado de International Committee of Medical Journals Editors (Vancouver).

Universidade de São Paulo. Faculdade de Medicina. Serviço de Biblioteca e Documentação. Guia de apresentação de dissertações, teses e monografias.

Elaborado por Anneliese Carneiro da Cunha, Maria Julia de A. L. Freddi, Maria F. Crestana, Marinalva de Souza Aragão, Suely Campos Cardoso, Valéria Vilhena. $3^{a}$ ed. São Paulo: Divisão de Biblioteca e Documentações; 2012.

Abreviatura dos títulos dos periódicos de acordo com List of Journals Indexed in Index Medicus. 


\section{SUMÁRIO}

Lista de abreviaturas e siglas

Lista de figuras

Lista de tabelas

Resumo

Summary

1 INTRODUÇÃO

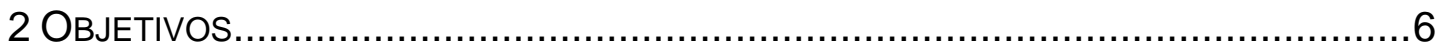

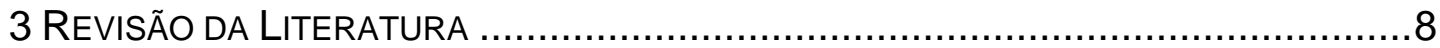

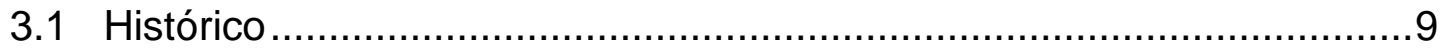

3.2 Indicações............................................................................ 11

3.3 Técnicas de Drenagem Descritas .................................................12

3.3.1 Drenagem anterógrada e transpapilar (rendez-vous ecoguiado) .....16

3.3.2 Hepatogastrostomia (acesso intra-hepático, transmural) ................23

3.3.3 Coledocoduodenostomia (acesso extra-hepático, transmural).........26

3.3.4 Acesso ecoguiado em casos de anatomia alterada do trato gastrointestinal .............................................................. 30

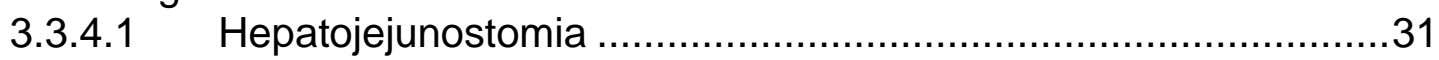

3.3.4.2 Coledocoantrostomia ..................................................... 31

3.4 Complicações e Opções de Tratamento ..........................................32

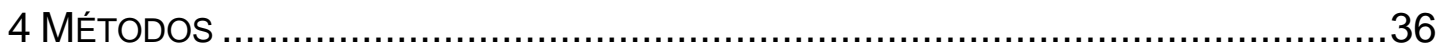

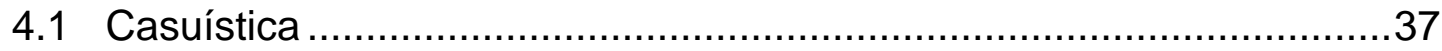

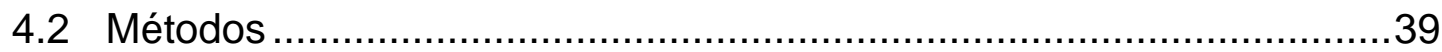

4.2.1 Conceitos de Eficácia e Segurança..............................................39

4.2.2 Indicação do Procedimento .................................................. 40

4.2.3 Dados clínicos prévios ao procedimento ...................................40

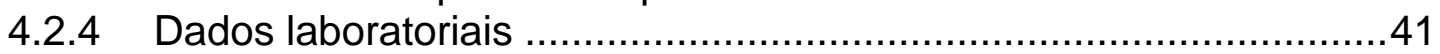

4.2.5 Caracterização de irressecabilidade ....................................... 42

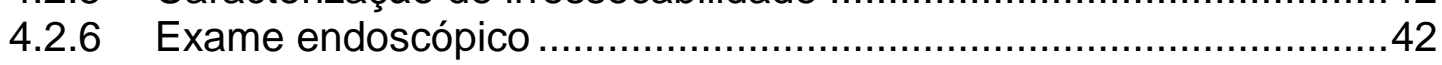

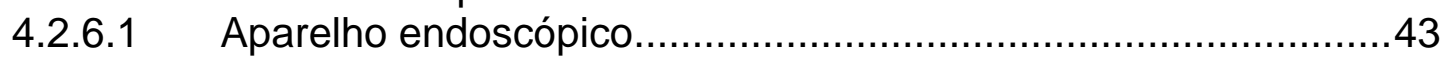

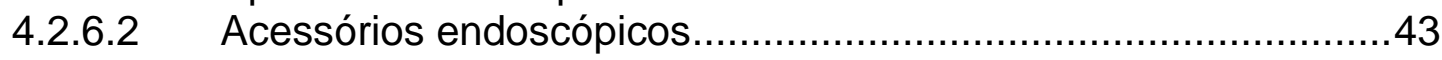

4.2.6.3 Equipamento de radioscopia............................................... 47

4.2.6.4 Preparo e técnica do exame endoscópico .............................48

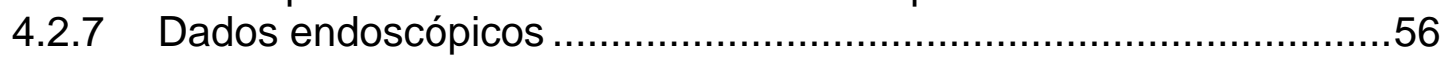

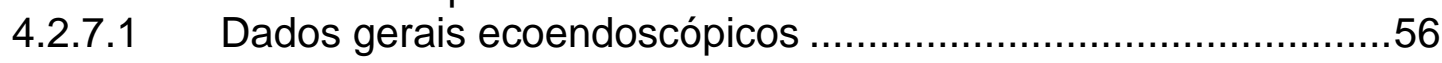

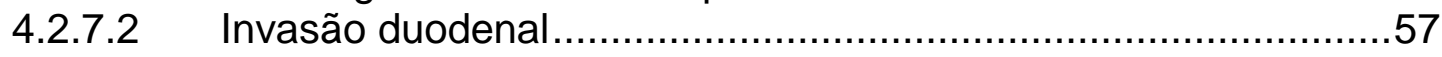

4.2.8 Caracterização das complicações relacionadas ao procedimento ...58

4.2.9 Seguimento do paciente .....................................................59

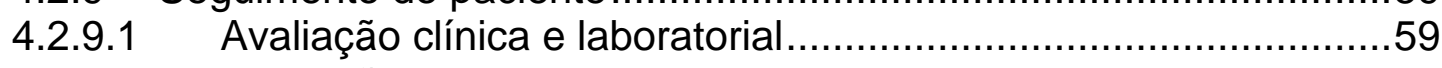

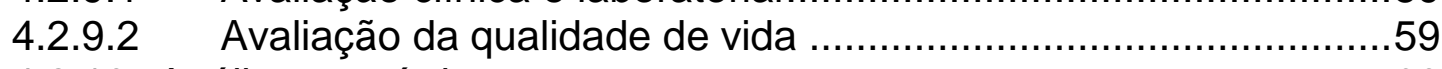

4.2.10 Análise estatística ............................................................60 


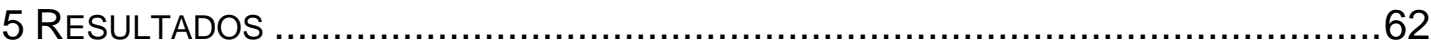

5.1 Dados Endoscópicos ...............................................................64

5.1.1 Dados gerais ecoendoscópicos.............................................64

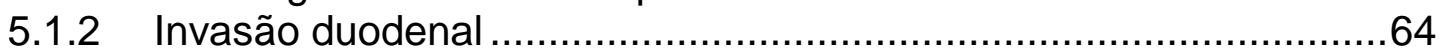

5.1.3 Dados do procedimento ecoguiado de drenagem .......................66

5.2 Complicações Relacionadas ao Procedimento .................................66

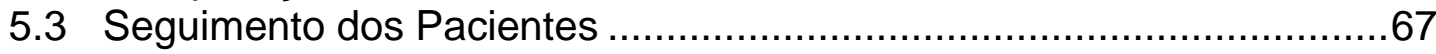

5.3.1 Avaliação clínica................................................................. 67

5.3.2 Avaliação laboratorial ...........................................................68

5.3.3 Avaliação da qualidade de vida .............................................. 70

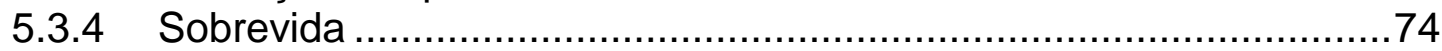

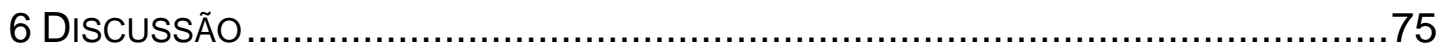

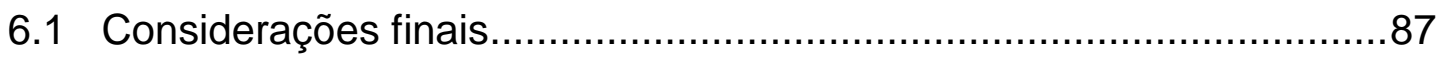

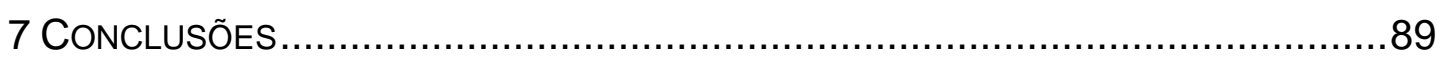

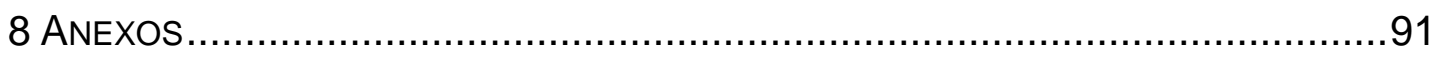

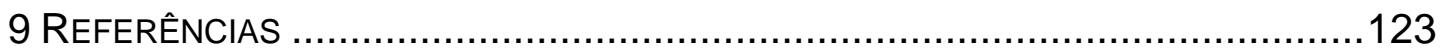




\section{LISTA DE ABREVIATURAS E SIGLAS}

$\begin{array}{ll}\text { CAPPesq } & \text { - Comissão de Ética para Análise de Projetos de Pesquisa } \\ \text { CDT } & \text { - Coledocoduodenostomia } \\ \text { CPRE } & \text { - Colangiopancreatografia retrógrada endoscópica } \\ \text { CRNM } & - \text { Colangiorressonância magnética } \\ \text { DBC } & - \text { Ducto biliar comum } \\ \text { DBE } & - \text { Drenagem biliar ecoguiada } \\ \text { DPTH } & - \text { Drenagem percutânea transhepática } \\ \text { EGS } & - \text { Estado geral de saúde } \\ \text { HC-FMUSP } & - \text { Hospital das Clínicas da Universidade de São Paulo } \\ \text { HGT } & - \text { Hepaticogastrostomia } \\ \text { TC } & - \text { Tomografia computadorizada } \\ \text { USE } & - \text { Ultrassonografia endoscópica }\end{array}$




\section{LISTA DE FIGURAS}

Figura 1 - Abordagens de drenagem biliar ecoguiada, que combinam duas vias de acesso possíveis com três vias de drenagem

Figura 2 - Imagem radiológica da via biliar contrastada após punção ecoguiada, demonstrando opacificação bemsucedida do ducto intra e extra-hepático

Figura 3 - Imagem radiológica do fio-guia posicionado na árvore biliar transpondo a área de estenose

Figura 4 - Imagem radiológica de videoduodenoscópio na segunda porção duodenal, recuperando o fio-guia posicionado por meio da técnica ecoguiada.

Figura 5 - Imagem radiológica da prótese metálica na via biliar inserida de maneira retrógrada pela técnica de rendezvous

Figura 6 - Imagem radiológica de prótese metálica transpondo a área de estenose após a técnica de drenagem anterógrada ecoguiada

Figura 7 - Imagem sequencial da técnica de hepatogastrostomia realizada em paciente com tumor de Klatskin. Observar o posicionamento prévio de prótese metálica no ducto hepático direito, o que torna o sistema biliar esquerdo inacessível à CPRE.

Figura 8 - Imagem de agulha de 19 gauges inserida através da parede duodenal no ducto biliar sob visualização endossonográfica

Figura 9 - Imagem radiológica da via biliar contrastada após punção ecoendoscópica

Figura 10 - (A) Imagem radiológica de prótese metálica autoexpansível posicionada por meio da técnica de coledocoduodenostomia no ducto biliar extra-hepático; (B) imagem endoscópica da extremidade distal da prótese metálica na parede duodenal

Figura 11 - Imagem de agulha flexível e condutora de corrente elétrica tipo needle-knife. 
Figura 12 - Agulha de acesso tipo Echotip, da Cook Company. Quando se obtém o acesso ao ducto biliar, o estilete pode ser removido e a agulha de ponta romba deixada no local, aumentando a capacidade de manipulação do fio-guia por meio do canal da agulha

Figura 13 - Imagem de próteses metálicas autoexpansíveis não recoberta e parcialmente recoberta, da esquerda para a direita, respectivamente

Figura 14 - Imagem de prótese metálica autoexpansível totalmente recoberta

Figura 15 - Sistema de introdução de prótese metálica autoexpansível

Figura 16 - Sequência de imagens ilustrando uma hepaticogastrostomia ecoguiada

Figura 17 - Sequência de imagens ilustrando uma coledocoduodenostomia ecoguiada

Figura 18 - Coledocoantrostomia - Punção da via biliar extrahepática e injeção de contraste (colangiografia)

Figura 19 - Coledocoantrostomia - Imagem endoscópica da prótese biliar no antro distal

Figura 20 - Coledocoantrostomia - Imagem radiológica da recanalização biliar por prótese metálica parcialmente coberta (aspecto final)

Figura 21 - Imagem radiológica da técnica de rendez-vous ecoguiado, demonstrando a passagem do fio-guia através da estenose biliar e em direção ao duodeno

Figura 22 - Imagem endoscópica da técnica de rendez-vous ecoguiado, demonstrando o fio-guia exteriorizado na região da papila duodenal maior

Figura 23 - Sequência de imagens radiológicas ilustrando a técnica de drenagem ecoguiada anterógrada extra-hepática em paciente com estenose biliar maligna e gastrectomia subtotal com reconstrução em Y-de-Roux .56

Figura 24 - (A) imagem endoscópica de infiltração duodenal secundária ao tumor pancreático; (B) imagem endoscópica de prótese metálica em bulbo duodenal, caracterizando fistulização biliar por coledocoduodenostomia; (C) imagem radiológica da prótese metálica biliar e duodenal e (D) imagem endoscópica da prótese metálica duodenal 


\section{LISTA DE TABELAS}

Tabela 1 - Características demográficas dos pacientes em estudo .38

Tabela 2 - Descrição das características clínicas e pessoais avaliadas antes do procedimento

Tabela 3 - Descrição dos exames ao longo do seguimento e resultado dos testes comparativos

Tabela 4 - Resultado das comparações multivariada dos parâmetros laboratoriais entre os momentos de avaliação

Tabela 5 - Descrição dos escores de qualidade de vida em cada domínio ao longo do seguimento e resultado dos testes comparativos

Tabela 6 - Tabela demonstrando o resultado das comparações múltiplas dos escores de qualidade de vida para os domínios capacidade funcional, saúde física, dor e Estado Geral de Saúde entre os momentos de avaliação

Tabela 7 - Resultado das comparações múltiplas dos escores de qualidade de vida para os domínios vitalidade, aspectos sociais, aspectos emocionais e saúde mental entre os momentos de avaliação

Tabela 8 - Descrição do tempo de sobrevida dos pacientes .74 


\section{RESUMO}

Takada J. Contribuição da drenagem ecoguiada à paliação endoscópica da obstrução biliar maligna [tese]. São Paulo: Faculdade de Medicina, Universidade de São Paulo; 2012.

Introdução: a maioria dos pacientes com neoplasia maligna da via biliar são diagnosticados em fase avançada. A drenagem biliar ecoguiada é uma alternativa às técnicas de drenagem percutânea trans-hepática e cirúrgicas na ocasião de falha do acesso convencional por colangiografia retrógrada endoscópica (CPRE). Objetivo: avaliar a eficácia e segurança da drenagem biliar ecoguiada em pacientes com obstrução biliar maligna e falha da CPRE. Analisar as complicações e qualidade de vida. Métodos: no período de abril de 2010 a setembro de 2011, 32 pacientes portadores de neoplasia maligna avançada da via biliar foram tratados no Serviço de Endoscopia Gastrointestinal do Hospital das Clínicas da Faculdade de Medicina da Universidade de São Paulo. Todos os pacientes apresentavam quadro clínico de icterícia obstrutiva e falha na drenagem da via biliar pela CPRE. O tratamento preconizado foi a drenagem da via biliar pela técnica ecoguiada, sob controle radiológico. Dos 32 pacientes, três foram excluídos devido à falha do procedimento ecoguiado. Vinte e nove $(90,62 \%)$ pacientes foram submetidos a drenagem biliar ecoguiada, avaliações clínica, laboratorial e de qualidade de vida. $\mathrm{Na}$ avaliação clínica foram observados a evolução dos sinais e sintomas, e complicações relacionadas ao procedimento. $\mathrm{Na}$ avaliação laboratorial, foram analisados os níveis de bilirrubina total, gamaglutamil-transferase, fosfatase alcalina e número de leucócitos. A qualidade de vida foi avaliada pelo questionário SF-36. Resultados: dos 32 pacientes,3 $(9,4 \%)$ foram excluídos devido a falha técnica. O sucesso técnico foi de 90.6\% (29/32) e o clínico de 100\% (29/29). Em relação aos dados gerais endossonográficos, verificou-se metástase à distância em 6 
(18,75\%) e invasão do eixo mesentero-portal em $26(81,25 \%)$ pacientes. $O$ diâmetro da via biliar extra-hepática apresentou mediana de 23,45 mm (20 $30 \mathrm{~mm}$ ) e da intra-hepática foi de 17,54 mm (10 - $24 \mathrm{~mm})$. A invasão duodenal ocorreu em $10(31,25 \%)$ pacientes e prótese metálica foi posicionada em $7(21,85 \%)$ casos. A coledocoduodenostomia ecoguiada foi o procedimento mais frequente $(58,62 \%)$. Complicações ocorreram em 6 $(18,75 \%)$ casos. Verificou-se uma queda significativa dos níveis de bilirubina $(p<0,001)$ e os pacientes obtiveram melhora significativa da qualidade de vida após o procedimento $(p<0,05)$. A sobrevida média foi de 90 dias. Conclusão: a drenagem biliar ecoguiada foi um procedimento eficaz e seguro, com taxa de complicações aceitável, proporcionando melhora significativa na qualidade de vida dos pacientes.

Descritores: Ecoendoscopia. Neoplasia biliar. Obstrução. Drenagem. Paliação. 


\section{SUMMARY}

Takada J. Contribution of echoguided drainage in the endoscopic palliation of malignant biliary obstruction [thesis]. São Paulo: Faculdade de Medicina, Universidade de São Paulo; 2012.

Introduction: most of patients with malignant neoplasia of the biliary tract are diagnosed at an advanced stage. Echoguided biliary drainage is an alternative to percutaneous transhepatic and surgical drainage techniques at the time of failure of conventional access by endoscopic retrograde cholangiography (ERCP). Objective: to evaluate the efficacy and safety of echoguided biliary drainage in patients with malignant biliary obstruction and failure of ERCP. To evaluate the complications and quality of life. Methods: from April 2010 to September 2011, 32 patients with advanced malignant biliary tract disease were treated at the Gastrointestinal Endoscopy Service, Clinics Hospital, Faculty of Medicine, University of Sao Paulo. All patients had a clinical picture of obstructive jaundice and failure in the drainage of the biliary tract by ERCP. Treatment was based on echoguided biliary drainage technique under radiological control. Of the 32 patients, three were excluded due to failure of the echoguided procedure. Twenty-nine (90.62\%) patients underwent echoguided biliary drainage, clinical, laboratory and quality of life evaluation. In the clinical evaluation were assessed the evolution of signs and symptoms, and procedure-related complications. In laboratory tests, we assessed the levels of total bilirubin, gamma glutamyl transferase, alkaline phosphatase and number of leukocytes. The quality of life was assessed by SF-36 questionary. Results: of 32 patients, three (9.4\%) were excluded due to technical failure. Technical success was $90.6 \%$ (29/32) and clinical $100 \%$ (29/29). In relation to the general endosonographic data, there was distant metastasis in $6(18.75 \%)$ and invasion of the mesenteric-portal axis in 26 $(81.25 \%)$ patients. The diameter of extrahepatic biliary tree was $23.45 \mathrm{~mm}$ 
(20 - 30mm) and intrahepatic was $17.54 \mathrm{~mm}(10-24 \mathrm{~mm})$. The duodenal invasion occurred in $10(31.25 \%)$ and metallic prosthesis was positioned in 7 (21.85) cases. Echoguided choledochoduodenostomy was the most common procedure $(58.62 \%)$. Complications occurred in $6(18.75 \%)$ cases. There was a significant decrease in bilirubin levels $(p<0.001)$ and patients had significant improvement in quality of life after the procedure $(p<0.05)$. The median survival was 90 days. Conclusion: echoguided biliary drainage was effective and safe procedure with acceptable complication rates, providing significant improvement in quality of life of patients.

Descriptors: Endoscopic ultrasound. Biliary cancer. Obstruction. Drainage. Palliation. 
1 INTRODUÇÃO 
A maioria dos pacientes com neoplasia maligna das vias biliares é diagnosticada em fase avançada da doença. No momento do diagnóstico, cerca de $85 \%$ deles não são candidatos ao tratamento cirúrgico com intenção curativa (Boring et al., 1994; Bergasa et al., 2006). Mesmo após ressecção cirúrgica como medida paliativa, os resultados a longo prazo são insatisfatórios, com taxas de sobrevida de cinco anos, variando entre $10 \%$ a 29\% (Trede, 1987).

Devido ao diagnóstico tardio e à extensão das lesões, os pacientes com neoplasias malignas da via biliar, em grande parte, apresentam-se ictéricos no momento do diagnóstico. O alívio da icterícia de padrão obstrutivo torna-se, portanto, essencial, na medida em que a estase biliar não tratada pode levar a quadro clínico caracterizado por prurido, anorexia, colangites de repetição, disfunção hepática e mesmo óbito precoce (Hatfield, 1990).

Em virtude de sua eficácia e da baixa morbimortalidade, a Colangiopancreatografia Retrógrada Endoscópica (CPRE) com passagem de prótese biliar é, atualmente, o método de escolha para o tratamento paliativo da icterícia obstrutiva nestes pacientes, com uma taxa de sucesso terapêutico de 90\% (Huibregtse et al., 1995). Entretanto, a CPRE pode falhar em $5 \%$ a $10 \%$ dos casos e, assim, o passo seguinte recomendado é a 
repetição do procedimento por um endoscopista sênior em um centro de referência terciário (Kumar et al., 1995).

Uma vez que o videoduodenoscópio alcança a segunda porção duodenal, aspectos técnicos que dificultam a canulação convencional da papila maior determinam, via de regra, o insucesso da CPRE. As dificuldades técnicas de manipulação terapêutica da via biliar por CPRE podem ser relacionadas também à dificuldade de passagem do fio guia pela lesão, "canulação difícil", alterações anatômicas peculiares à confluência biliopancreática ou mesmo derivações cirúrgicas biliodigestivas, situação esta em que o acesso do aparelho não é factível. A infiltração tumoral da papila ou mesmo do duodeno complementa as situações de dificuldade ao acesso biliopancreático convencional (Martin, 1994; Lobo, 1998).

Como já destacado, anatomia alterada por estenose tumoral ou cirurgia prévia pode impedir a progressão do aparelho, como ocorre em pacientes com gastrectomia total, gastrectomia parcial com reconstrução em Y de Roux e gastroplastia redutora, dentre outras (Wright et al., 2002). Este obstáculo pode ser superado pelo uso de enteroscópios de balão único ou duplo; entretanto é uma modalidade terapêutica trabalhosa, e a limitada disponibilidade de acessórios apllicados à enteroscopia tem levado a taxas de insucesso entre $2 \%$ a $40 \%$ (Aabakken et al., 2007; Chu et al., 2008).

Derivações cirúrgicas com o intuito de estabelecer continuidade entre o trato biliar obstruído e o trato gastrointestinal têm sido praticadas tanto em pacientes com maior expectativa de sobrevida quanto naqueles que se mostram com doença avançada no momento da cirurgia com intenção 
curativa. Comparada ao procedimento endoscópico, a modalidade cirúrgica tem demonstrado taxas de morbidade e mortalidade de $30 \%$ e $10 \%$, respectivamente (Trede, 1987; Boring et al., 1994).

No contexto de procedimentos minimamente invasivos, a Drenagem Percutânea Transhepática (DPTH) é alternativa praticada em pacientes que não são candidatos à CPRE. Porém, a DPTH está associada a complicações que podem chegar a $30 \%$ dos casos, destacando-se fístula biliar, hemorragia e abscesso hepático (Ferrucci et al., 1980; Harbin et al., 1980). Na situação peculiar de uma drenagem interna não ser possível, os pacientes submetidos a este método acabam por ter de conviver com dreno externo, que promove a perda não fisiológica de suco biliar, aliado ao desconforto do paciente e à dificuldade de manipulação do dispositivo, prejudicando de maneira considerável a qualidade de vida.

Com a finalidade de suplantar a taxa de falha da CPRE em situações peculiares e os altos índices de morbimortalidade que existem nos métodos alternativos de acesso biliar minimamente invasivo (DPTH e derivações biliodigestivas), destaca-se procedimento endoscópico que utiliza ultrassonografia endoscópica terapêutica, combinada com bases técnicas de CPRE convencional, proporcionando alternativa para a descompressão ductal (Kahaleh et al., 2006). Esta técnica denominada Drenagem Biliar Ecoguiada (DBE) tem sido reportada às custas de séries de publicações verificadas na literatura.

O presente estudo vislumbra agregar informações técnicas relativas ao procedimento de $\mathrm{DBE}$, bem como aspectos de melhora clínica do 
paciente em condição de tratamento paliativo e, com isso, contribuir com a solidificação do procedimento endoscópico ecoguiado em nosso meio e na literatura. 
2 Objetivos 
Avaliar a eficácia e segurança da DBE em pacientes com obstrução biliar maligna e com falha da colangiografia endoscópica retrógrada prévia. Analisar as complicações e o impacto na qualidade de vida. 
3 REVISÃo dA LITERATURA 


\subsection{Histórico}

A técnica de DBE é um procedimento híbrido que surgiu a partir do desenvolvimento de dois procedimentos bem estabelecidos: a CPRE e a ecoendoscopia convexa linear com punção aspirativa por agulha fina (PerezMiranda et al., 2010).

Em relação à CPRE, é o método padrão-ouro na terapêutica da obstrução biliar realizada há décadas, o que levou à grande experiência da equipe médica e à criação de vários instrumentais endoscópicos, que tornaram a terapêutica endoscópica um procedimento bem-sucedido e com baixa taxa de complicações (Fogel et al., 2001; Schöfl, 2001; Vila et al., 2012).

Com o advento do ecoendoscópio convexo linear em meados dos anos 1990, observou-se que seria possível a terapêutica cirúrgicoendoscópica em estruturas observadas em tempo real por meio da janela ultrassonográfica, em conjunto com o desenvolvimento de canais de trabalho de maior calibre acoplados ao aparelho. Isso permitiu que, em um primeiro momento, fosse aprimorada a técnica de biópsia mediante a aspiração por agulha fina (Carr-Locke, 2002). Assim, observando-se a proximidade do sistema hepatobiliar com as paredes do trato gastrointestinal alto e, ainda, associando a experiência da ecoendoscopia intervencionista com o arsenal de instrumental terapêutico e as habilidades adquiridas com a CPRE, 
aventou-se a possibilidade da colangiografia ecoguiada nos casos em que a CPRE se mostrasse malsucedida no acesso às afecções biliopancreáticas (Perez-Miranda et al., 2010).

Wiersema et al. (1996) publicaram a primeira série de sete pacientes submetidos às colangiografias ecoguiadas bem-sucedidas após falha da CPRE. Foi o marco necessário para que a ecoendoscopia fosse aceita como um método diagnóstico invasivo no estudo da via biliar. Contudo, os procedimentos desta série não contemplaram a drenagem ecoguiada com passagem de prótese biliar.

Assim, Giovannini et al. (2001) publicaram o primeiro caso de drenagem da via biliar com a técnica ecoguiada, realizando fistulização entre o bulbo duodenal e a via biliar extra-hepática (procedimento denominado coledocoduodenostomia) por meio da inserção de uma prótese plástica em um paciente com neoplasia irressecável de pâncreas.

Em seguida ao primeiro relato de coledocoduodenostomia ecoguiada, várias séries documentaram a DBE como um procedimento alternativo à drenagem cirúrgica ou percutânea transhepática diante do insucesso da CPRE. Um avanço alternativo relevante nesse conceito foi o desenvolvimento da técnica de rendez-vous ecoguiado (passagem anterógrada de um fio-guia pela papila ou anastomose biliodigestiva) para a obtenção da colangiografia retrógrada, conceito este introduzido por Mallery et al. em 2004. Nessa ocasião, o ducto pancreático foi puncionado, um fio-guia introduzido em sentido anterógrado até a região da papila duodenal e captado pelo canal de um videoduodenoscópio convencional para a realização da canulação retrógrada. 
Convém lembrar que a literatura pertinente a este tema tem demonstrado várias rotas de acesso transmural ecoguiado, com intuito de criar uma recanalização não anatômica entre a via biliar e o lúmen gastrointestinal.

\subsection{Indicações}

método deve ser considerado somente em pacientes sintomáticos com obstrução confirmada da via biliar, submetidos previamente à CPRE malsucedida (Kahaleh et al., 2006). Nestes casos, as afecções malignas são a principal indicação. Em relação às indicações dos procedimentos de DBE, pode-se dizer que:

- O procedimento tipo hepatogastrostomia é apropriado na obstrução do hilo hepático com dilatação mínima do ramo intra-hepático esquerdo de $8 \mathrm{~mm}$ (Artifon et al., 2007).

- O procedimento tipo coledocoduodenostomia é pertinente na obstrução distal do confluente biliopancreático com dilatação mínima de $10 \mathrm{~mm}$ a montante da estenose (Kahaleh et al., 2006).

- Os procedimentos tipo hepatojejunostomia ou coledocoantrostomia em derivações biliodigestivas prévias são indicados em obstrução biliar intra ou extra-hepática e podem ser a primeira opção de acesso biliar endoscópico, haja vista a impossibilidade do videoduodenoscópio alcançar a segunda porção duodenal de modo retrógrado convencional (Artifon et al., 2011a). 


\subsection{Técnicas de Drenagem Descritas}

O racional da técnica baseia-se no uso da ultrassonografia endoscópica com Doppler colorido como recurso seguro para acessar diretamente a via biliar tanto em seu trajeto intra como extra-hepático. Com isso, seriam possíveis as seguintes condutas (Perez-Miranda et al., 2010):

- Realizar o procedimento no mesmo ato de uma CPRE malsucedida, diminuindo o tempo de internação, custos e desconforto do paciente.

- Promover drenagem da via biliar com base fisiológica, sem a necessidade de colocação de drenos externos, favorecendo a melhora da qualidade de vida do paciente.

- Acessar a via biliar sob visão direta e em tempo real, tornando-se um procedimento preciso e com marcado potencial de segurança.

Uma variedade de rotas transmurais de acesso e modelos de descompressão são descritos; todavia, o conceito básico fundamenta-se no acesso ecoguiado à via biliar através do lúmen gastrointestinal, seguido de técnicas usuais à CPRE com controle fluoroscópico.

Existem dois tipos de acessos ecoguiados à via biliar (intra-hepático ou extra-hepático) e três vias de drenagem (transmural, transpapilar anterógrada e transpapilar retrógrada ou rendez-vous) (Figura 1). 


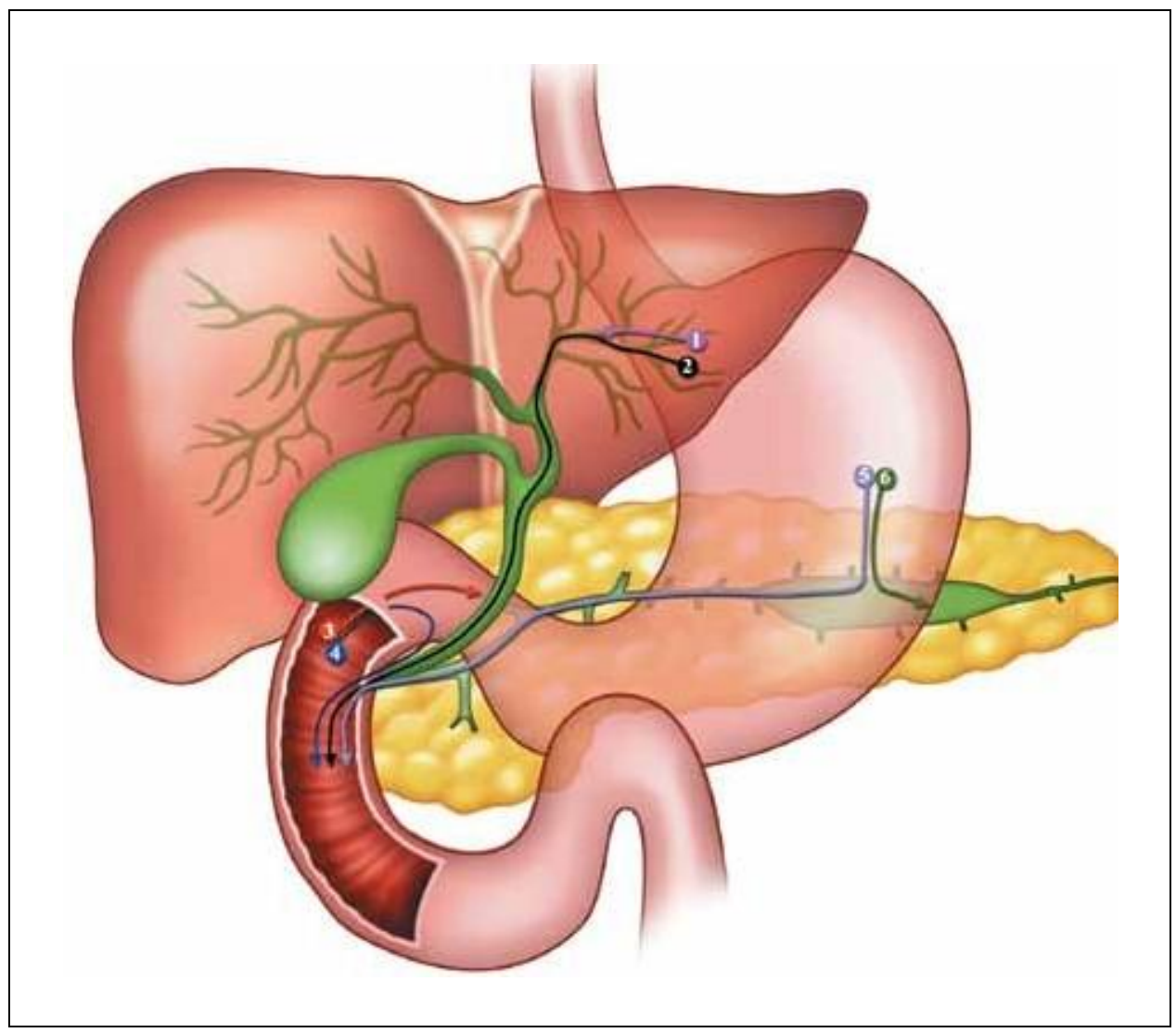

Figura 1 - Abordagens de drenagem biliar ecoguiada, que combinam duas vias de acesso possíveis com três vias de drenagem. As vias de acesso são intrahepáticas $(1,2)$ e extra-hepáticas $(3,4)$. Após o acesso ductal através de quaisquer destas vias, a drenagem transmural pode ser obtida por meio de hepaticogastrostomia (1) ou coledocoduodenostomia. (3) Drenagem biliar transpapilar pode ser obtida anterogradamente (rendez-vous) $(2,4)$ [Fonte Perez-Miranda et al. (2010)]

A escolha da via de drenagem depende das características da obstrução neoplásica, calibre da via biliar intra e extra-hepática e particularidades anatômicas, como cirurgias do andar superior do trato gastrointestinal. Existe a possibilidade de escolha entre ducto intra ou extrahepático em $20 \%$ dos casos (Kahaleh et al., 2006). Nos $80 \%$ restantes, o acesso é determinado pelo nível de obstrução (hilar versus distal) e pela possibilidade de melhor visibilização ultrassonográfica pelas janelas para a via biliar (que pode se mostrar mais difícil em pacientes com gastrectomias prévias ou outras cirurgias do andar superior do abdômen). 
Em geral, a via de drenagem deverá ser escolhida antes da ecopunção, por meio de adequada identificação das estruturas biliopancreáticas mediante exame ecoendoscópico bem detalhado, evitando, assim, o risco de lesão a estruturas adjacentes, como vasos sanguíneos ou lesão da via biliar por punção inadequada.

$\mathrm{Na}$ via transpapilar anterógrada, o fio-guia é exteriorizado pela papila e a prótese progride anterogradamente a partir do canal de trabalho do ecoendoscópio (Nguyen-Tang et al., 2010). Na transpapilar retrógrada ou rendez-vous ecoguiado, o fio-guia é exteriorizado pela papila, sendo capturado por um videoduodenoscópio posicionado na segunda porção duodenal, possibilitando a passagem da prótese de modo retrógrado, de maneira similar à CPRE (Mallery et al., 2004; Kim et al., 2010). Na drenagem transmural, o posicionamento da prótese determina trajeto fistuloso entre o lúmen gastrointestinal e a via biliar (Gupta et al., 2007). Esta verdadeira anastomose biliodigestiva não anatômica denomina-se recanalização biliar.

É necessário que o controle fluoroscópico seja preciso, particularizando seu campo de visão, a ponta do aparelho e a agulha de ecopunção. Com a introdução do aparelho de ecoendoscopia, é possível a verificação da anatomia do paciente e do nível de obstrução biliar para a confirmação da lesão e anatomia biliopancreática prévia. $\mathrm{O}$ ideal é que o segmento ductal dilatado esteja o mais próximo possível da parede gastrointestinal e que não exista a interposição de vasos sanguíneos de grosso calibre ou outras estruturas que dificultem a ecopunção e manipulação biliar, identificados pela ultrassonografia com recurso de Doppler (Tarantino et al., 2008; Brauer et al., 2009). 
Quanto maior a dilatação da via biliar e proximidade ao ducto biliar da parede gastrointestinal, maior será a taxa de sucesso do procedimento. Embora ductos de calibre menores que $2 \mathrm{~mm}$ possam ser acessados e puncionados por ecoendoscopia, ductos apresentando diâmetro mínimo entre 4 e $5 \mathrm{~mm}$ e distância do transdutor com a parede gastrointestinal de até $2 \mathrm{~mm}$ são situações que facilitam, sobremaneira, o procedimento (Kahaleh et al., 2006).

O acesso é tipicamente obtido pela inserção de uma agulha de 19 ou 22 gauges na via biliar de interesse, dando-se preferência à agulha de 19 gauges, por permitir a passagem de fio-guia teflonado mais calibroso, de 0,035 polegadas, o que facilita a manipulação e instrumentação terapêutica da via biliar.

Uma vez puncionada a via biliar, é necessária a mínima manipulação para minimizar os riscos de acidentes de punção, como lesões de estruturas adjacentes, fístula biliar e deslocamento do fio-guia da via biliar em direção ao lúmen intestinal. A aspiração do conteúdo após a punção é um passo relevante não apenas para confirmação da posição da agulha na via biliar, como também para diminuir a pressão intraductal (o que, teoricamente, diminuiria o risco imediato de extravasamento de bile) e permitir a análise microbiológica do material obtido.

Com o acesso estabelecido e seguro à via biliar, a escolha entre drenagem transpapilar (ou transanastomótica) ou transmural será determinada pela facilidade de progressão do fio-guia em sentido transpapilar ou não. Na primeira situação, a opção é o rendez-vous ecoguiado e na última 
procede-se a recanalização transmural intra ou extra-hepática, dependendo do nível da lesão obstrutiva.

Assim, serão descritas em detalhes as técnicas anterógrada e transpapilar (rendez-vous ecoguiado), hepatogastrostomia, coledocoduodenostomia e drenagem ecoguiada em pacientes com anatomia alterada.

\subsubsection{Drenagem anterógrada e transpapilar (rendez-vous ecoguiado)}

O rendez-vous ecoguiado foi relatado pela primeira vez por Mallery et al., em 2004. A técnica consiste em punção guiada por Ultrassonografia Endoscópica (USE) da via biliar através das paredes gástrica ou entérica, passagem anterógrada do fio-guia através da área de estenose e/ou da papila com o intuito de acesso retrógrado ao ducto biliar via CPRE convencional. Portanto, para a realização do rendez-vous ecoguiado, o acesso endoscópico à papila e a troca do aparelho de ecoendoscopia para videoduodenoscópio é detalhe técnico obrigatório.

O acesso ecoguiado transgástrico ou transentérico sob orientação ultrassonográfica foi descrito tanto para as técnicas de rendez-vous ecoguiado como para a drenagem anterógrada (Mallery et al., 2004; Nguyen-Tang et al., 2010). Dessa maneira, detalhe técnico comum para ambas as técnicas é a necessidade da passagem bem-sucedida do fio-guia pela estenose biliar até um segmento intestinal de delgado a jusante. No entanto, diferente da técnica de rendez-vous em que o ultrassom endoscópico é usado apenas para acessar o ducto biliar a montante da obstrução e passar o fio-guia em sentido anterógrado através da papila (para 
posterior realização de CPRE convencional), na técnica de drenagem anterógrada ecoguiada existe a criação de uma verdadeira fístula entre o trato gastrintestinal e o ducto biliar, que será moldada pela inserção transmural da prótese. A drenagem anterógrada ecoguiada, portanto, agrega os desafios tanto da técnica de rendez-vous ecoguiado (passagem anterógrada do fio-guia em direção transpapilar), como transmural (formação de fístula bilio-entérica). Este fato a torna um procedimento com um potencial de complicações maior que o rendez-vous ecoguiado (NguyenTang et al., 2010). Por outro lado, elimina a etapa difícil do rendez-vous com troca do aparelho de ecoendoscopia pelo aparelho de videoduodenoscopia.

Em relação ao local de punção, a escolha da via de acesso dependerá da anatomia regional biliopancreática, diagnóstico de base da lesão (benigno versus maligno), tipo de prótese (plástica versus metálica) e preferência do cirurgião, entre outros (Puspok et al., 2005). A DBE começa tipicamente com acesso transgástrico ou transentérico para a via biliar tanto intra como extra-hepática. Se os ductos intra-hepáticos forem significativamente dilatados (8 $\mathrm{mm}$ ou mais), a preferência é a abordagem intra-hepática, pois facilita a colocação direta anterógrada da prótese através da ampola de Vater, eliminando a necessidade do procedimento trabalhoso de rendez-vous. A passagem anterógrada de prótese pela abordagem extrahepática relatada em pacientes com estenoses biliar e duodenal simultâneas, impedindo o acesso à papila, é procedimento desafiador e que necessita monitoramento preciso ao se liberar a extremidade proximal da prótese. 
A abordagem intra-hepática é realizada com o ecoendoscópio posicionado na cárdia ou curvatura menor do estômago para possibilitar a visibilização do sistema biliar intra-hepático esquerdo dilatado (Bories et al., 2007). Após varredura com recurso de Doppler colorido excluir a vascularização no trajeto da agulha, esta é avançada ao ducto intrahepático, a bile é aspirada e uma pequena quantidade de contraste é injetada para confirmação do posicionamento adequado e visualização do ducto biliar (Figura 2). Um fio-guia de sustentação é, então, avançado de maneira anterógrada pelo canal da agulha em sentido biliar distal além da obstrução e pela ampola ou anastomose biliodigestiva para o interior do intestino delgado (Figura 3).

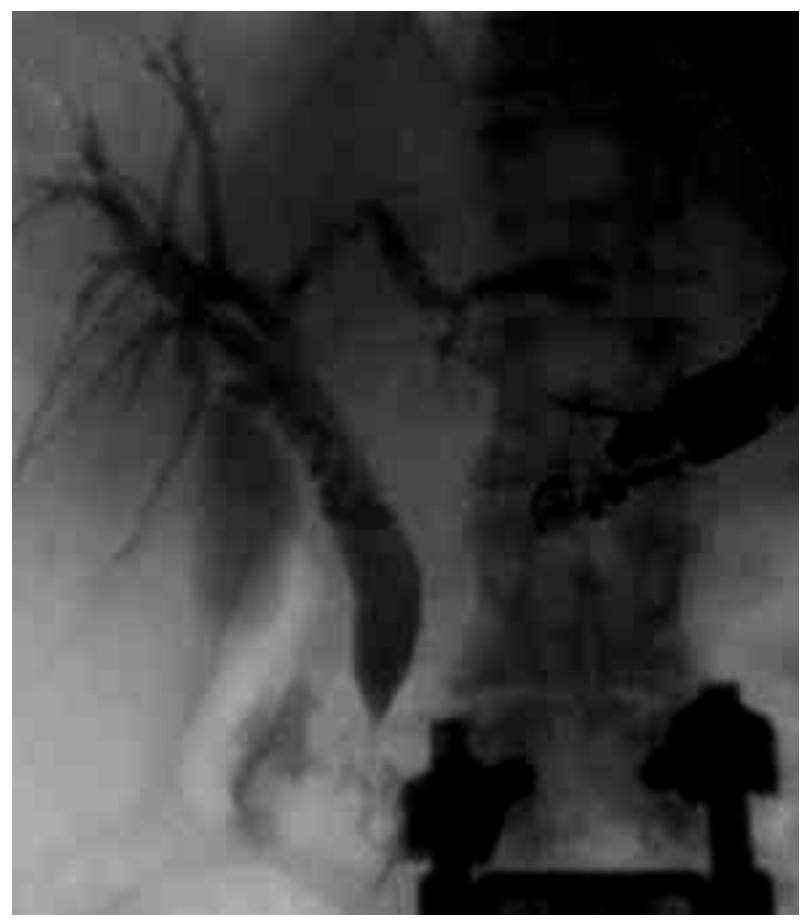

Figura 2 - Imagem radiológica da via biliar contrastada após punção ecoguiada, demonstrando opacificação bem-sucedida do ducto intra e extra-hepático 


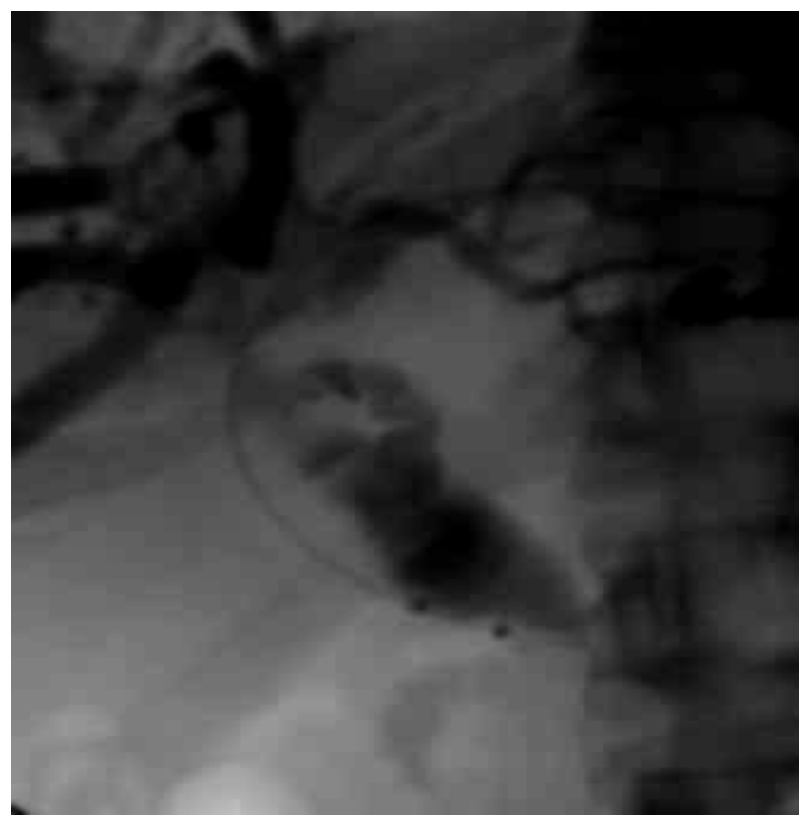

Figura 3 - Imagem radiológica do fio-guia posicionado na árvore biliar transpondo a área de estenose

Com a passagem do fio-guia bem-sucedida, recomenda-se avançá-lo pelo lúmen intestinal tanto quanto possível (30 a $40 \mathrm{~cm}$ ), a fim de prevenir o deslocamento tipo "chicote" durante a passagem da prótese ou troca do aparelho no caso do rendez-vous (Mallery et al., 2004; Kim et al., 2010). A dilatação do trajeto fistuloso (bilioentérico, hepatogástrico ou coledocoduodenal) não é necessária se, após o adequado posicionamento do fio-guia, a técnica de rendez-vous for escolhida. No entanto, sempre que um cateter-guia for necessário para manipular o fio-guia no sentido anterógrado através do estreitamento e da papila, ou quando for realizada a inserção anterógrada da prótese, a criação da fístula é a opção seguinte. Este procedimento é realizado utilizando-se de acessórios tipo cateter com balão dilatador, bainha diatérmica tipo estilete de ponta (needle-knife) ou cistóstomo. 
Quando optado por rendez-vous, o ecoendoscópico é retirado com a agulha acoplada em um movimento sincronizado de introdução do fio-guia sob controle radiológico. Após a sua retirada, o videoduodenoscópio é introduzido e conduzido até a segunda porção duodenal, utilizando-se da radioscopia para monitorar a possível formação de alças pelo fio-guia na luz gástrica, evitando-se o deslocamento do fio-guia do ducto biliar. Outra opção para estabilizar o fio-guia durante a troca do endoscópio é retirar primeiro a agulha do ecoendoscópio, inserir um cateter flexível sobre o fio e depois remover o aparelho. Uma vez atingida a região papilar, uma alça de polipectomia ou um papilótomo é usado para a captura do fio-guia e retirada do mesmo através do canal acessório (Figura 4). Em caso de dificuldade técnica para a apreensão do fio-guia, a técnica de "rendez-vous em paralelo" tem sido descrita (Gupta et al., 2007; Kim et al., 2010). Segue-se, assim, a passagem de prótese pela CPRE convencional (Figura 5).

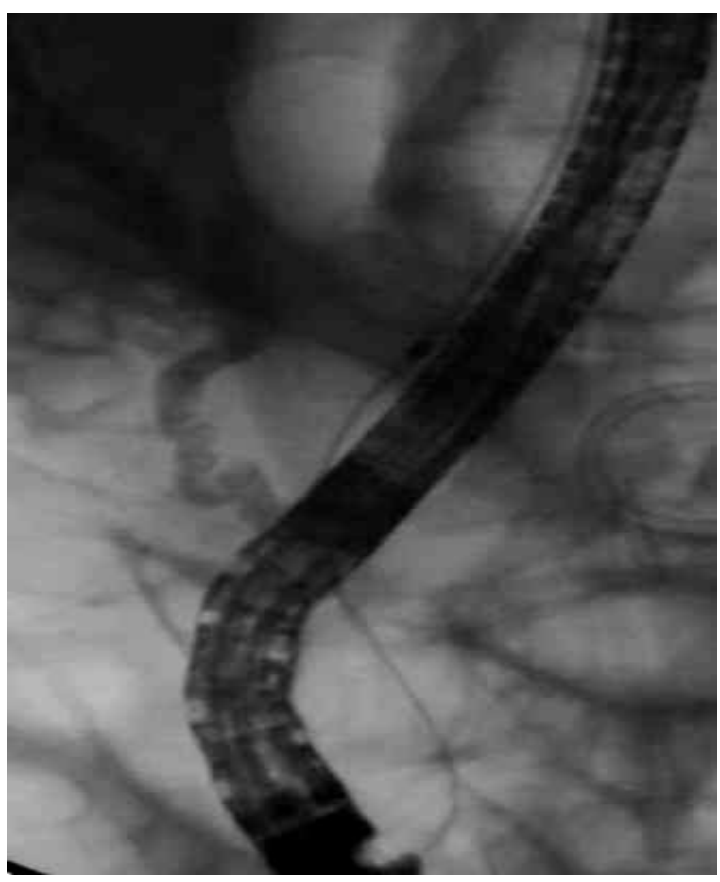

Figura 4 - Imagem radiológica de videoduodenoscópio na segunda porção duodenal, recuperando o fio-guia posicionado por meio da técnica ecoguiada 


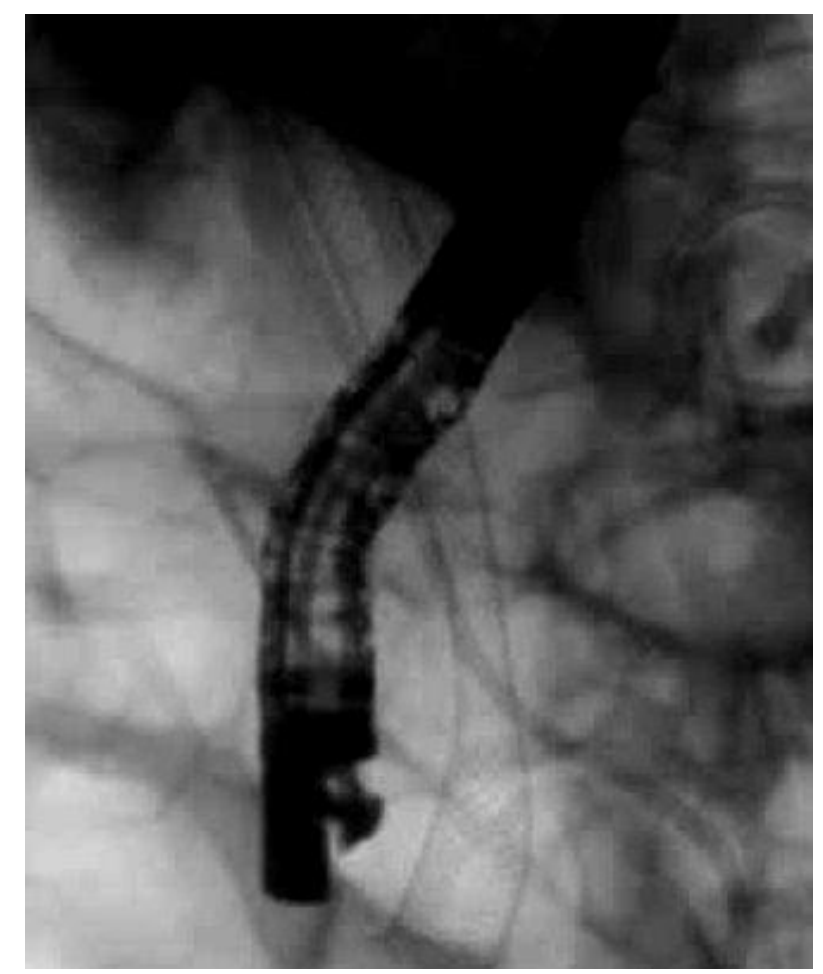

Figura 5 - Imagem radiológica da prótese metálica na via biliar inserida de maneira retrógrada pela técnica de rendez-vous

Para a drenagem anterógrada, o objetivo da dilatação é possibilitar a passagem fácil de uma prótese plástica de $10 \mathrm{Fr}$ de diâmetro ou prótese metálica autoexpansível de $30 \mathrm{Fr}$ de diâmetro para possibilitar a descompressão sustentada. Há tendência de se optar pela inserção de prótese metálica autoexpansível total ou parcialmente recoberta para tratamento paliativo de longo prazo da neoplasia maligna (Artifon et al., 2007; Bories et al., 2007; Park et al., 2009) (Figura 6). 


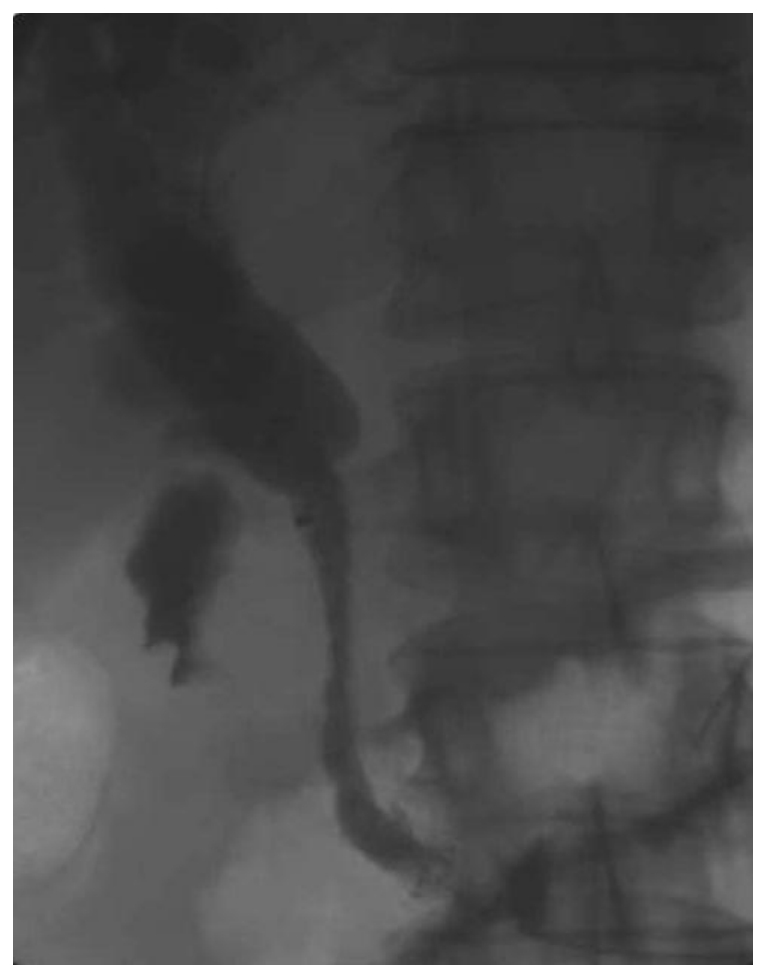

Figura 6 - Imagem radiológica de prótese metálica transpondo a área de estenose após a técnica de drenagem anterógrada ecoguiada

A abordagem extra-hepática geralmente necessita de posicionamento do ecoendoscópio no duodeno, mas também pode ser posicionado no antro distal quando da presença de infiltração neoplásica do bulbo duodenal (Artifon et al., 2010). Após a varredura do local utilizando ultrassom com recurso de Doppler, a agulha de punção é introduzida no ducto biliar e o fioguia é avançado de maneira anterógrada através da ampola de Vater (ou anastomose biliodigestiva), mantendo-a redundante na luz duodenal. Os demais passos do procedimento são semelhantes aos descritos anteriormente para a abordagem intra-hepática. A abordagem extra-hepática pode compor o rendez-vous ecoguiado. Um pré-requisito para esta via de acesso extra-hepática é a obstrução biliar distal. Destaca-se por ser apropriada via de acesso para pacientes sem dilatação do ducto biliar intra- 
hepático ou aqueles com ascite significativa e tem sido relatada inclusive para pacientes com afecções benignas da via biliar, que apresentam falha na CPRE (Calvo et al., 2001; Puspok et al., 2005).

Se o fio-guia não puder ser avançado no duodeno ou alça intestinal, pode-se optar pela criação de uma fístula propriamente dita pelas técnicas de hepatogastrostomia, hepatojejunostomia, coledocoantrostomia e coledocoduodenostomia, como se dissertará a seguir. Vale ressaltar que estas técnicas são acessos não-anatômicos à via biliar

\subsubsection{Hepatogastrostomia (acesso intra-hepático, transmural)}

A hepatogastrostomia (HGT) guiada por USE foi relatada pela primeira vez em 2003. Burmester et al. (2003) realizaram o procedimento em um paciente com gastrectomia prévia e reconstrução a Billroth II, apresentando câncer pancreático irressecável e falha da CPRE por infiltração tumoral da papila maior. As especificações anatômicas e o nível de obstrução biliar são determinantes da técnica da HGT. O acesso intrahepático é a escolha em pacientes que se apresentam com quadro de obstruções proximais (hilar) e é o método mais conveniente em pacientes com gastrectomia distal, já que, na maioria destes casos, não é possível o acesso à janela ultrassonográfica para a via biliar extra-hepática no cenário peculiar de distorções anatômicas (Artifon et al., 2007; Tarantino et al., 2008; Maranki et al., 2009).

Comparada à drenagem anterógrada ecoguiada, a favor da HGT está o fato de se evitar a difícil e geralmente conturbada passagem anterógrada da 
prótese pela área de estenose (necessária na técnica de drenagem anterógrada transpapilar). Diferente da técnica de rendez-vous ecoguiada, a hepatogastrostomia não exige a transposição do fio-guia pela área de estenose e é técnica factível em casos de papila duodenal não acessível endoscopicamente, o que, em geral, ocorre em pacientes com anatomia cirurgicamente alterada ou estenoses duodenais. A hepatogastrostomia também promove acesso fácil ao ducto biliar intra-hepático sem a necessidade de nova punção ecoguiada (Tarantino et al., 2008; Maranki et al., 2009).

O procedimento inicia com a identificação do ramo intra-hepático esquerdo dilatado (via de regra no segmento hepático III) mais próximo da parede gástrica e de trajeto de punção livre de estruturas vasculares por meio do estudo com recurso de ultrassom Doppler. A posição clássica do ecoendoscópio setorial situa-se junto à cárdia, na parede posterior do corpo proximal e próximo à pequena curvatura. Em pacientes com hérnia hiatal por deslizamento de grande extensão, deve-se realizar a punção ecoguiada em região mais caudal do que habitual. Realiza-se, então, uma punção transgástrica do ramo intra-hepático periférico esquerdo dilatado, utilizando-se agulha de punção de 19 gauges; a posição é confirmada pela aspiração da bile, seguida de colangiografia com injeção gradual e lenta de contraste, delineando, deste modo, a anatomia da via biliar e da lesão estenosante. A seguir, a passagem de fio-guia de 0,035 polegadas pelo canal da agulha de ecopunção e a retirada da mesma, deixando o fio-guia em posição intra-hepática, são os passos técnicos padronizados à técnica (Artifon et al., 2012b). 
A hepatogastrostomia, de regra, envolve ampliação ou dilatação do trajeto hepatogástrico, obtido com uma bainha diatérmica tipo estilete de ponta (needle-knife) ou cistótomo, ampliando-se o pertuito na parede gástrica e sendo avançado em todo o parênquima hepático até se alcançar o ducto hepático esquerdo (Artifon et al., 2007; Maranki et al., 2009). Depois de retirar a bainha diatérmica sobre o fio-guia, efetua-se a hepatogastrostomia com a inserção transmural de prótese plástica ou metálica autoexpansível (total ou parcialmente recoberta) com a extremidade proximal locada na via biliar intra-hepática e a distal no corpo gástrico proximal. A radioscopia confirma o adequado posicionamento da prótese e seu funcionamento mediante drenagem adequada do contraste para a cavidade gástrica (Figura 7).

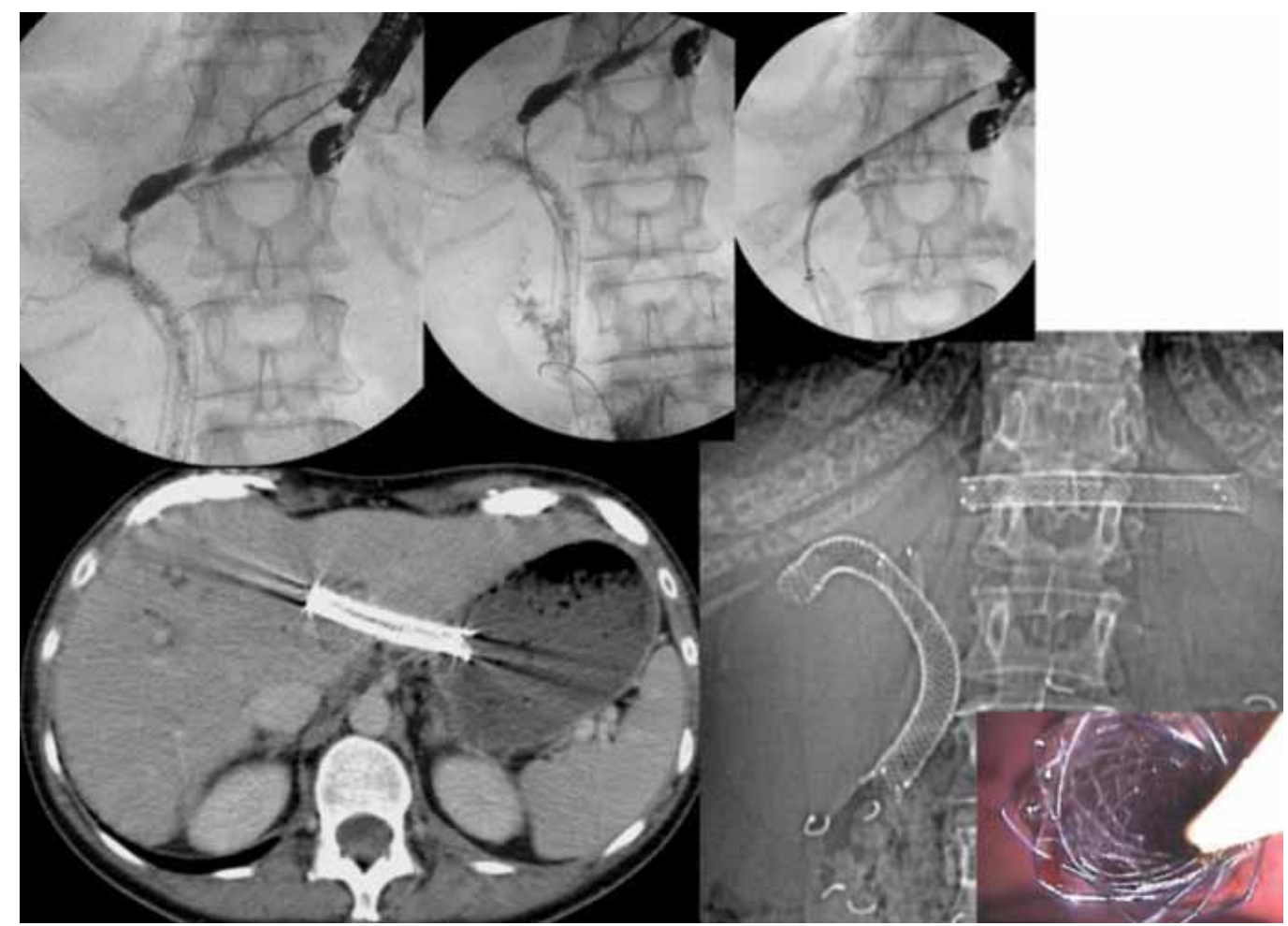

Figura 7-Imagem sequencial da técnica de hepatogastrostomia realizada em paciente com tumor de Klatskin. Observar o posicionamento prévio de prótese metálica no ducto hepático direito, o que torna o sistema biliar esquerdo inacessível à CPRE 


\subsubsection{Coledocoduodenostomia (acesso extra-hepático, transmural)}

Na drenagem biliar extra-hepática guiada por USE, o Ducto Biliar Comum (DBC) é acessado a partir de uma abordagem transduodenal ou transgástrica (geralmente a partir do antro distal). A técnica de drenagem denominada Coledocoduodenostomia (CDT) compreende a fistulização transmural da via biliar extra-hepática com a luz duodenal. Além das razões comuns a todos os procedimentos de DBE (possibilidade de procedimento em tempo único, promoção de drenagem biliar interna e aplicabilidade do método em distorções anatômicas) na coledocoduodenostomia, existem outras vantagens que serão apresentadas a seguir (Perez-Miranda et al., 2010).

Primeiramente, o DBC é mais facilmente visibilizado sob USE do que os ductos biliares intra-hepáticos, ao contrário do que acontece com o ultrassom convencional abdominal, o que implica em um acesso relativamente fácil, minimizando os riscos mesmo nos casos de dilatação mínima $(8 \mathrm{~mm})$ da via biliar extra-hepática. Ao contrário da abordagem intrahepática (seja percutânea, seja ecoguiada), a técnica também se mostra mais factível em pacientes com ascite, pelo fato de que o DBC se encontra em localização retroperitoneal (Artifon et al., 2012a).

Ao se considerar a drenagem anterógrada uma técnica não recomendada no acesso extra-hepático (Puspok et al., 2005; Nguyen-Tang et al., 2010), a escolha entre drenagem transmural e transpapilar guiada por USE concentra-se entre a CDT e rendez-vous ecoguiado. Contudo, a dificuldade de passagem do fio-guia pela área de estenose e/ou papila tornam o rendez-vous uma técnica nem sempre exequível, com uma taxa de 
insucesso de $20 \%$ a $45 \%$ (Kim et al., 2010). Assim, mesmo sendo pouco mais invasiva, a CDT tem se revelado um procedimento mais simples e com maiores taxas de sucesso na ocasião do insucesso da CPRE, quando comparada a outras abordagens no acesso extra-hepático. Mesmo quando o rendez-vous é a técnica de drenagem pretendida, a drenagem transmural pode servir como um procedimento de resgate em casos de insucesso da primeira opção (Maranki et al., 2009; Brauer et al., 2009).

Os requisitos básicos para a realização da técnica (acessórios apropriados, equipe treinada) são, basicamente, os mesmos utilizados para outras técnicas de drenagem ecoguiada. Todavia, a coledocoduodenostomia possui peculiaridades ao método que a difere das outras técnicas. $\mathrm{O}$ primeiro requisito é a obstrução biliar distal; a coledocoduodenostomia não é adequada para a obstrução biliar proximal (hilar). O segundo requisito é a necessidade de visibilização do ducto biliar extra-hepático, o que torna o procedimento inadequado em pacientes com gastrectomia prévia e gastrojejunostomia (por exemplo, Y-de-Roux), uma vez que o DBC é normalmente visibilizado a partir do estômago distal ou bulbo duodenal (Wilson et al., 2010). Como na maioria das demais abordagens transmurais ecoguiadas, a coledocoduodenostomia é predominantemente indicada em pacientes com obstrução biliar maligna (Artifon et al., 2011b).

Inicialmente, o hepatocolédoco dilatado é visibilizado a partir do bulbo duodenal, por meio do ecoendoscópio setorial linear. É realizado um estudo detalhado do trajeto da punção utilizando o recurso do ultrassom Doppler para se certificar de que estruturas vasculares não sejam lesadas durante a 
ecopunção. O posicionamento da agulha é fator técnico relevante, uma vez que a orientação desta em sentido cranial torna a coledocoduodenostomia mais fácil, na medida em que diminui o ângulo de avanço da prótese em direção ao ducto biliar. Por outro lado, a orientação da agulha em sentido distal é alcançada quando o rendez-vous ecoguiado é escolhido como tentativa de drenagem inicial. Seja qual for a escolha da orientação, a agulha de ecopunção (preferencialmente de 19 gauges) é inserida no ducto biliar sob visibilização endossonográfica. Para confirmar o acesso ductal, a bile é aspirada e, posteriormente, se injeta meio de contraste diluído o ducto biliar para a colangiografia, delineando a anatomia da via biliar e da lesão estenosante. Em seguida, um fio-guia de 0,035 polegadas é inserido pelo canal da agulha de ecopunção e sua posição na via biliar confirmada por radioscopia.

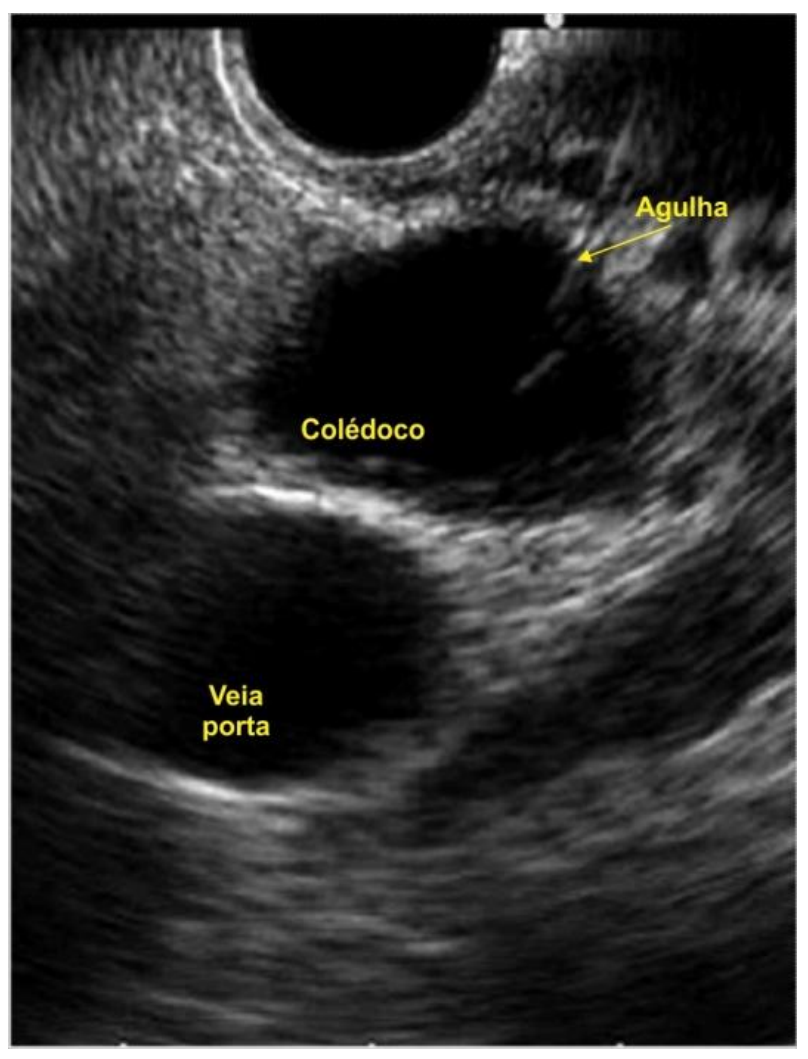

Figura 8 - Imagem de agulha de 19 gauges inserida através da parede duodenal no ducto biliar sob visualização endossonográfica 


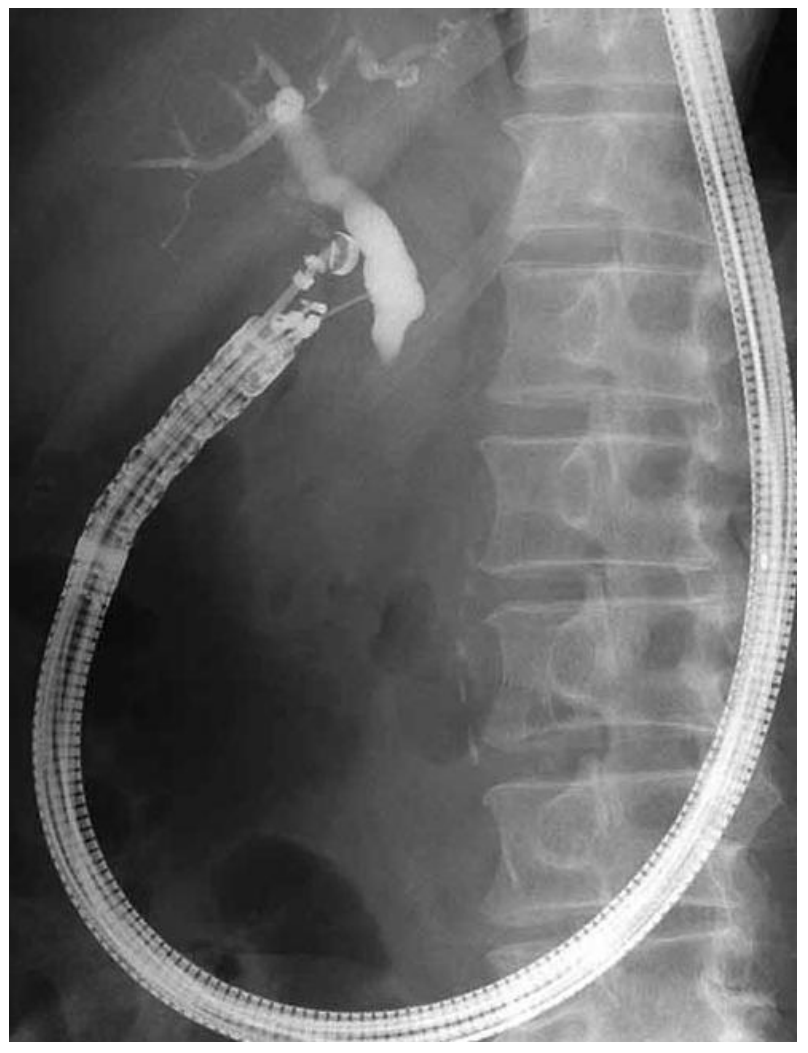

Figura 9 - Imagem radiológica da via biliar contrastada após punção ecoendoscópica

Após o acesso do fio-guia ao ducto biliar, não raramente é necessária a dilatação ou ampliação do trajeto da punção antes da inserção da prótese. Muitas vezes, utiliza-se cateter-balão dilatador, cistótomo ou cateter tipo needle-knife. Enfim, prótese plástica ou metálica autoexpansível (total ou parcialmente recoberta), com a extremidade distal posicionada na via biliar e a proximal no bulbo duodenal, define a recanalização do tipo coledocoduodenostomia (Figura 10). 

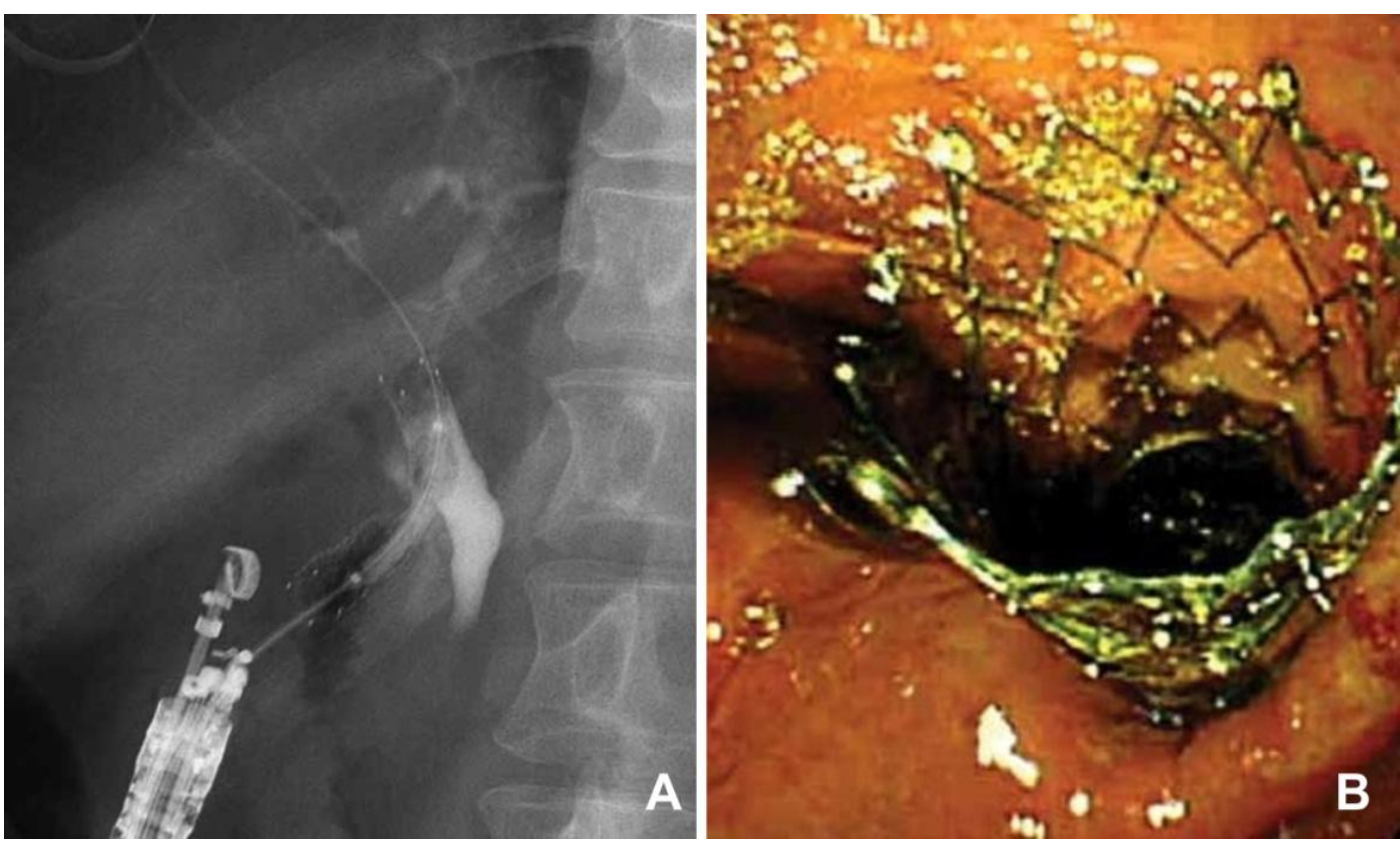

Figura 10 - (A) Imagem radiológica de prótese metálica autoexpansível posicionada por meio da técnica de coledocoduodenostomia no ducto biliar extrahepático; (B) imagem endoscópica da extremidade distal da prótese metálica na parede duodenal

\subsubsection{Acesso ecoguiado em casos de anatomia alterada do trato gastrointestinal}

As cirurgias derivativas do trato gastrointestinal alto, além de modificarem o trânsito intestinal, podem tornar o acesso à segunda porção

duodenal difícil ou improvável e, consequentemente, impossibilitar a terapêutica endoscópica biliar através da CPRE ou enteroscopia. Neste contexto, as derivações cirúrgicas biliodigestivas, gastroenteroanastomoses e cirurgias bariátricas são desafios que encontram no acesso biliar ecoguiado uma alternativa eficaz no tratamento da icterícia de padrão obstrutivo, possibilitando o acesso ao ducto hepático esquerdo dilatado ou à via biliar extra-hepática a partir de janela gástrica (ou do coto gástrico) ou jejunal (em casos de gastrectomia total). 


\subsubsection{Hepatojejunostomia}

É uma técnica de drenagem ecoguiada da via biliar intra-hepática, aplicada em pacientes submetidos à gastrectomia prévia com reconstrução em Y-de-Roux, onde não é possível o acesso endoscópico convencional à via biliar extra-hepática. Burmester et al. (2003) descreveram a colocação de prótese transmural criando uma fístula entre a alça jejunal e a via biliar intrahepática em um paciente submetido previamente à gastrectomia total, ou seja, hepatojejunostomia ecoguiada. Em nosso meio, Artifon et al. (2011b). reproduziram o procedimento em paciente ictérico com gastrectomia total prévia e reconstrução em Y-de-Roux.

\subsubsection{Coledocoantrostomia}

Trata-se de técnica de DBE, por meio da visibilização da via biliar extra-hepática pela janela antral em pacientes com distorções anatômicas extensas do bulbo duodenal, destacando-se a infiltração completa do eixo piloro duodenal. Esta técnica foi descrita, pioneiramente, por Artifon et al. (2010) e corresponde à variante de DBE aplicada em paciente que se apresenta com câncer pancreático irressecável, invadindo, simultaneamente, a região da papila e bulbo duodenal, fato que, obviamente, impede a realização da colangiografia retrógrada endoscópica ou coledocoduodenostomia ecoguiada a partir do bulbo duodenal. 


\subsection{Complicações e Opções de Tratamento}

As complicações relacionadas às técnicas de DBE são relatadas em até $20 \%$ dos casos, sendo em $8 \%$ consideradas complicações maiores e incluem: fístula biliar, peritonite biliar, empiema, colangite, hemorragia da parede gastrointestinal ou de estruturas adjacentes, hematoma ou abscesso hepático (Kahaleh et al., 2006; Bories et al., 2007; Maranki et al., 2009; Kim et al., 2010). Dificuldades técnicas podem ocorrer e são semelhantes às encontradas durante os procedimentos de drenagem radiológica percutânea. Estas dificuldades incluem a dificuldade na progressão do fio-guia por uma via biliar tortuosa na ocasião de extensas obstruções que podem requerer dilatações.

A maior limitação das técnicas de drenagem ecoguiada anterógrada e rendez-vous é a manipulação do fio-guia no sentido distal à estenose, uma vez que, principalmente no acesso biliar intra-hepático, tal manobra mostrase um desafio na manipulação do fio-guia com o objetivo de transpor a lesão biliar (Mallery et al., 2004; Kim et al., 2010). A agulha de punção ecoendoscópica de características rígida e cortante não possibilita interação favorável com o fio-guia, ocorrendo o oposto durante a CPRE, em que a passagem fácil do fio-guia é permitida pelo uso de cateteres flexíveis. As tentativas sem êxito de passagem distal do fio-guia podem levar a acidentes de punção e deslocamento do fio-guia. Por isso, a recomendação é realizar sempre a punção biliar no local mais próximo possível à papila duodenal, sob controles ultrassonográfico e radiológico simultâneos, com a orientação da agulha tangencial ao ducto. 
Ao se levar em conta que durante as técnicas de drenagem ecoguiada transmural (hepatogastrostomia, coledocoduodenostomia, coledocoantrostomia e hepatojejunostomia) existe a criação de verdadeiro orifício fistuloso, as complicações relacionadas a estas novas técnicas de acesso não anatômicas à via biliar são, na maioria das vezes, relacionadas ao extravazamento de bile no retroperitônio (com acesso transduodenal) ou cavidade peritoneal (com acesso transgástrico). Usualmente, a fístula biliar é relatada como leve, autolimitada e não exige mais do que medidas conservadoras (Ang et al., 2007; Tarantino et al., 2008; Artifon et al., 2010). Em casos selecionados, intervenções como drenagem percutânea são necessárias e em raros casos aventa-se a possibilidade de cirurgia, daí a importância do procedimento de DBE ter a validação multidisciplinar de sua indicação.

As principais causas relacionadas à fístula biliar são decorrentes da drenagem precária da via biliar obstruída, a saber:

- Orifício fistuloso inadequado.

- Posicionamento inadequado da prótese (incluindo encurtamento de próteses metálicas autoexpansíveis).

- Obstrução ou migração mediata da prótese.

O conhecimento e experiência na manipulação dos acessórios endoscópicos pertinentes à realização da drenagem ecoguiada, bem como acerca das variações sutis na posição do ecoendoscópio (gástrica ou duodenal) e orientação (para cima e para baixo), são fatores determinantes para se evitarem acidentes de punção, perda do trajeto e deslocamento 
precoce da prótese inserida, aumentando, assim, as taxas de sucesso e minimizando os índices de complicação.

Em relação à migração precoce da prótese, diversas estratégias são utilizadas por diferentes autores para minimizar este risco. Destaca-se a recomendação de passagem concomitante de um dreno nasobiliar, a combinação de prótese metálica não recoberta com prótese metálica recoberta interna, a colocação anterógrada de prótese metálica adicional, promovendo descompressão a jusante do ducto biliar, e a expansão forçada com balão dilatador biliar aplicado à região de maior compressão da prótese implantada (Kumar et al., 1995; Choudari et al., 2000).

Com o propósito de evitar a migração precoce da prótese, deve-se ter cautela para monitorar por radioscopia o posicionamento da extremidade intraductal da prótese e, simultaneamente, por endoscopia, a posição enteral (ou intragástrica) da prótese. Este último aspecto é de particular relevância quando se utilizam próteses metálicas autoexpansíveis, que tendem a encurtar a partir da expansão completa, o que ocorre algumas horas após o procedimento. Para evitar tal deslocamento causado pelo encurtamento, um segmento da prótese metálica de pelo menos 15 a $20 \mathrm{~mm}$ deve ser deixado no interior da luz gastrointestinal (Wright et al. 2002; Kim et al., 2010).

Com relação ao tratamento, nos casos de migração precoce da prótese (isto é, trajeto fistuloso imaturo), deve-se considerar uma nova drenagem biliar guiada por ecoendoscopia, drenagem percutânea ou derivação cirúrgica, dependendo da condição do paciente na ocasião da complicação. Em se tratando de migração tardia da prótese, determinando 
uma fístula de trajeto estabelecido, opta-se por tratamento conservador sem inserção de prótese adicional ou, na maioria dos casos, drenagem biliar repetida colocando nova prótese (se o trajeto fistuloso ainda estiver visível). Caso o trajeto da fístula não possa ser visibilizada ou se encontrar ocluído, opta-se por drenagem biliar percutânea ou ecoguiada (Burmester et al., 2003; Tarantino et al., 2008; Perez-Miranda et al., 2010).

No caso de prótese plástica ocluída, a fim de se manter o trajeto formado, insere-se primeiramente um fio-guia no seu interior, este é apreendido com uma alça de polipectomia e recuperado sobre o fio-guia. Em seguida, nova prótese é posicionada, usando-se o videoduodenoscópio e caracterizando o rendez-vous ecoguiado. Se ocorrer obstrução de uma prótese metálica, pode-se tentar limpar o material de biofilme que oclui a luz e, em alguns casos, ser necessária a colocação de nova prótese em seu interior, caracterizando a chamada abordagem técnica tipo "stent-in-stent" (Artifon et al., 2010). 


\section{MÉTodos}




\subsection{Casuística}

No período de abril de 2010 a setembro de 2011 (18 meses), foram incluídos no presente estudo um total de 32 pacientes com neoplasia maligna da via biliar, sendo $3(9,3 \%)$ excluídos devido à falha do procedimento ecoendoscópico. Os pacientes incluídos no protocolo foram submetidos à drenagem biliar ecoendoscópica após a ocorrência de falha prévia na tentativa por colangiopancreatografia endoscópica e prospectivamente acompanhados no Serviço de Endoscopia Gastrointestinal do Hospital das Clínicas da Universidade de São Paulo (HC-FMUSP). O presente estudo foi aprovado pelo comitê de ética (CAPPesq) nº 0707/09. Todos os pacientes assinaram o Termo de Consentimento Livre e Esclarecido (Anexos A, B, C e D).

Os seguintes critérios de inclusão foram adotados:

- Paciente com idade igual ou superior a 18 anos.

- Neoplasia obstrutiva irressecável de via biliar e sem sucesso na drenagem biliar interna por CPRE prévia.

- Ausência de estenoses esofagogástricas ou invasão tumoral no local ou distal à região de punção e colocação da prótese.

Os seguintes critérios de exclusão foram adotados:

- Coagulopatia grave e sem sucesso na compensação clínica.

- Ascite volumosa ou na região da punção. 
- Recusa à realização do procedimento.

- Ausência de janela acústica endossonográfica adequada para a punção.

\section{Gênero}

O gênero masculino foi observado em 14 (48,3\%) pacientes e o gênero feminino em 15 (51,7\%).

\section{Grupo étnico}

Houve predomínio do grupo étnico caucasiano com 18 (62,06\%) pacientes e no grupo negroide com 11 (37,94\%).

\section{Idade}

A idade variou de 34 a 95 anos, com média de 67,03 anos.

Tabela 1 - Características demográficas dos pacientes em estudo

\begin{tabular}{lcc}
\hline \multicolumn{1}{r}{ Variável } & Frequência & $\%$ \\
\hline \hline Gênero & & \\
Feminino & 15 & 51,7 \\
Masculino & 14 & 48,3 \\
Grupo étnico & & \\
Caucasianos & 18 & 62,1 \\
Negroides & 11 & 37,9 \\
& Média & DP \\
Idade & 67,03 & 16,15 \\
Total & $\mathbf{2 9}$ & $\mathbf{1 0 0}$ \\
\hline
\end{tabular}




\subsection{Métodos}

O estudo baseou-se na avaliação clínica, ecoendoscópica e de qualidade de vida por meio do uso do índice SF- 36. Todos os exames de avaliação clínica protocolar e de dados ecoendoscópicos foram realizados no Serviço de Endoscopia Digestiva do HC-FMUSP. Todos os procedimentos foram feitos em regime ambulatorial, por um ecoendoscopista experiente, e o seguimento por meio de consultas agendadas e/ou por contato telefônico com o paciente ou o responsável legal.

As causas de falha no acesso anatômico convencional pela CPRE e que permitiram a inclusão dos pacientes no presente estudo foram as seguintes:

- Dificuldade de canulação convencional da papila duodenal maior.

- Infiltração neoplásica da papila duodenal maior.

- Infiltração neoplásica piloro-duodenal.

- Cirurgia derivativa prévia em que não se permitiu o acesso por CPRE.

- Neoplasia biliar distal com papila intradiverticular.

\subsubsection{Conceitos de Eficácia e Segurança}

Estes conceitos foram caracterizados pela avaliação dos sucessos técnico e clínico do procedimento ecoguiado de drenagem biliar.

O sucesso técnico foi caracterizado quando ocorreu êxito do procedimento ecoguiado na recanalização biliar não anatômica mediante a inserção de prótese metálica. O sucesso clínico foi nominado quando houve redução da bilirrubina total sérica em pelo menos $50 \%$ do valor inicial em seguimento de sete dias. 


\subsubsection{Indicação do Procedimento}

A indicação da DBE ocorreu por meio de discussão multidisciplinar, destacando-se o consentimento livre e esclarecido apresentado aos pacientes e obtidos para a confecção deste manuscrito.

As afecções neoplásicas de caráter maligno diagnosticadas nos pacientes deste estudo foram o câncer de cabeça de pâncreas em 19 $(65,51 \%)$ pacientes, colangiocarcinoma em $5(17,24 \%)$, massa linfonodal metastática em 2 (6,25\%), hepatocarcinoma 2 (6,25\%) e tumor neuroendócrino pancreático em 1 (3,12\%).

\subsubsection{Dados clínicos prévios ao procedimento}

$\mathrm{Na}$ avaliação clínica antes da drenagem ecoguiada, foram verificados dados de icterícia, dor abdominal, ascite, febre, perda de peso e cirurgias prévias. A icterícia e perda de peso ocorreram em todos os pacientes do estudo. A dor abdominal foi referida em 21 (72,40\%) pacientes, febre em 2 $(6,9 \%)$ e ascite foi evidenciada em $6(20,70 \%)$. Cirurgias prévias foram descritas em 8 (27,60\%) pacientes. A perda de peso média foi de $9 \mathrm{~kg}$. 
Tabela 2 - Descrição das características clínicas e pessoais avaliadas antes do procedimento

\begin{tabular}{lcc}
\hline Variável & Frequência & $\%$ \\
\hline \hline Dor & & \\
Não & 8 & 27,6 \\
Sim & 21 & 72,4 \\
Icterícia & & \\
Sim & 29 & 100,0 \\
Febre & & \\
Não & 27 & 93,1 \\
Sim & 2 & 6,9 \\
Ascite & & \\
Não & 23 & 79,3 \\
Sim & 6 & 20,7 \\
Cirurgia prévia & & \\
Não & 21 & 72,4 \\
Sim & 8 & 27,6 \\
& Média & DP \\
Perda de peso (Kg) & 9,03 & 4,61 \\
Total & $\mathbf{2 9}$ & $\mathbf{1 0 0}$ \\
\hline
\end{tabular}

\subsubsection{Dados laboratoriais}

$\mathrm{Na}$ avaliação laboratorial antes e após a DBE, foram realizadas avaliações séricas do número de leucócitos, bilirrubinas totais e frações, gamaglutamil-transferase e fosfatase alcalina. Vale ressaltar que outros testes laboratoriais não foram objeto de análise após a DBE. Os valores normais para adultos foram:

- Leucócitos: 3.800 a 9.800 leucócitos $/ \mathrm{mm}^{3}$ de sangue.

- Gama glutamil transferase: 8 a $41 \mathrm{U} / \mathrm{L}$ (mulheres) e 12 a $73 \mathrm{U} / \mathrm{L}$ (homens).

- Fosfatase alcalina: 35 a 104 U/L (mulheres) e 40 a 129 U/L (homens).

- Bilirrubinas total: 0,20 a $1,00 \mathrm{mg} / \mathrm{dL}$; direta: 0,00 a $0,20 \mathrm{mg} / \mathrm{dL}$; indireta: 0,20 a $0,80 \mathrm{mg} / \mathrm{dL}$. 


\subsubsection{Caracterização de irressecabilidade}

No presente estudo, a neoplasia maligna da via biliar foi considerada irressecável quando da presença de invasão do eixo mesentero-portal em pelo menos 50\%, bem como evidência de metástase à distância. Outrossim, as evidências supracitadas de irressecabilidade foram nominadas por meio de métodos de imagem não invasivos, como a Colangiorressonância Magnética (CRNM), Tomografia Computadorizada (TC), e também de métodos de imagem invasivos, caracterizados pela ecoendoscopia realizada em todos os exames deste estudo.

\subsubsection{Exame endoscópico}

A ultrassonografia endoscópica combina recursos de alta tecnologia, onde um aparelho endoscópico com visão oblíqua de 45 graus tem acoplado em sua ponta distal sistema de varredura setorial ultrassonográfica de alta frequência e canal terapêutico que proporciona procedimentos assistidos. Dados relacionados aos detalhes técnicos deste equipamento serão apresentados adiante. Vale ressaltar que o primeiro passo do procedimento ocorre por meio de visibilização por imagem endoscópica convencional e, após, mediante visão ecoendoscópica.

Os pacientes foram mantidos em observação por duas a quatro horas após o procedimento. Presença de dor abdominal refratária à medicação analgésica ou irritação peritoneal foi considerada fator relevante para a avaliação cirúrgica imediata. 


\subsubsection{Aparelho endoscópico}

- Duodenoscópio terapêutico (TJF-260; Olympus Medical Systems, Tokyo, Japan).

- Vídeo ecoendoscópio com probe setorial ou linear (GF-UCT 240-AL 10; Olympus).

- Fonte de luz (CLVS-10).

- Central processadora de imagem colorida (CV-100).

- Monitor de imagem tipo "Trinitron".

- Eletrocautério endoCut ICC200, ERBE Elektromedizin GmbH, Tübingen, Alemanha.

\subsubsection{Acessórios endoscópicos}

As agulhas padrão para punção aspirativa guiada por USE são bem visibilizadas endossonograficamente e utilizadas para acesso sem o uso de corrente elétrica ao ducto biliar. Com o uso de agulha de 19 gauges (WilsonCook Corporation), pode-se inserir um fio-guia de 0,035 polegadas pelo canal da agulha, ao ducto biliar dilatado. Uma das principais adversidades do acesso ecoguiado ao ducto biliar com este tipo de agulha é a dificuldade em manipular o fio-guia nas angulações. O problema principal é o "desencapamento" do revestimento do fio-guia, o que pode levar à falha do procedimento. Para resolver o problema de danos ao fio-guia com agulhas de punção aspirativa por USE, utilizou-se um modelo especializado de agulha denominado EchoTip ${ }^{\circledR}$ (Cook Medical), o qual possui um estilete afilado que torna relativamente fácil sua inserção no ducto biliar. Quando o 
estilete é retirado, a bainha externa da agulha é deixada no local com uma ponta não cortante e romba, o que evita danos ao fio-guia durante a sua manipulação.

Em relação aos acessórios de ampliação do trajeto formado após a punção ecoguiada, dois tipos de dispositivos estão disponíveis:

- Agulha flexível e condutora tipo needle-knife (papilótomo Zimmon, Cook Endoscopy, Winston-Salem, Carolina do Norte), utilizada para pré-corte, produz acesso axial por meio de delgado fio metálico de alta resistência elétrica que se estende $2 \mathrm{~mm}$ além da ponta do cateter.

- Cistótomo ou fistulótomo (Cook Endoscopy, Winston-Salem, NC; Endoflex, Tubingen, Alemanha), tradicionalmente utilizado para a drenagem do pseudocisto pacreático, tem uma parte de corte romba, arredondada na ponta, que produz o corte circunferencial na região do trajeto de punção, por meio de corrente eletrotérmica (Figura 11).

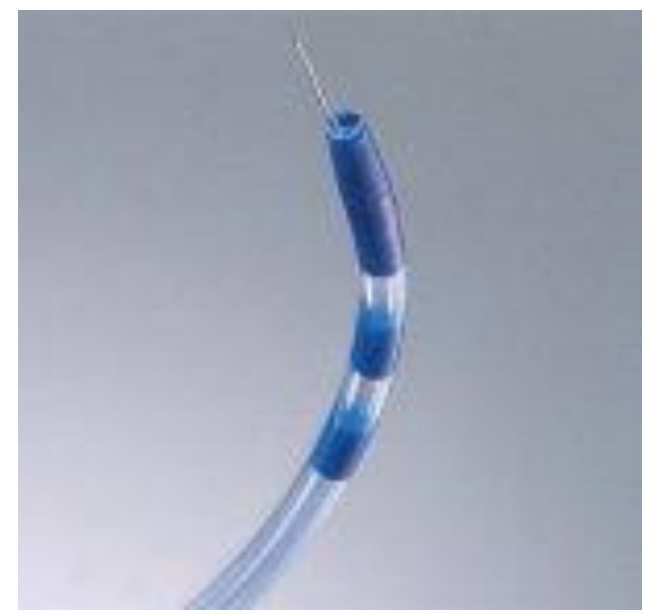

Figura 11 - Imagem de agulha flexível e condutora de corrente elétrica tipo needleknife (papilótomo Zimmon, Cook Endoscopy, Winston-Salen, Carolina do Norte). Apresenta fio metálico retrátil em sua ponta, que é utilizado para a ampliação do trajeto obtido ao ducto biliar 
Os cistótomos são ligeiramente mais rígidos do que as agulhas tipo needle-knife e produzem um trauma térmico maior na parede do trato gastrointestinal, o que reduz a necessidade de dilatação antes da inserção de stent. Os cistótomos são, portanto, particularmente úteis em casos onde se encontra resistência ao avanço de dispositivos flexíveis sobre o fio-guia previamente posicionado na via biliar. Os de calibre mais fino (6 Fr) são preferíveis aos de maior calibre (10 Fr) pela melhor flexibilidade. As agulhas tipo needle-knife, por outro lado, sendo mais flexíveis, podem ser usadas à mão livre, sob controle endoscópico, como dispositivo de acesso inicial.

Em casos selecionados, é necessária dilatação do trajeto da punção, usando-se um cateter biliar de dilatação (dilatador biliar de Soehendra, Cook Endoscopy), um balão dilatador biliar (Maxpass, Olympus Medical Systems, Tóquio, Japão) ou ambos sequencialmente (dilatador axial primeiro, em seguida dilatador com balão).

O objetivo deste procedimento é dilatar a fístula transmural criada antes da inserção da prótese. A necessidade de dilatação é máxima quando não se utiliza cautério para o acesso inicial à parede gastrointestinal, quando se pretende usar uma prótese plástica de maior calibre (10 Fr), ou prótese metálica, e quando a distância até o ducto biliar ou a resistência sentida durante o avanço inicial da agulha for maior (Figura 12). 


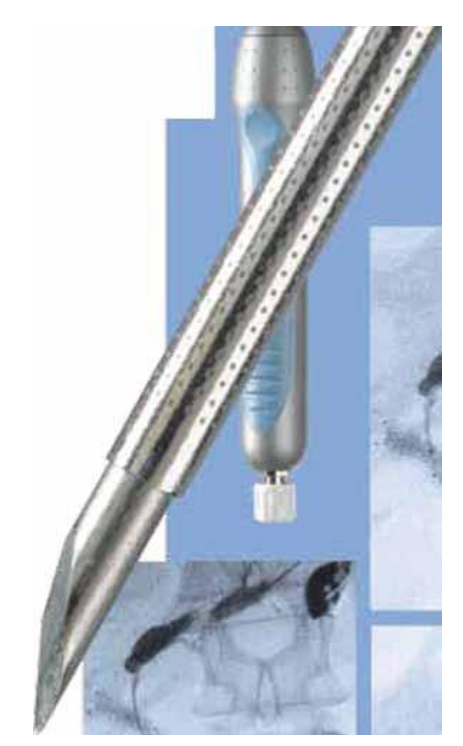

Figura 12 - Agulha de acesso tipo Echotip, da Cook Company. Quando se obtém o acesso ao ducto biliar, o estilete pode ser removido e a agulha de ponta romba deixada no local, aumentando a capacidade de manipulação do fioguia por meio do canal da agulha

Finalmente, uma prótese metálica autoexpansível é inserida no local da punção para se determinar a recanalização da via biliar (Figuras 13, 14 e 15).

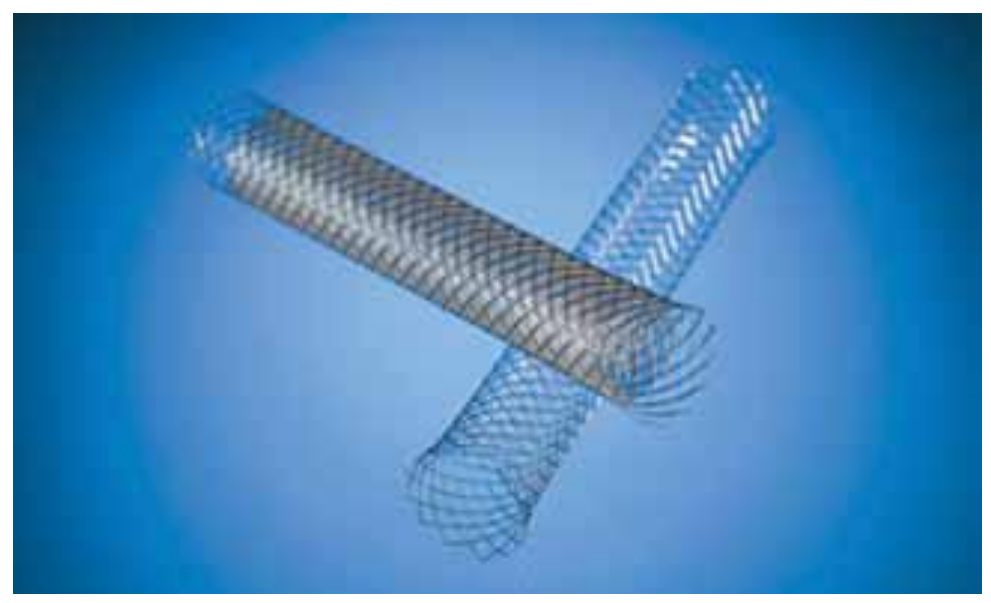

Figura 13 - Imagem de próteses metálicas autoexpansíveis não recoberta e parcialmente recoberta, da esquerda para a direita, respectivamente 


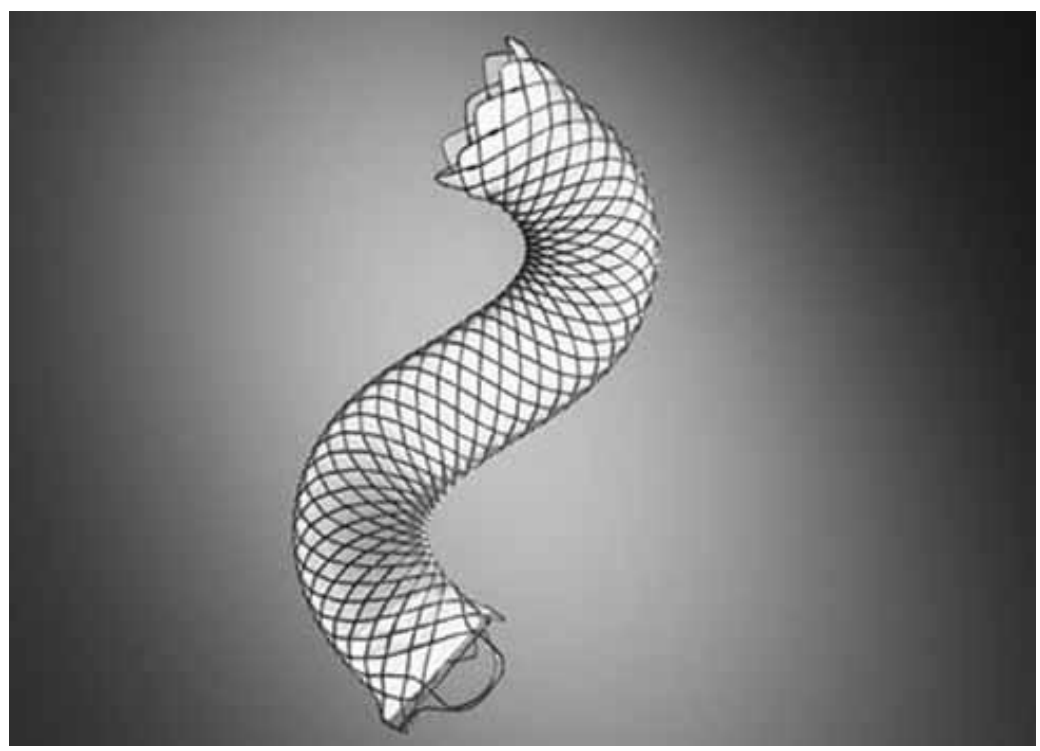

Figura 14 - Imagem de prótese metálica autoexpansível totalmente recoberta

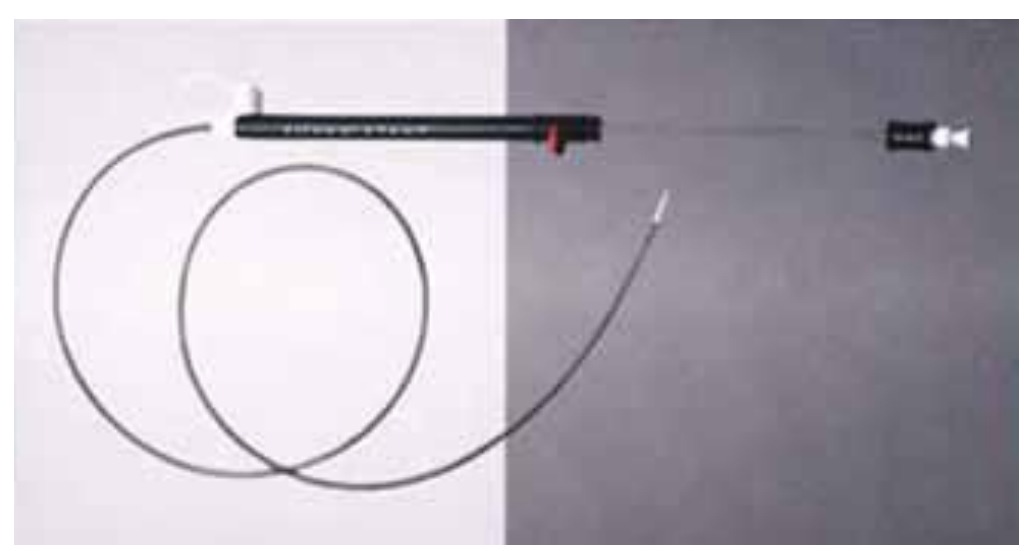

Figura 15 - Sistema de introdução de prótese metálica autoexpansível

\subsubsection{Equipamento de radioscopia}

Foi utilizado aparelho de raio $\mathrm{X}$ móvel de alta frequência com braço em C:CX2000A.

Especificações técnicas: Varredura de 1200; frequência 75 mhz; câmera de vídeo tipo CCD 752. 


\subsubsection{Preparo e técnica do exame endoscópico}

\section{Preparo}

De rotina, os pacientes foram submetidos ao procedimento com jejum de pelo menos oito horas naqueles sem suspeita de estase e de 12 horas quando havia suspeita. Foram administradas, por via oral, 40 gotas de dimeticona diluídas em $10 \mathrm{~mL}$ de água, 10 minutos antes do exame endoscópico. A anestesia tópica da faringe foi feita com cloridrato de lidocaína a 10\%, spray, com dose máxima de 100 mg. Convém lembrar que cada dose de spray contém $10 \mathrm{mg}$. A sedação endovenosa foi realizada com midazolan $(0,05 \mathrm{mg} / \mathrm{kg})$ associado a fentanil $(2 \mathrm{mcg} / \mathrm{kg})$ como dose inicial, seguido de administração controlada de propofol (1,5 mg/kg na indução).

\section{Técnica do exame endoscópico}

Os procedimentos endoscópicos foram caracterizados pelas técnicas de hepaticogastrostomia ecoguiada, hepaticojejunostomia ecoguiada, coledocoduodenostomia ecoguiada, coledocoantrostomia ecoguiada, drenagem ecoguiada anterógrada e rendez-vous ecoguiado.

\section{Hepaticogastrostomia ecoguiada}

- Identificação do ramo intra-hepático esquerdo dilatado, com o ecoendoscópio setorial posicionado junto à cárdia, na parede posterior e próximo à pequena curvatura.

- Identificação do ramo dilatado mais próximo da câmara gástrica e do trajeto de punção livre de estruturas vasculares por meio do ultrassom Doppler colorido. 
- Punção transgástrica do ramo intra-hepático dilatado, com agulha 19 gauges, confirmada mediante a aspiração de bile, seguida de colangiografia com injeção gradual e lenta de contraste, delineando a anatomia biliar e da lesão estenosante.

- Passagem de fio-guia hidrofílico de 0,035 polegadas por meio da agulha de ecopunção.

- Retirada da agulha deixando o fio-guia em posição intraductal.

- Dilatação do trajeto hepatogástrico com estilete de ponta (needleknife) ou cistótomo de 6 Fr.

- Passagem de prótese biliar metálica autoexpansível (total ou parcialmente recoberta) com a extremidade distal posicionada na via biliar e a proximal no corpo gástrico (Figura 16).

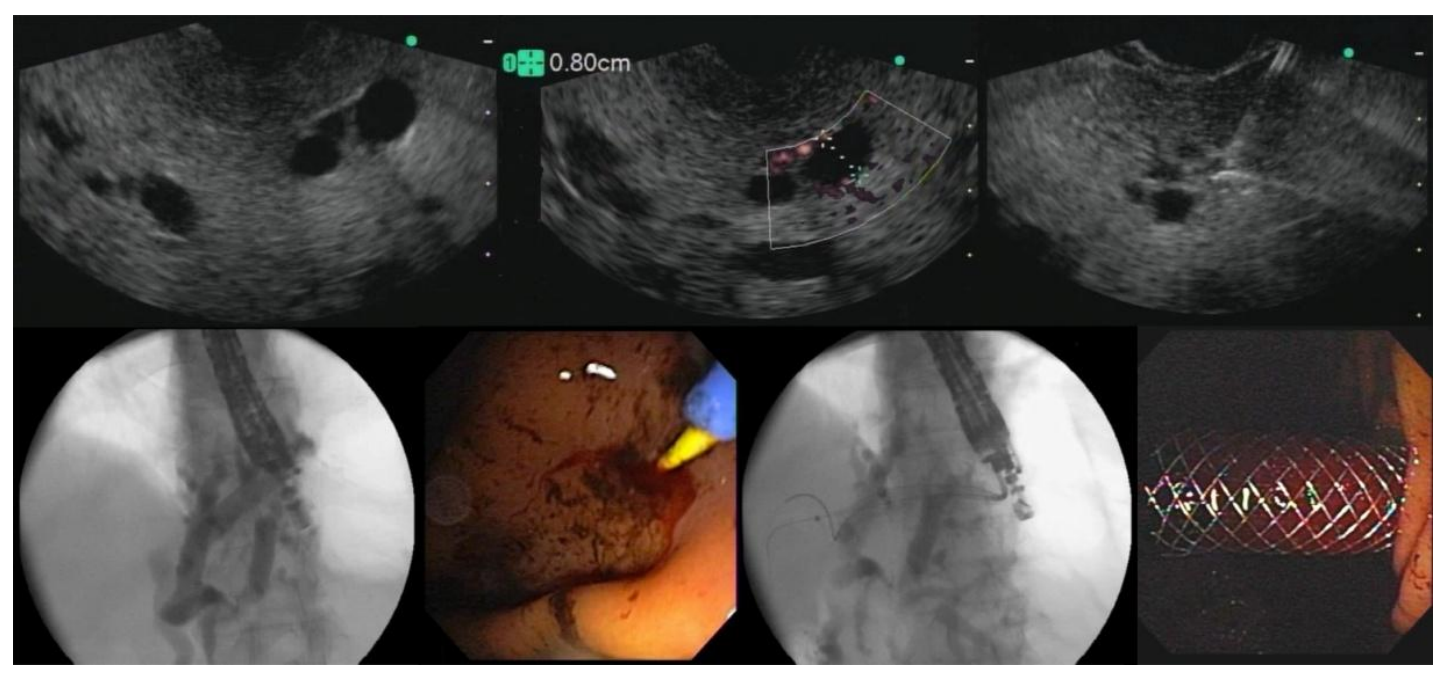

Figura 16 - Sequência de imagens ilustrando uma hepaticogastrostomia ecoguiada. Em sentido horário, notam-se: dilatação de via biliar intra-hepática, ecoendoscopia com Doppler, punção ecoguiada, colangiografia evidenciando estenose biliar maligna, ampliação da fístula com agulha tipo needle-knife, passagem de prótese metálica autoexpansível e visão endoscópica da face gástrica da prótese metálica 


\section{Hepaticojejunostomia ecoguiada}

- Identificação do ramo intra-hepático esquerdo dilatado (dilatação mínima de $8 \mathrm{~mm}$ ), com o ecoendoscópio setorial posicionado junto à parede jejunal, logo após a anastomose esôfago-jejunal.

- Identificação do ramo dilatado mais próximo da alça jejunal e de trajeto de punção livre de estruturas vasculares por meio do ultrassom Doppler colorido.

- Punção transjejunal do ramo intra-hepático dilatado, com agulha 19 gauges, confirmada mediante aspiração de bile, seguida de colangiografia com injeção gradual e lenta de contraste, delineando a anatomia biliar e da lesão estenosante.

- Passagem de fio-guia hidrofílico de 0,035 polegadas por meio da agulha de ecopunção.

- Retirada da agulha, deixando o fio-guia em posição intraductal.

- Dilatação do trajeto hepatojejunal com estilete de ponta (needleknife) ou cistótomo de 6 Fr.

- Passagem de prótese biliar metálica autoexpansível (total ou parcialmente recoberta) com a extremidade distal posicionada na via biliar e a proximal na alça jejunal. 


\section{Coledocoduodenostomia ecoguiada}

- Identificação do hepatocolédoco dilatado por via transduodenal, com o ecoendoscópio setorial posicionado no bulbo duodenal.

- Identificação de trajeto de punção livre de estruturas vasculares mediante Doppler.

- Punção transduodenal do hepatocolédoco dilatado, com agulha 19 gauges, confirmada pela aspiração de bile e posterior colangiografia, delineando a anatomia biliar e da lesão estenosante.

- Passagem de fio-guia hidrofílico de 0,035 polegadas com uma agulha de ecopunção atingindo a via biliar extra-hepática.

- Retirada da agulha, deixando o fio-guia em posição intraductal.

- Dilatação do trajeto coledocoduodenal com estilete de ponta (needle-knife) ou cistótomo de $6 \mathrm{Fr}$.

- Passagem de prótese biliar metálica autoexpansível (total ou parcialmente recoberta) com a extremidade distal posicionada na via biliar e a proximal no bulbo duodenal (Figura17).

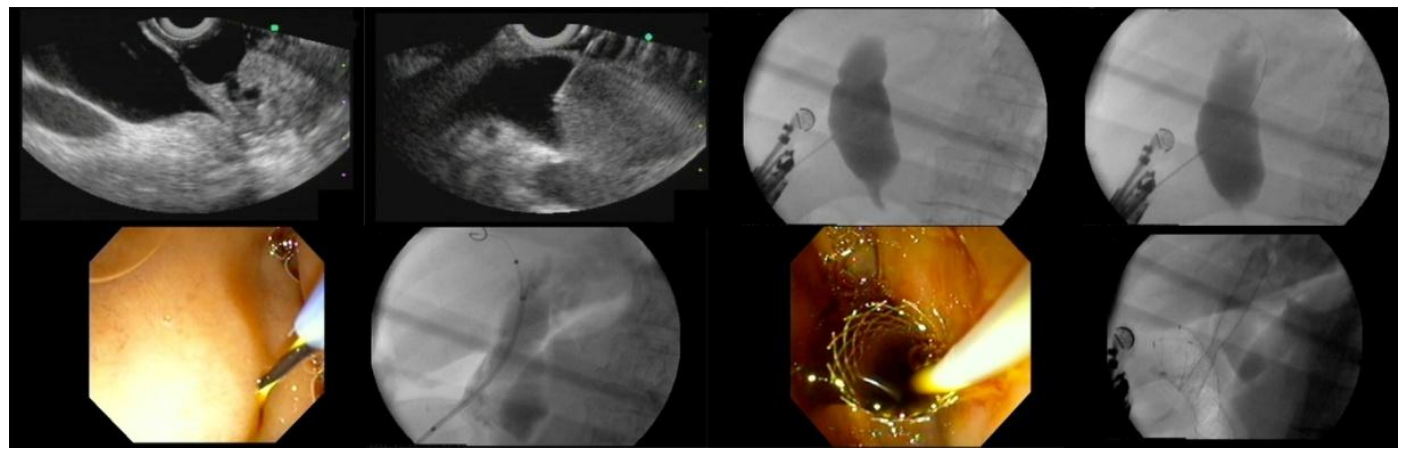

Figura 17 - Sequência de imagens ilustrando uma coledocoduodenostomia ecoguiada. Em sentido horário, notam-se: dilatação de via biliar extrahepática, visão ecográfica da punção, colangiografia evidenciando estenose biliar maligna, passagem de fio-guia transtumoral, ampliação da fístula com agulha tipo needle-knife, passagem de prótese biliar metálica autoexpansível, visão endoscópica da liberação da prótese biliar e visão por radioscopia das próteses biliar e duodenal 


\section{Coledocoantrostomia ecoguiada}

- Identificação do hepatocolédoco dilatado por via transgástrica, com o ecoendoscópio setorial posicionado no antro gástrico distal.

- Identificação de trajeto de punção livre de estruturas vasculares via Doppler.

- Punção transgástrica do hepatocolédoco dilatado, com agulha 19 gauges, confirmada mediante a aspiração de bile e posterior colangiografia, delineando a anatomia biliar e a lesão estenosante.

- Passagem de fio-guia hidrofílico de 0,035 polegadas por meio da agulha de ecopunção, atingindo a via biliar extra-hepática.

- Retirada da agulha, deixando o fio-guia em posição intraductal.

- Dilatação do trajeto coledocogástrico com estilete de ponta (needleknife) ou cistótomo de 6 Fr.

- Passagem de prótese biliar metálica autoexpansível (total ou parcialmente recoberta) com a extremidade distal posicionada na via biliar e a proximal no antro gástrico.

- Na presença de ducto esquerdo normal e extra-hepático dilatado, realiza-se ecopunção transgástrica em direção à porção cranial do colédoco, seguida pelos mesmos passos citados acima (primeiro item). $\mathrm{O}$ acesso transmural transpapilar anterógrado ou a coledocoantrostomia são as opções pertinentes nesta condição anatômica (Figuras 18, 19 e 20). 


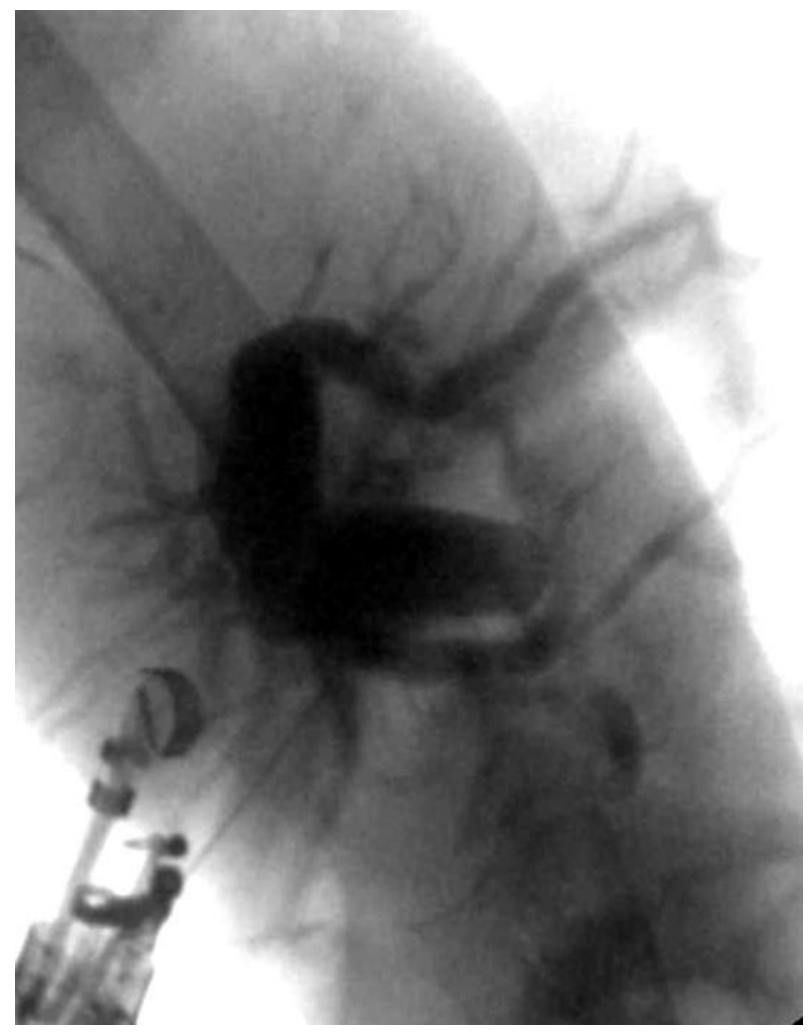

Figura 18 - Coledocoantrostomia - Punção da via biliar extra-hepática e injeção de contraste (colangiografia)

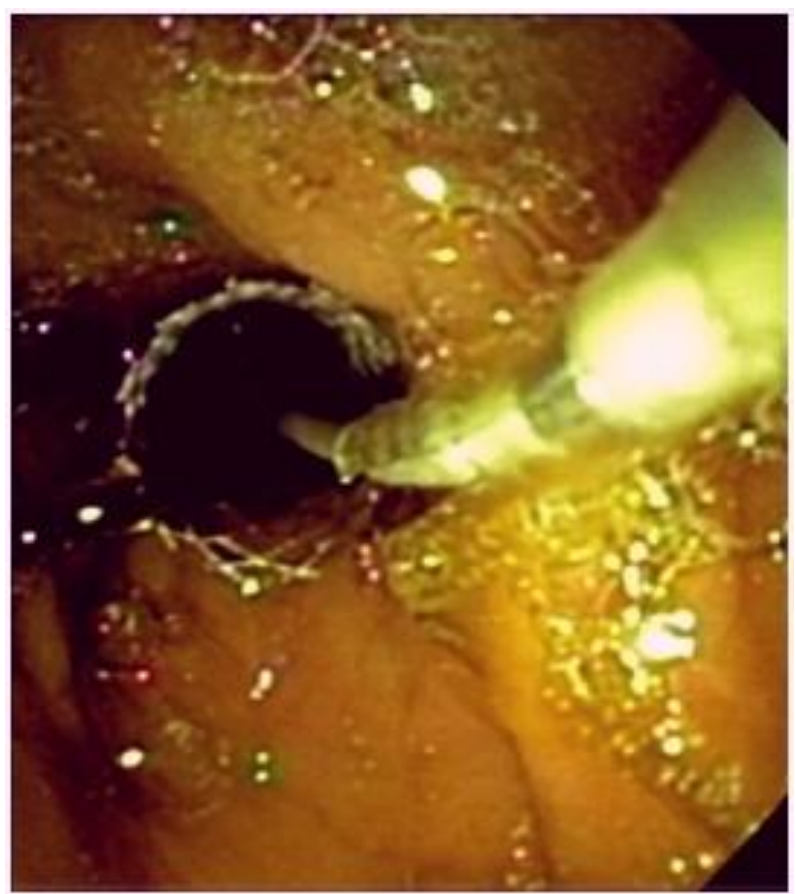

Figura 19 - Coledocoantrostomia - Imagem endoscópica da prótese biliar no antro distal 


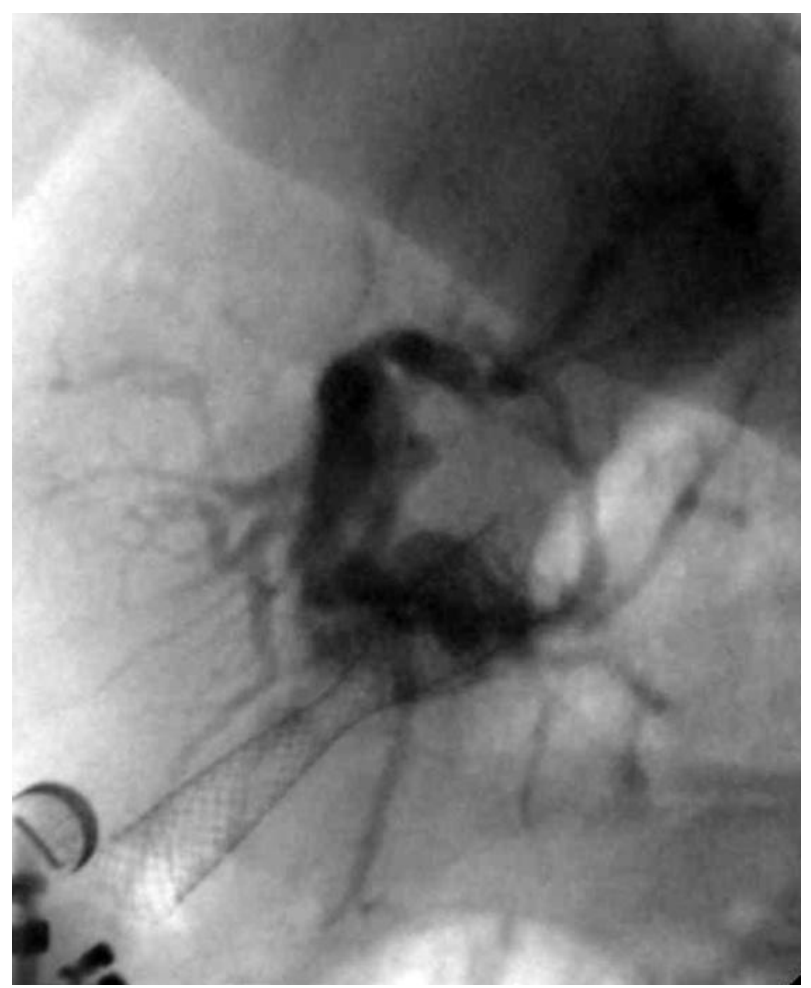

Figura 20 - Coledocoantrostomia - Imagem radiológica da recanalização biliar por prótese metálica parcialmente coberta (aspecto final)

Drenagem anterógrada ecoguiada e rendez-vous ecoguiado

Como já citado na Revisão de Literatura, o acesso transgástrico ou transentérico sob orientação ultrassonográfica foi descrito tanto para as técnicas de rendez-vous ecoguiado como para a drenagem anterógrada. Em comum para ambas as técnicas existe a necessidade da passagem bemsucedida do fio-guia através da estenose biliar até um segmento intestinal de delgado a jusante. Diferente da técnica de rendez-vous, em que o ultrassom endoscópico é usado apenas para acessar o ducto biliar obstruído e passar o fio-guia em sentido anterógrado através da papila (para posterior realização de CPRE padronizada), na técnica de drenagem anterógrada ecoguiada ocorre a passagem transpapilar da prótese em direção ao trato gastrointestinal (Figuras 21, 22 e 23). 


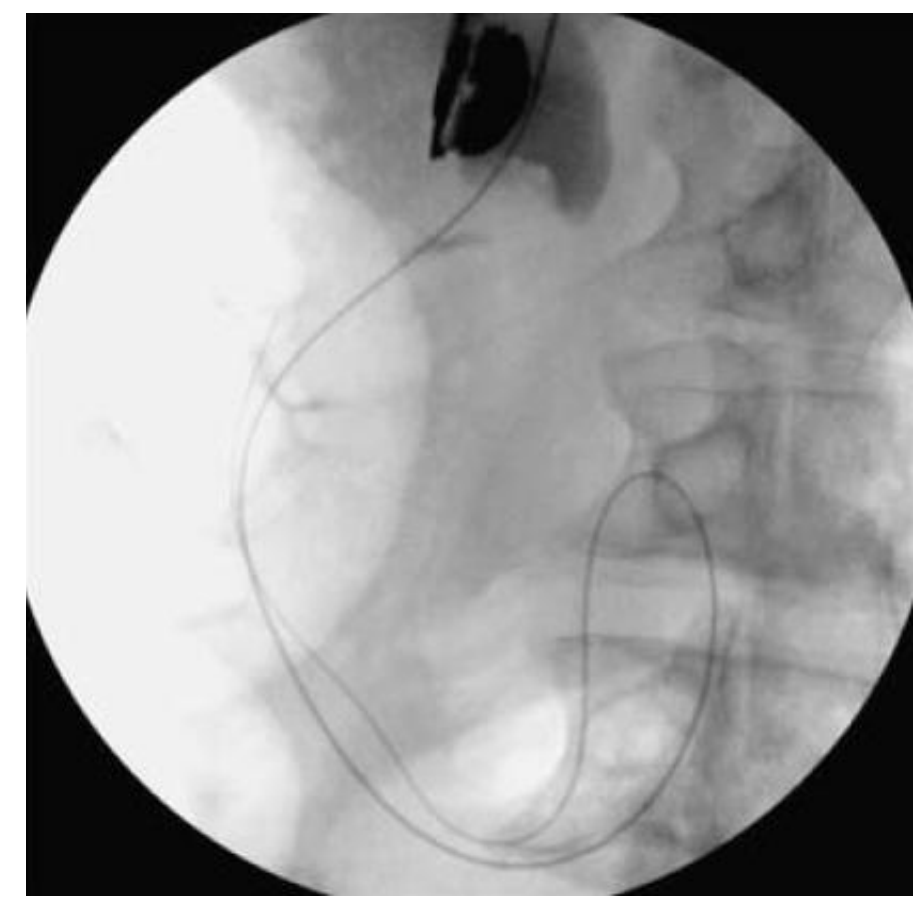

Figura 21 - Imagem radiológica da técnica de rendez-vous ecoguiado, demonstrando a passagem do fio-guia através da estenose biliar e em direção ao duodeno

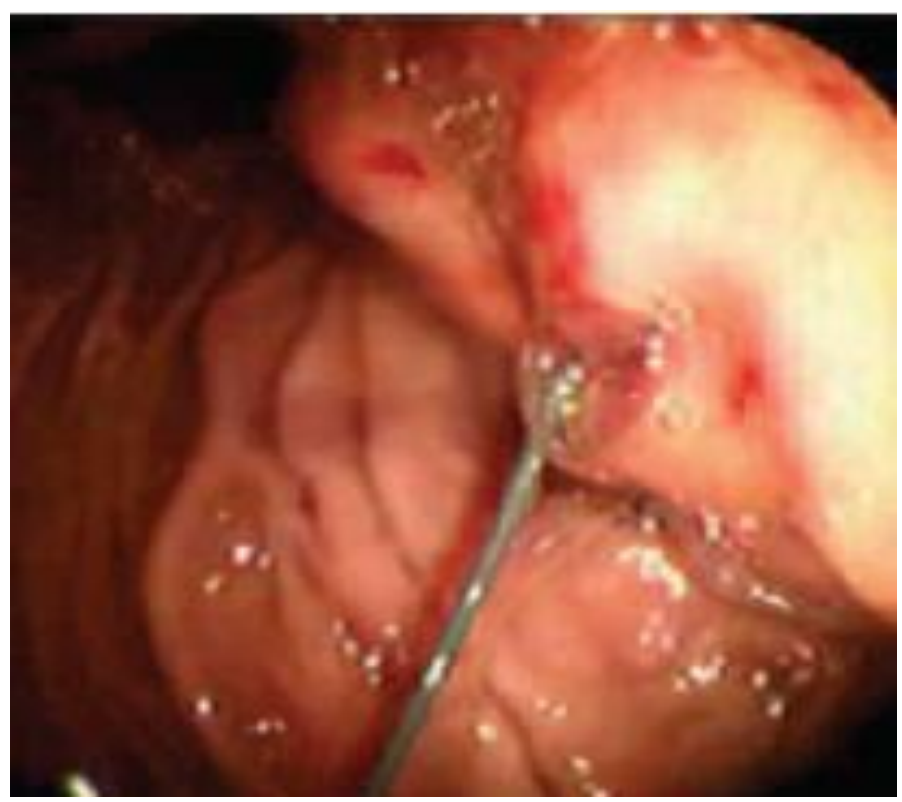

Figura 22 - Imagem endoscópica da técnica de rendez-vous ecoguiado, demonstrando o fio-guia exteriorizado na região da papila duodenal maior 


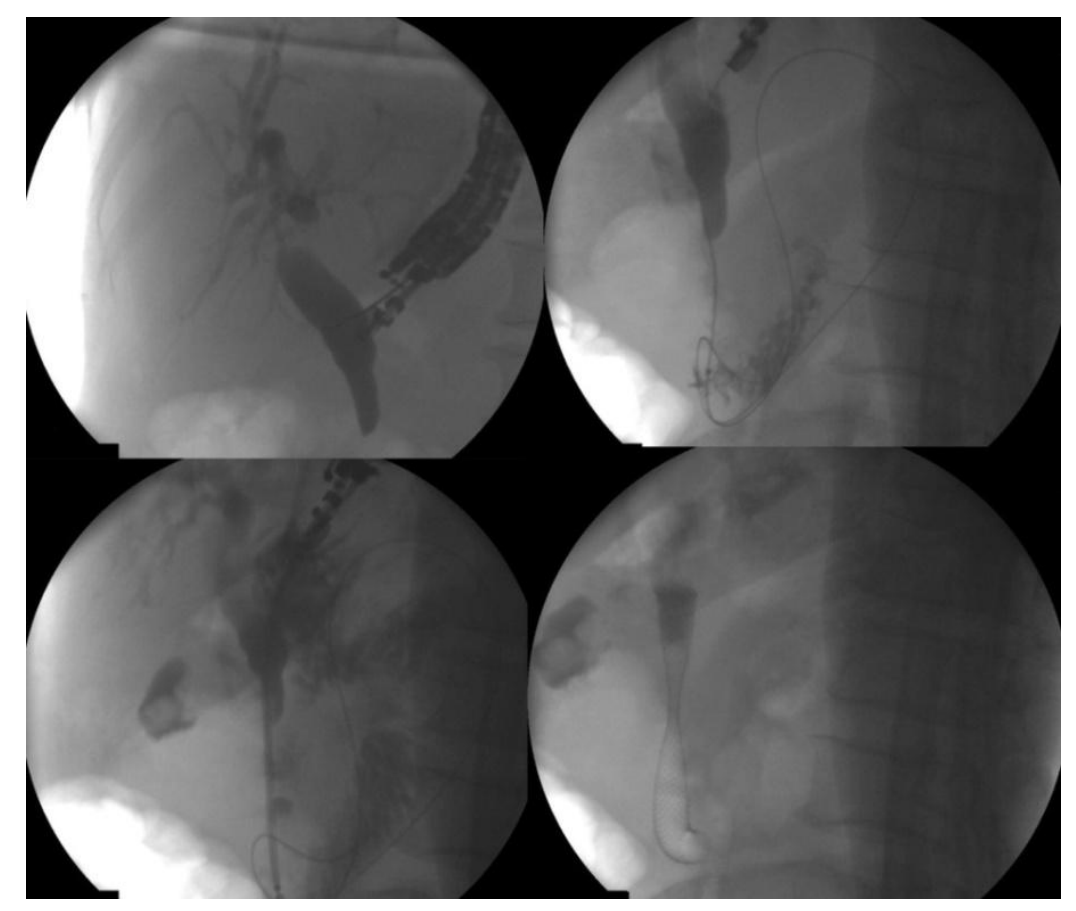

Figura 23 - Sequência de imagens radiológicas ilustrando a técnica de drenagem ecoguiada anterógrada extra-hepática em paciente com estenose biliar maligna e gastrectomia subtotal com reconstrução em Y-de-Roux. Em sentido horário, notam-se: colangiografia após punção ecoguiada extrahepática, passagem de fio-guia transtumoral, liberação de prótese metálica autoexpansível e recanalização anatômica da via biliar com drenagem adequada de contraste

\subsubsection{Dados endoscópicos}

\subsubsection{Dados gerais ecoendoscópicos}

$\mathrm{Na}$ avaliação ecoendoscópica, foram considerados dados particularizados aos aspectos dos procedimentos ultrassonográficos de drenagem biliar assistida, a saber:

- Alterações anatômicas do trato gastrointestinal alto.

- Irressecabilidade da lesão.

- Presença de ascite de pequenas proporções verificadas nas janelas examinadas durante os exames perigástrico e duodenal.

- Relação das estruturas adjacentes com ultrassom Doppler colorido.

- Espessura da parede do trato gastrointestinal. 
- Distância a ser percorrida até a via biliar (distância probe ao hepatocolédoco.

- Diâmetro da via biliar na ocasião da drenagem.

\subsubsection{Invasão duodenal}

O comprometimento duodenal com invasão por contiguidade da neoplasia maligna biliar foi caracterizada, à endoscopia convencional, como falta de distensibilidade, friabilidade mucosa e áreas lineares de solução de continuidade da mucosa, localizadas na face medial da segunda porção duodenal e/ou bulbo com ou sem diminuição da luz intestinal. À ecoendoscopia, os achados que caracterizavam a invasão duodenal foram: perda da interface hiperecoica (relativo à camada adventícia) entre a lesão e a parede duodenal, espessamento hipoecoico e com perda das ecocamadas da parede duodenal subjacente à lesão, inclusive com neovascularização intensa verificada com recurso do ultrassom Doppler colorido.

Foram posicionadas próteses metálicas enterais, combinada a passagem ecoguiada de prótese biliar, nos pacientes que apresentassem os seguintes cenários clínicos:

- Invasão circunferencial com estreitamento do lúmen acima do limite de $50 \%$.

- Extensão longitudinal da lesão, com ou sem acometimento circunferencial, correspondendo à extensão de $10 \mathrm{~cm}$ em direção distal ou proximal.

- Invasão do eixo piloro-duodenal. 


\subsubsection{Caracterização das complicações relacionadas ao procedimento}

$\mathrm{Na}$ avaliação das complicações pertinentes aos procedimentos de drenagem ecoguiada, foram considerados: abscesso, dor abdominais, perfuração gastrointestinal, hemorragia, colangite, pancreatite aguda, fístula biliar e migração da prótese.

A dor abdominal considerada foi a dor persistente após seis horas do procedimento, de moderada para forte intensidade, localizada em epigástrio ou flanco direito.

A perfuração gastrointestinal relacionada ao contexto do procedimento ecoguiado foi considerada quando da passagem do aparelho pelo trajeto orogastroduodenal ou pela manipulação papilar prévia, ou, ainda, pelo procedimento ecoguiado propriamente dito.

O abscesso abdominal foi considerado quando da presença de coleção abdominal caracterizada por método de imagem não invasivo, associado a dados clínicos de dor, febre e leucocitose persistentes.

A pancreatite aguda após o procedimento foi considerada em pacientes com dor persistente, associada a aumento da amilase sérica acima de três vezes o limite da normalidade.

A fístula biliar verificada na ocasião do procedimento caracterizou-se pelo extravasamento de contraste na região sub-hepática. Em caráter tardio, tal complicação foi nominada pela evidência de coleção peri ou sub-hepática com ou sem sintomas abdominais.

A migração da prótese foi particularizada de acordo com dados temporais, tipo de prótese, posição da migração e complexidade, a saber: 
- Temporal: precoce (até sete dias do procedimento), mediata (de sete a 30 dias) e tardia (após 30 dias).

- Tipos de prótese: biliar e duodenal.

- Posições: proximal, distal e intraperitoneal.

- Complexidade: com ou sem hemorragia/ulceração duodenal associadas.

\subsubsection{Seguimento do paciente}

\subsubsection{Avaliação clínica e laboratorial}

O seguimento dos pacientes no presente estudo ocorreu por acompanhamento ambulatorial por médicos do Serviço de Endoscopia Digestiva do HC-FMUSP. Dados clínicos e laboratoriais foram avaliados antes do procedimento endoscópico ecoguiada e sete, 30, 60 e 90 dias após. Na ocasião de eventual óbito dos pacientes durante a fase de seguimento, os dados foram compilados para a análise de sobrevida. Dados clínicos, laboratoriais e de imagem foram incluídos com a intenção de auxiliar na identificação e no tratamento de eventuais complicações.

\subsubsection{Avaliação da qualidade de vida}

O reconhecimento da necessidade de monitoração e avaliação do tratamento, pelo ponto de vista do paciente, fez surgir instrumentos, criados com a finalidade de medir subjetivamente as condições de bem-estar dos indivíduos. As repetidas aplicações desses instrumentos no decorrer de um 
período podem definir a melhora ou piora do paciente em diferentes aspectos, tanto físicos como emocionais, tornando-se úteis para avaliação de determinada intervenção.

Ressaltamos, neste trabalho, a necessidade de possuirmos 0 parâmetro de avaliação qualidade de vida, para nortear a decisão quanto a melhor forma de paliação a este grupo de pacientes. A referida avaliação ocorreu por meio do índice Medical Outcomes Study 36 - Item Short- Form Health Survey (SF-36). Constitui-se de um questionário multidimensional formado por 36 itens, englobados em oito domínios: capacidade funcional, aspectos físicos, dor, estado geral da saúde (EGS), vitalidade, aspectos sociais, aspectos emocionais e saúde mental. Apresenta um escore final de 0 a 100, no qual o zero corresponde a pior estado geral de saúde e 100 a melhor estado de saúde (Anexo E e F).

\subsubsection{Análise estatística}

As características clínicas e demográficas dos pacientes foram descritas com uso de frequências absolutas e relativas e as características quantitativas pré-operatórias foram descritas com uso de medidas-resumo (média e desvio padrão).

Os exames laboratoriais e os escores de qualidade de vida em cada domínio foram descritos segundo o momento de avaliação com uso de medidas-resumo (média, desvio padrão, mediana, mínimo e máximo) e foi avaliada a normalidade de distribuição de probabilidades de cada parâmetro com uso de testes Kolmogorov-Smirnov (Kirkwood e Sterne, 2006); para os 
parâmetros estudados, não foi aceita essa suposição $(p<0,05)$ em algum dos momentos de avaliação.

As comparações dos parâmetros avaliados entre os momentos de avaliação foram realizadas com 0 uso de equação de estimação generalizada com matriz de correlações autorregressiva de ordem um entre os momentos, com distribuição marginal Gama e função de ligação identidade (McCullagh e Nelder, 1989), sendo a melhor distribuição de probabilidades para os parâmetros avaliados devido à assimetria na distribuição dos dados. Para os modelos que apresentaram significância estatística, a análise foi seguida de comparações múltiplas de Bonferroni (Neter et al., 1996) para saber entre quais momentos ocorrem as diferenças nos variáveis de exames e qualidade de vida.

A opção por um modelo paramétrico com distribuição não normal em detrimento de comparações não paramétricas deu-se em virtude da grande quantidade de óbitos que acontecem neste tipo de paciente e na análise não paramétrica, a comparação só seria possível nos pacientes vivos até o final do estudo.

Foi utilizada a função Kaplan-Meier (Kleinbaum, 1996) para estimar o tempo médio e mediano de sobrevida dos pacientes após a cirurgia.

Os testes foram realizados com nível de significância de 5\%. 


\section{Resultados}


Os resultados advindos do presente estudo compuseram análise prospectiva de 32 pacientes no total, sendo que $3(9,4 \%)$ foram excluídos devido a falha técnica. O sucesso técnico foi de 90,6\% (29/32) e o clínico de $100 \%(29 / 29)$.

As causas de falha no acesso anatômico convencional pela CPRE e que permitiram a inclusão dos pacientes no presente estudo foram:

- Dificuldade de canulação convencional da papila duodenal maior em $21(72,41 \%)$ pacientes.

- Infiltração neoplásica da papila duodenal maior em cinco $(17,24 \%)$ pacientes.

- Infiltração neoplásica piloro-duodenal em 1 (3,44\%) paciente.

- Cirurgia derivativa prévia em que não se permitiu o acesso por CPRE em $1(3,44 \%)$ caso.

- Neoplasia biliar distal com papila intradiverticular em $1 \quad(3,44 \%)$ paciente. 


\subsection{Dados Endoscópicos}

\subsubsection{Dados gerais ecoendoscópicos}

Inicialmente, os 32 pacientes do presente estudo foram submetidos à avaliação de estadiamento loco-regional da lesão obstrutiva biliar e biópsias por aspiração por meio de exame ecoendoscópico setorial. Em relação ao diâmetro da via biliar, verificou-se que a extra-hepática apresentou mediana de 23,45 mm (20 - $30 \mathrm{~mm})$ e a intra-hepática foi de 17,54 mm (10 - $24 \mathrm{~mm})$. Os achados ultrassonográficos descritos a seguir contribuíram tanto para a avaliação do estadiamento do paciente, bem como para a caracterização da irressecabilidade da lesão:

- Metástase à distância em 6 (18,75\%) pacientes.

- Invasão do eixo mesentero-portal em 26 (81,25\%) pacientes.

- Ascite em 6 (18,75\%) pacientes

\subsubsection{Invasão duodenal}

A invasão duodenal ocorreu em 10 (31,25\%) pacientes e foi posicionada prótese metálica enteral em 7 (21,75\%) casos. Não ocorreram complicações imediatas, tampouco tardias relacionadas ao procedimento de liberação duodenal da prótese metálica. Em 3 (9,37\%) pacientes com invasão não extensa e assintomática duodenal, de acordo com os parâmetros anteriormente citados na sessão de método, optou-se apenas por seguimento (Figura 24). 

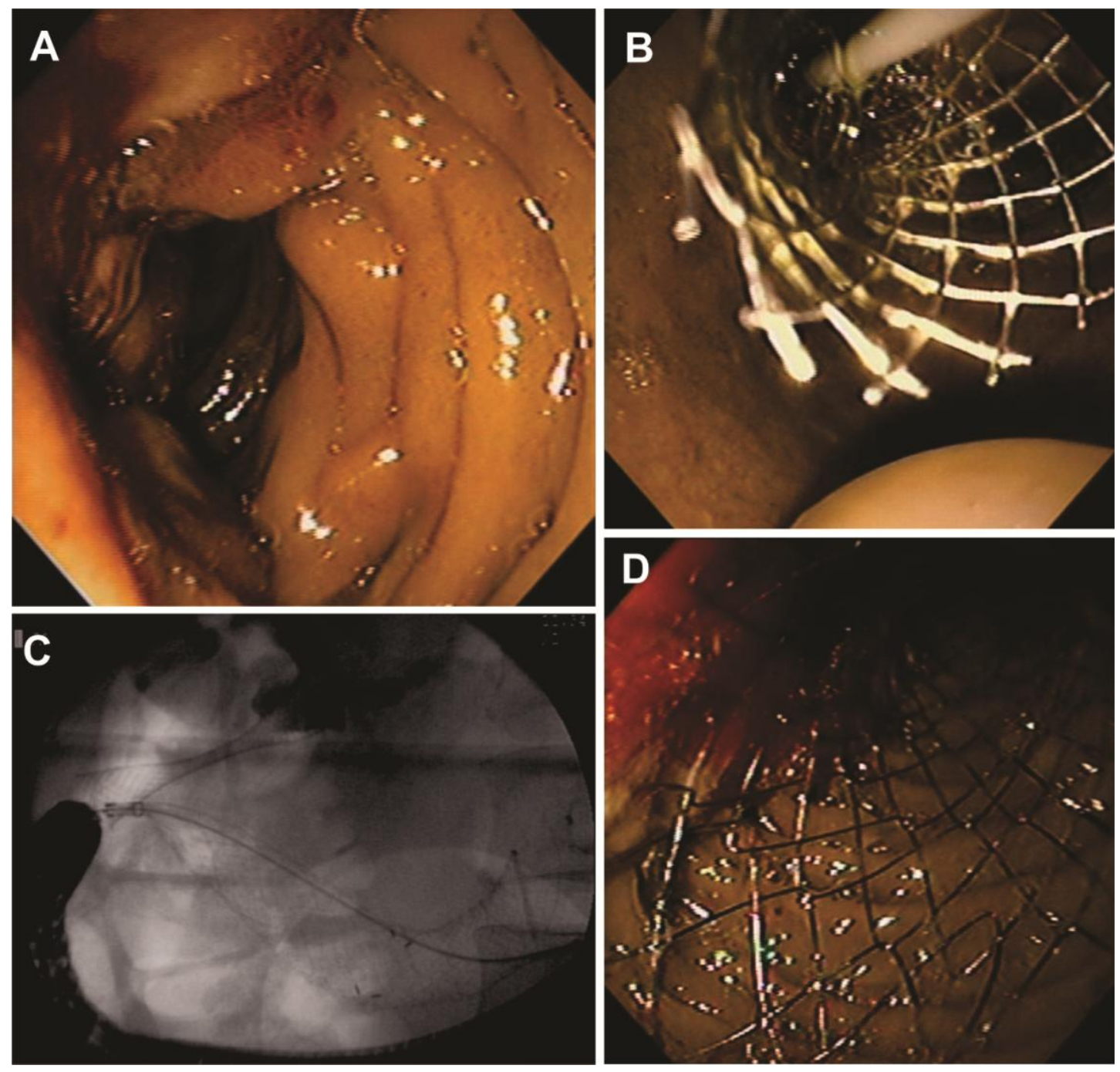

Figura 24 - (A) imagem endoscópica de infiltração duodenal secundária ao tumor pancreático; (B) imagem endoscópica de prótese metálica em bulbo duodenal, caracterizando fistulização biliar por coledocoduodenostomia; (C) imagem radiológica da prótese metálica biliar e duodenal e (D) imagem endoscópica da prótese metálica duodenal 


\subsubsection{Dados do procedimento ecoguiado de drenagem}

A DBE foi realizada em 29 (90,62\%) pacientes pelas seguintes técnicas:

- Coledocoduodenostomia em 17 (58,62\%) pacientes.

- Hepaticogastrostomia em 6 (20,68\% pacientes).

- Drenagem anterógrada em 2 (6,89\%) pacientes.

- Coledocoantrostomia em 2 (6,89\%) pacientes.

- Hepaticojejunostomia em 1 (3,44\%) paciente.

- Rendez-vous ecoguiado em 1 (3,44\%) paciente.

A inserção de prótese enteral foi necessária em quatro casos (12,5\%). O diâmetro médio da via biliar na ocasião do procedimento foi de 20,49 mm e o tempo médio de procedimento foi de 47 minutos. Em todos os casos, optou-se pela passagem de prótese metálica biliar autoexpansível parcialmente coberta.

\subsection{Complicações Relacionadas ao Procedimento}

As complicações ocorreram em 6 (18,75\%) pacientes. Um $(3,44 \%)$ evoluiu com quadro clínico de dor abdominal intensa logo após o procedimento e respondeu prontamente à analgesia e hidratação. Dois (6,89\%) apresentaram quadro de hemorragia na extremidade intraluminal da prótese evidenciada em um segundo exame endoscópico e foram tratados com injeção intramucosa de solução decimal de adrenalina e plasma de argônio, respectivamente.

Fístula biliar precoce foi evidenciada em 1 (3,44\%) paciente mediante tomografia computadorizada de abdômen, que demonstrou uma coleção em loja sub-hepática de $4 \mathrm{~cm}$ em seu maior eixo. O paciente apresentou 
evolução favorável apenas com tratamento conservador, não necessitando de procedimentos minimamente invasivos.

Em um paciente $(3,44 \%)$ submetido à técnica de hepaticogastrostomia ecoguiada ocorreu migração precoce da prótese pelo deslocamento de sua extremidade intragástrica para a cavidade abdominal. $\bigcirc$ paciente foi encaminhado à cirurgia e a prótese foi novamente locada entre a via biliar intrahepática e a cavidade gástrica.

A migração da prótese se deu como resultado de complicação tardia em $1(3,44 \%)$ paciente e foi evidenciada por exame de Rx convencional. Esta complicação ocorreu aos 40 dias do procedimento. A conduta no presente caso foi totalmente conservadora, na medida em que o trajeto fistuloso encontrava-se bem formado e pérvio, o que não implicou em morbidade adicional ao paciente.

\subsection{Seguimento dos Pacientes}

\subsubsection{Avaliação clínica}

No presente estudo, a DBE foi realizada como medida paliativa, com o propósito de melhorar a qualidade de vida destes pacientes. Dez $(34,48 \%)$ deles, ao longo do seguimento, referiram dores epigástrica e retroesternal em queimação. Ressalta-se que há possibilidade de desenvolvimento de gastrite alcalina nestes pacientes; contudo, ao considerar a sobrevida e a melhoria da qualidade de vida, este evento foi tido como pouco significativo e passível de controle clínico, utilizando-se medidas comportamentais e inibidores de bomba de prótons em dose plena. 


\subsubsection{Avaliação laboratorial}

$\mathrm{Na}$ Tabela 3 observa-se que os parâmetros laboratoriais avaliados (bilirrubina total, gama glutamil transferase, fosfatase alcalina e número de leucócitos) nos 29 pacientes submetidos à DBE demonstraram melhora estatisticamente significativa ao longo dos momentos avaliados $(p<0,05)$.

Tabela 3 - Descrição dos exames ao longo do seguimento e resultado dos testes comparativos

\begin{tabular}{|c|c|c|c|c|c|c|c|c|}
\hline Variável & Momento & Média & DP & Mediana & Mínimo & Máximo & $\mathbf{N}$ & $p$ \\
\hline \multirow{5}{*}{ BT } & Pré & 14,09 & 5,69 & 14,2 & 3,54 & 27,12 & 29 & \multirow{5}{*}{$<0,001$} \\
\hline & 7 dias & 4,26 & 2,69 & 3,4 & 2,2 & 15,7 & 29 & \\
\hline & 1 mês & 2,29 & 0,85 & 2,1 & 0,85 & 5,5 & 29 & \\
\hline & 2 meses & 1,83 & 0,50 & 1,8 & 0,8 & 3 & 25 & \\
\hline & 3 meses & 1,83 & 0,49 & 1,9 & 0,7 & 2,5 & 13 & \\
\hline \multirow{5}{*}{ Ggt } & Pré & 867,50 & 400,67 & 738 & 292 & 1671,4 & 29 & \multirow{5}{*}{$<0,001$} \\
\hline & 7 dias & 193,69 & 122,21 & 154 & 76 & 567 & 29 & \\
\hline & 1 mês & 128,66 & 100,52 & 105 & 65 & 533 & 29 & \\
\hline & 2 meses & 95,96 & 20,27 & 90 & 67 & 169 & 26 & \\
\hline & 3 meses & 87,77 & 16,98 & 87 & 58 & 125 & 13 & \\
\hline \multirow{5}{*}{ FA } & Pré & 520,62 & 206,42 & 473 & 233 & 928 & 29 & \multirow{5}{*}{$<0,00$} \\
\hline & 7 dias & 134,83 & 71,17 & 112 & 75 & 345 & 29 & \\
\hline & 1 mês & 92,97 & 44,09 & 89 & 4 & 298 & 29 & \\
\hline & 2 meses & 91,92 & 14,57 & 94,5 & 59 & 115 & 26 & \\
\hline & 3 meses & 93,08 & 9,80 & 90 & 78 & 112 & 13 & \\
\hline \multirow{5}{*}{ Leucócitos } & Pré & 9301,72 & 5141,88 & 7530 & 1960 & 24910 & 29 & \multirow{5}{*}{0,042} \\
\hline & 7 dias & 10327,59 & 12727,22 & 7600 & 5600 & 76000 & 29 & \\
\hline & 1 mês & 8200,00 & 953,19 & 8000 & 6400 & 9900 & 29 & \\
\hline & 2 meses & 7533,77 & 1277,37 & 7500 & 5400 & 9400 & 26 & \\
\hline & 3 meses & 7861,54 & 1087,46 & 7900 & 5800 & 9000 & 13 & \\
\hline
\end{tabular}

BT - Bilirrubina total; Ggt - gama glutamil transferase; FA - fosfatase alcalina.

Os valores de bilirrubina total, gama-glutamil-transferase e fosfatase alcalina diminuíram estatisticamente, em média, da pré-drenagem comparando aos demais momentos avaliados $(p<0,05)$ e do sétimo dia para os momentos seguintes avaliados $(p<0,05)$; a partir de um mês, não houve alteração média estatisticamente significativa nos parâmetros laboratoriais $(p>0,05)$. O valor de leucócitos, apesar de ter apresentado 
alteração média estatisticamente significativa ( $p=0,042$ - Tabela 3), não foi possível estabelecer entre quais momentos ocorreram as diferenças neste parâmetro devido à grande variabilidade nesta medida $(p>0,05)$ (Tabela 4).

Tabela 4 - Resultado das comparações multivariada dos parâmetros laboratoriais entre os momentos de avaliação

\begin{tabular}{|c|c|c|c|c|c|c|c|}
\hline \multirow{2}{*}{ Variável } & \multirow{2}{*}{ Comparação } & \multirow{2}{*}{$\begin{array}{c}\text { Diferença } \\
\text { média }\end{array}$} & \multirow{2}{*}{$\begin{array}{c}\text { Erro } \\
\text { Padrão }\end{array}$} & \multirow{2}{*}{ gl } & \multirow{2}{*}{$\mathbf{p}$} & \multicolumn{2}{|c|}{ IC (95\%) } \\
\hline & & & & & & Inferior & Superior \\
\hline \multirow{10}{*}{ BT } & Pré - 7 dias & 9,83 & 0,98 & 1 & $<0,001$ & 7,91 & 11,75 \\
\hline & Pré - 1 mês & 11,79 & 0,99 & 1 & $<0,001$ & 9,86 & 13,73 \\
\hline & Pré - 2 meses & 12,26 & 1,03 & 1 & $<0,001$ & 10,24 & 14,28 \\
\hline & Pré - 3 meses & 12,27 & 1,01 & 1 & $<0,001$ & 10,29 & 14,25 \\
\hline & 7 dias - 1 mês & 1,96 & 0,37 & 1 & $<0,001$ & 1,23 & 2,69 \\
\hline & 7 dias - 2 meses & 2,43 & 0,51 & 1 & $<0,001$ & 1,44 & 3,42 \\
\hline & 7 dias - 3 meses & 2,44 & 0,51 & 1 & $<0,001$ & 1,45 & 3,43 \\
\hline & 1 mês - 2 meses & 0,47 & 0,17 & 1 & 0,066 & 0,13 & 0,80 \\
\hline & 1 mês - 3 meses & 0,48 & 0,19 & 1 & 0,146 & 0,09 & 0,86 \\
\hline & 2 meses - 3 meses & 0,01 & 0,11 & 1 & $>0,999$ & $-0,21$ & 0,23 \\
\hline \multirow{10}{*}{ Ggt } & Pré - 7 dias & 673,81 & 73,33 & 1 & $<0,001$ & 530,08 & 817,54 \\
\hline & Pré - 1 mês & 738,84 & 71,64 & 1 & $<0,001$ & 598,43 & 879,26 \\
\hline & Pré - 2 meses & 771,87 & 72,61 & 1 & $<0,001$ & 629,57 & 914,18 \\
\hline & Pré - 3 meses & 779,94 & 73,23 & 1 & $<0,001$ & 636,41 & 923,47 \\
\hline & 7 dias - 1 mês & 65,03 & 13,43 & 1 & $<0,001$ & 38,71 & 91,36 \\
\hline & 7 dias - 2 meses & 98,07 & 21,60 & 1 & $<0,001$ & 55,73 & 140,40 \\
\hline & 7 dias - 3 meses & 106,13 & 22,74 & 1 & $<0,001$ & 61,57 & 150,70 \\
\hline & 1 mês - 2 meses & 33,03 & 16,61 & 1 & 0,467 & 0,48 & 65,58 \\
\hline & 1 mês - 3 meses & 41,10 & 20,31 & 1 & 0,430 & 1,30 & 80,90 \\
\hline & 2 meses - 3 meses & 8,07 & 6,56 & 1 & $>0,999$ & $-4,80$ & 20,93 \\
\hline \multirow{10}{*}{ FA } & Pré - 7 dias & 385,79 & 42,23 & 1 & $<0,001$ & 303,03 & 468,56 \\
\hline & Pré - 1 mês & 427,66 & 39,50 & 1 & $<0,001$ & 350,23 & 505,08 \\
\hline & Pré - 2 meses & 428,62 & 37,28 & 1 & $<0,001$ & 355,56 & 501,69 \\
\hline & Pré - 3 meses & 427,42 & 38,55 & 1 & $<0,001$ & 351,87 & 502,98 \\
\hline & 7 dias - 1 mês & 41,86 & 11,54 & 1 & 0,003 & 19,25 & 64,48 \\
\hline & 7 dias - 2 meses & 42,83 & 12,41 & 1 & 0,006 & 18,51 & 67,15 \\
\hline & 7 dias - 3 meses & 41,63 & 11,98 & 1 & 0,005 & 18,14 & 65,12 \\
\hline & 1 mês - 2 meses & 0,97 & 8,23 & 1 & $>0,999$ & $-15,17$ & 17,10 \\
\hline & 1 mês - 3 meses & $-0,23$ & 7,68 & 1 & $>0,999$ & $-15,29$ & 14,82 \\
\hline & 2 meses - 3 meses & $-1,20$ & 4,14 & 1 & $>0,999$ & $-9,31$ & 6,91 \\
\hline \multirow{10}{*}{ Leucócitos } & Pré - 7 dias & $-1025,86$ & 2607,22 & 1 & $>0,999$ & $-6135,91$ & 4084,19 \\
\hline & Pré - 1 mês & 1101,72 & 942,80 & 1 & $>0,999$ & $-746,12$ & 2949,57 \\
\hline & Pré - 2 meses & 1770,54 & 1013,89 & 1 & 0,808 & $-216,65$ & 3757,73 \\
\hline & Pré - 3 meses & 1436,51 & 945,95 & 1 & $>0,999$ & $-417,53$ & 3290,54 \\
\hline & 7 dias - 1 mês & 2127,59 & 2319,12 & 1 & $>0,999$ & $-2417,80$ & 6672,97 \\
\hline & 7 dias - 2 meses & 2796,41 & 2340,31 & 1 & $>0,999$ & $-1790,51$ & 7383,32 \\
\hline & 7 dias - 3 meses & 2462,37 & 2252,14 & 1 & $>0,999$ & $-1951,74$ & 6876,48 \\
\hline & 1 mês - 2 meses & 668,82 & 269,64 & 1 & 0,131 & 140,33 & 1197,31 \\
\hline & 1 mês - 3 meses & 334,78 & 300,18 & 1 & $>0,999$ & $-253,55$ & 923,12 \\
\hline & 2 meses - 3 meses & $-334,04$ & 386,56 & 1 & $>0,999$ & $-1091,69$ & 423,62 \\
\hline
\end{tabular}




\subsubsection{Avaliação da qualidade de vida}

Ao serem avaliados os escores médios obtidos com o questionário SF-36 ao longo do estudo (sete, 30, 60 e 90 dias pósprocedimento) pelo Gráfico 1, todos os domínios de qualidade de vida apresentaram aumento nos escores e o que menor aumento ocorreu no domínio EGS.

Gráfico 1-Escores médios de qualidade de vida ao longo do seguimento

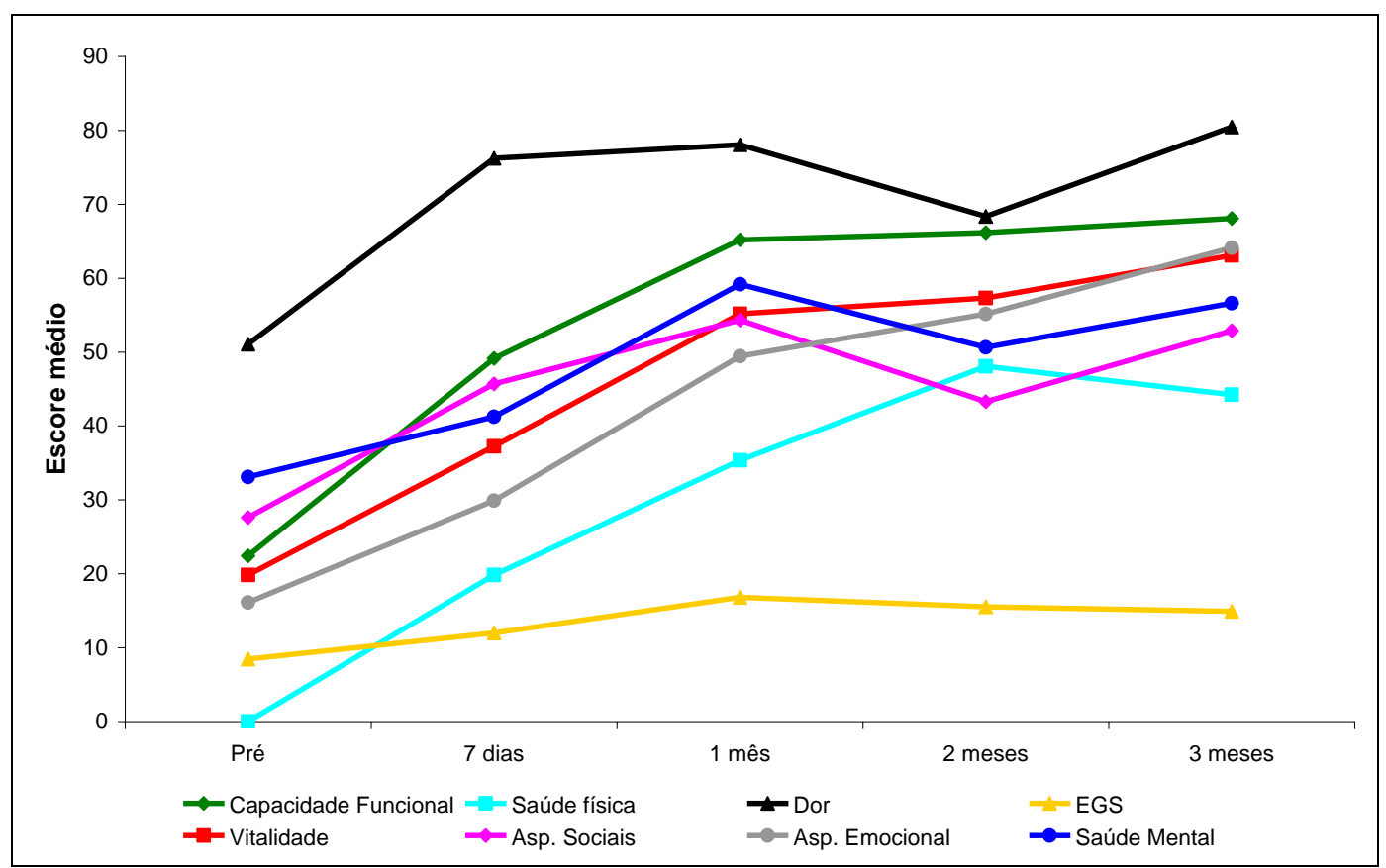

EGS - estado geral de saúde

A Tabela 5 mostra que há alteração média estatisticamente significativa em todos os domínios relativos à qualidade de vida avaliada pelo índice SF-36 $(p<0,05)$. 
Tabela 5 - Descrição dos escores de qualidade de vida em cada domínio ao longo do seguimento e resultado dos testes comparativos

\begin{tabular}{|c|c|c|c|c|c|c|c|c|}
\hline Variável & Momento & Média & DP & Mediana & Mínimo & Máximo & $\mathbf{N}$ & $p$ \\
\hline \multirow{5}{*}{$\begin{array}{l}\text { Capacidade } \\
\text { Funcional }\end{array}$} & Pré & 222,41 & "13,07 & 20 & 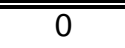 & 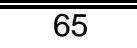 & 29 & \multirow{5}{*}{$<0,001$} \\
\hline & 7 dias & 49,14 & 15,12 & 50 & 20 & 85 & 29 & \\
\hline & 1 mês & 65,17 & 13,40 & 65 & 30 & 90 & 29 & \\
\hline & 2 meses & 66,15 & 13,36 & 67,5 & 35 & 85 & 26 & \\
\hline & 3 meses & 68,08 & 11,09 & 70 & 40 & 85 & 13 & \\
\hline \multirow{5}{*}{ Saúde física } & Pré & 0,00 & 0,00 & 0 & 0 & 0 & 29 & \multirow{5}{*}{$<0,001$} \\
\hline & 7 dias & 19,83 & 22,54 & 25 & 0 & 75 & 29 & \\
\hline & 1 mês & 35,34 & 22,68 & 25 & 0 & 75 & 29 & \\
\hline & 2 meses & 48,08 & 24,42 & 50 & 0 & 100 & 26 & \\
\hline & 3 meses & 44,23 & 18,13 & 50 & 25 & 75 & 13 & \\
\hline \multirow{5}{*}{ Dor } & Pré & 51,07 & 31,80 & 41 & 21 & 100 & 29 & \multirow{5}{*}{$<0,001$} \\
\hline & 7 dias & 76,21 & 18,60 & 74 & 52 & 100 & 29 & \\
\hline & 1 mês & 78,03 & 16,86 & 74 & 51 & 100 & 29 & \\
\hline & 2 meses & 68,35 & 17,03 & 72 & 32 & 100 & 26 & \\
\hline & 3 meses & 80,46 & 13,02 & 74 & 62 & 100 & 13 & \\
\hline \multirow{5}{*}{ EGS } & Pré & 8,45 & 6,28 & 10 & 0 & 25 & 29 & \multirow{5}{*}{$<0,001$} \\
\hline & 7 dias & 12,00 & 6,71 & 10 & 0 & 32 & 29 & \\
\hline & 1 mês & 16,79 & 7,51 & 17 & 5 & 37 & 29 & \\
\hline & 2 meses & 15,54 & 7,30 & 15 & 0 & 32 & 26 & \\
\hline & 3 meses & 14,92 & 4,41 & 17 & 10 & 22 & 13 & \\
\hline \multirow{5}{*}{ Vitalidade } & Pré & 19,83 & 6,05 & 20 & 10 & 30 & 29 & \multirow{5}{*}{$<0,001$} \\
\hline & 7 dias & 37,24 & 7,14 & 40 & 25 & 50 & 29 & \\
\hline & 1 mês & 55,17 & 6,88 & 55 & 35 & 65 & 29 & \\
\hline & 2 meses & 57,31 & 9,62 & 57,5 & 40 & 70 & 26 & \\
\hline & 3 meses & 63,08 & 5,96 & 65 & 50 & 70 & 13 & \\
\hline \multirow{5}{*}{ Asp. Sociais } & Pré & 27,59 & 14,32 & 25 & 0 & 62,5 & 29 & \multirow{5}{*}{$<0,001$} \\
\hline & 7 dias & 45,69 & 12,62 & 50 & 25 & 75 & 29 & \\
\hline & 1 mês & 54,31 & 10,71 & 50 & 37,5 & 75 & 29 & \\
\hline & 2 meses & 43,27 & 14,24 & 37,5 & 25 & 75 & 26 & \\
\hline & 3 meses & 52,88 & 10,40 & 50 & 37,5 & 75 & 13 & \\
\hline \multirow{5}{*}{$\begin{array}{l}\text { Asp. } \\
\text { Emocional }\end{array}$} & Pré & 16,09 & 22,92 & 0,0 & 0,0 & 66,7 & 29 & \multirow{5}{*}{$<0,001$} \\
\hline & 7 dias & 29,89 & 33,74 & 33,3 & 0,0 & 100,0 & 29 & \\
\hline & 1 mês & 49,43 & 35,21 & 33,3 & 0,0 & 100,0 & 29 & \\
\hline & 2 meses & 55,13 & 31,19 & 50,0 & 0,0 & 100,0 & 26 & \\
\hline & 3 meses & 64,10 & 21,35 & 66,7 & 33,3 & 100,0 & 13 & \\
\hline \multirow{5}{*}{$\begin{array}{l}\text { Saúde } \\
\text { Mental }\end{array}$} & Pré & 33,10 & 8,61 & 36 & 20 & 56 & 29 & \multirow{5}{*}{$<0,001$} \\
\hline & 7 dias & 41,24 & 7,57 & 40 & 28 & 60 & 29 & \\
\hline & 1 mês & 59,17 & 6,79 & 60 & 48 & 72 & 29 & \\
\hline & 2 meses & 50,62 & 18,71 & 56 & 0 & 76 & 29 & \\
\hline & 3 meses & 56,62 & 5,85 & 56 & 44 & 64 & 13 & \\
\hline
\end{tabular}

EGS, estado geral de saúde.

As Tabelas 6 e 7 demonstram que houve melhora estatisticamente significativa nos escores de qualidade de vida nos domínios: capacidade funcional, saúde física, vitalidade, aspectos emocionais e saúde mental no decorrer dos períodos avaliados ( $p<0,05)$; a partir de um mês, não se 
constatou melhora média estatisticamente significativa. Nos domínios dor, EGS e aspectos sociais, houve melhora média estatisticamente significativa do pré em relação aos demais momentos $(p<0,05)$.

Tabela 6 - Tabela demonstrando o resultado das comparações múltiplas dos escores de qualidade de vida para os domínios capacidade funcional, saúde física, dor e Estado Geral de Saúde entre os momentos de avaliação

\begin{tabular}{|c|c|c|c|c|c|c|c|}
\hline \multirow{2}{*}{ Variável } & \multirow{2}{*}{ Comaparação } & \multirow{2}{*}{$\begin{array}{c}\text { Diferença } \\
\text { média } \\
\end{array}$} & \multirow{2}{*}{$\begin{array}{c}\text { Erro } \\
\text { Padrão } \\
\end{array}$} & \multirow{2}{*}{ gl } & \multirow[b]{2}{*}{$\mathbf{p}$} & \multicolumn{2}{|c|}{ IC (95\%) } \\
\hline & & & & & & Inferior & Superior \\
\hline & Pré - 7 dias & $-26,72$ & 2,04 & 1 & $<<0,001$ & "-30,73 & -22,72 \\
\hline & Pré - 1 mês & $-42,76$ & 2,36 & 1 & $<0,001$ & $-47,38$ & $-38,14$ \\
\hline & Pré - 2 meses & $-42,92$ & 2,68 & 1 & $<0,001$ & $-48,16$ & $-37,67$ \\
\hline & Pré - 3 meses & $-43,47$ & 2,85 & 1 & $<0,001$ & $-49,06$ & $-37,89$ \\
\hline Capacidade & 7 dias - 1 mês & $-16,03$ & 2,25 & 1 & $<0,001$ & $-20,45$ & $-11,62$ \\
\hline \multirow[t]{9}{*}{ Funcional } & 7 dias - 2 meses & $-16,19$ & 2,73 & 1 & $<0,001$ & $-21,55$ & $-10,84$ \\
\hline & 7 dias - 3 meses & $-16,75$ & 2,81 & 1 & $<0,001$ & $-22,26$ & $-11,24$ \\
\hline & 1 mês - 2 meses & $-0,16$ & 1,71 & 1 & $>0,999$ & $-3,51$ & 3,19 \\
\hline & 1 mês - 3 meses & $-0,72$ & 2,37 & 1 & $>0,999$ & $-5,36$ & 3,93 \\
\hline & 2 meses - 3 meses & $-0,56$ & 2,47 & 1 & $>0,999$ & $-5,40$ & 4,29 \\
\hline & Pré - 7 dias & $-19,83$ & 4,11 & 1 & $<0,001$ & $-27,89$ & $-11,77$ \\
\hline & Pré - 1 mês & $-35,34$ & 4,14 & 1 & $<0,001$ & $-43,45$ & $-27,24$ \\
\hline & Pré - 2 meses & $-48,27$ & 4,68 & 1 & $<0,001$ & $-57,44$ & $-39,10$ \\
\hline & Pré - 3 meses & $-43,77$ & 4,68 & 1 & $<0,001$ & $-52,95$ & $-34,60$ \\
\hline Saúde & 7 dias - 1 mês & $-15,52$ & 4,79 & 1 & 0,012 & $-24,90$ & $-6,14$ \\
\hline \multirow[t]{9}{*}{ Física } & 7 dias - 2 meses & $-28,44$ & 6,09 & 1 & $<0,001$ & $-40,38$ & $-16,51$ \\
\hline & 7 dias - 3 meses & $-23,95$ & 6,27 & 1 & 0,001 & $-36,24$ & $-11,66$ \\
\hline & 1 mês - 2 meses & $-12,93$ & 5,63 & 1 & 0,218 & $-23,97$ & $-1,88$ \\
\hline & 1 mês - 3 meses & $-8,43$ & 6,15 & 1 & $>0,999$ & $-20,49$ & 3,63 \\
\hline & 2 meses - 3 meses & 4,50 & 5,56 & 1 & $>0,999$ & $-6,40$ & 15,39 \\
\hline & Pré - 7 dias & $-25,14$ & 3,41 & 1 & $<0,001$ & $-31,81$ & $-18,46$ \\
\hline & Pré - 1 mês & $-26,97$ & 4,61 & 1 & $<0,001$ & $-36,00$ & $-17,93$ \\
\hline & Pré - 2 meses & $-16,15$ & 5,39 & 1 & 0,027 & $-26,71$ & $-5,60$ \\
\hline & Pré - 3 meses & $-22,56$ & 5,51 & 1 & $<0,001$ & $-33,37$ & $-11,75$ \\
\hline \multirow{10}{*}{ Dor } & 7 dias - 1 mês & $-1,83$ & 2,24 & 1 & $>0,999$ & $-6,22$ & 2,57 \\
\hline & 7 dias - 2 meses & 8,98 & 3,34 & 1 & 0,072 & 2,43 & 15,54 \\
\hline & 7 dias - 3 meses & 2,58 & 3,74 & 1 & $>0,999$ & $-4,75$ & 9,90 \\
\hline & 1 mês - 2 meses & 10,81 & 2,95 & 1 & 0,002 & 5,04 & 16,59 \\
\hline & 1 mês - 3 meses & 4,40 & 3,69 & 1 & $>0,999$ & $-2,82$ & 11,63 \\
\hline & 2 meses - 3 meses & $-6,41$ & 3,24 & 1 & 0,479 & $-12,76$ & $-0,06$ \\
\hline & Pré - 7 dias & $-3,55$ & 1,26 & 1 & 0,048 & $-6,02$ & $-1,08$ \\
\hline & Pré - 1 mês & $-8,34$ & 1,48 & 1 & $<0,001$ & $-11,26$ & $-5,43$ \\
\hline & Pré - 2 meses & $-6,77$ & 1,52 & 1 & $<0,001$ & $-9,75$ & $-3,79$ \\
\hline & Pré - 3 meses & $-4,35$ & 1,88 & 1 & 0,208 & $-8,04$ & $-0,66$ \\
\hline \multirow{6}{*}{ EGS } & 7 dias - 1 mês & $-4,79$ & 1,30 & 1 & 0,002 & $-7,34$ & $-2,24$ \\
\hline & 7 dias - 2 meses & $-3,22$ & 1,52 & 1 & 0,339 & $-6,19$ & $-0,24$ \\
\hline & 7 dias - 3 meses & $-0,80$ & 1,88 & 1 & $>0,999$ & $-4,48$ & 2,89 \\
\hline & 1 mês - 2 meses & 1,57 & 1,30 & 1 & $>0,999$ & $-0,98$ & 4,12 \\
\hline & 1 mês - 3 meses & 4,00 & 1,71 & 1 & 0,198 & 0,63 & 7,36 \\
\hline & 2 meses - 3 meses & 2,42 & 1,51 & 1 & $>0,999$ & $-0,54$ & 5,38 \\
\hline
\end{tabular}

EGS, estado geral de saúde. 
Tabela 7 - Resultado das comparações múltiplas dos escores de qualidade de vida para os domínios vitalidade, aspectos sociais, aspectos emocionais e saúde mental entre os momentos de avaliação

\begin{tabular}{|c|c|c|c|c|c|c|c|}
\hline \multirow{2}{*}{ Variável } & \multirow{2}{*}{ Comaparação } & \multirow{2}{*}{$\begin{array}{c}\text { Diferença } \\
\text { média }\end{array}$} & \multirow{2}{*}{$\begin{array}{c}\text { Erro } \\
\text { Padrão }\end{array}$} & \multirow{2}{*}{ gl } & \multirow[b]{2}{*}{$\mathbf{p}$} & \multicolumn{2}{|c|}{ IC (95\%) } \\
\hline & & & & & & Inferior & Superior \\
\hline \multirow{10}{*}{ Vitalidade } & Pré - 7 dias & $-17,41$ & 1,55 & 1 & $<0,001$ & $-20,46$ & $-14,37$ \\
\hline & Pré - 1 mês & $-35,34$ & 1,44 & 1 & $<0,001$ & $-38,17$ & $-32,52$ \\
\hline & Pré - 2 meses & $-37,42$ & 1,98 & 1 & $<0,001$ & $-41,30$ & $-33,53$ \\
\hline & Pré - 3 meses & $-42,80$ & 2,11 & 1 & $<0,001$ & $-46,94$ & $-38,65$ \\
\hline & 7 dias - 1 mês & $-17,93$ & 1,51 & 1 & $<0,001$ & $-20,90$ & $-14,97$ \\
\hline & 7 dias - 2 meses & $-20,01$ & 1,74 & 1 & $<0,001$ & $-23,43$ & $-16,59$ \\
\hline & 7 dias - 3 meses & $-25,38$ & 2,07 & 1 & $<0,001$ & $-29,45$ & $-21,32$ \\
\hline & 1 mês - 2 meses & $-2,08$ & 1,57 & 1 & $>0,999$ & $-5,16$ & 1,01 \\
\hline & 1 mês - 3 meses & $-7,45$ & 2,47 & 1 & 0,025 & $-12,29$ & $-2,61$ \\
\hline & 2 meses - 3 meses & $-5,38$ & 2,78 & 1 & 0,534 & $-10,83$ & 0,08 \\
\hline \multirow{10}{*}{$\begin{array}{l}\text { Aspectos } \\
\text { Sociais }\end{array}$} & Pré - 7 dias & $-18,10$ & 1,98 & 1 & $<0,001$ & $-21,99$ & $-14,22$ \\
\hline & Pré - 1 mês & $-26,72$ & 2,09 & 1 & $<0,001$ & $-30,82$ & $-22,63$ \\
\hline & Pré - 2 meses & $-15,11$ & 2,66 & 1 & $<0,001$ & $-20,32$ & $-9,90$ \\
\hline & Pré - 3 meses & $-21,02$ & 3,18 & 1 & $<0,001$ & $-27,26$ & $-14,78$ \\
\hline & 7 dias - 1 mês & $-8,62$ & 2,03 & 1 & $<0,001$ & $-12,60$ & $-4,64$ \\
\hline & 7 dias - 2 meses & 2,99 & 1,90 & 1 & $>0,999$ & $-0,73$ & 6,72 \\
\hline & 7 dias - 3 meses & $-2,91$ & 3,04 & 1 & $>0,999$ & $-8,86$ & 3,04 \\
\hline & 1 mês - 2 meses & 11,61 & 2,20 & 1 & $<0,001$ & 7,30 & 15,93 \\
\hline & 1 mês - 3 meses & 5,71 & 2,83 & 1 & 0,440 & 0,15 & 11,26 \\
\hline & 2 meses - 3 meses & $-5,91$ & 3,58 & 1 & 0,989 & $-12,92$ & 1,11 \\
\hline \multirow{10}{*}{$\begin{array}{l}\text { Aspectos } \\
\text { Emocionais }\end{array}$} & Pré - 7 dias & $-13,79$ & 6,40 & 1 & 0,312 & $-26,34$ & $-1,24$ \\
\hline & Pré - 1 mês & $-33,33$ & 7,45 & 1 & $<0,001$ & $-47,93$ & $-18,73$ \\
\hline & Pré - 2 meses & $-38,34$ & 7,38 & 1 & $<0,001$ & $-52,80$ & $-23,88$ \\
\hline & Pré - 3 meses & $-47,27$ & 7,17 & 1 & $<0,001$ & $-61,33$ & $-33,21$ \\
\hline & 7 dias - 1 mês & $-19,54$ & 5,98 & 1 & 0,011 & $-31,25$ & $-7,83$ \\
\hline & 7 dias - 2 meses & $-24,55$ & 8,10 & 1 & 0,025 & $-40,43$ & $-8,66$ \\
\hline & 7 dias - 3 meses & $-33,48$ & 8,55 & 1 & 0,001 & $-50,23$ & $-16,73$ \\
\hline & 1 mês - 2 meses & $-5,01$ & 8,16 & 1 & $>0,999$ & $-20,99$ & 10,98 \\
\hline & 1 mês - 3 meses & $-13,94$ & 9,06 & 1 & $>0,999$ & $-31,70$ & 3,82 \\
\hline & 2 meses - 3 meses & $-8,93$ & 7,29 & 1 & $>0,999$ & $-23,23$ & 5,37 \\
\hline \multirow{10}{*}{$\begin{array}{l}\text { Saúde } \\
\text { Mental }\end{array}$} & Pré - 7 dias & $-8,14$ & 2,11 & 1 & 0,001 & $-12,26$ & $-4,01$ \\
\hline & Pré - 1 mês & $-26,07$ & 2,09 & 1 & $<0,001$ & $-30,16$ & $-21,98$ \\
\hline & Pré - 2 meses & $-23,37$ & 2,17 & 1 & $<0,001$ & $-27,62$ & $-19,12$ \\
\hline & Pré - 3 meses & $-23,48$ & 2,15 & 1 & $<0,001$ & $-27,70$ & $-19,26$ \\
\hline & 7 dias - 1 mês & $-17,93$ & 1,69 & 1 & $<0,001$ & $-21,23$ & $-14,63$ \\
\hline & 7 dias - 2 meses & $-15,23$ & 2,10 & 1 & $<0,001$ & $-19,36$ & $-11,11$ \\
\hline & 7 dias - 3 meses & $-15,34$ & 2,32 & 1 & $<0,001$ & $-19,90$ & $-10,79$ \\
\hline & 1 mês - 2 meses & 2,70 & 1,80 & 1 & $>0,999$ & $-0,83$ & 6,23 \\
\hline & 1 mês - 3 meses & 2,59 & 1,88 & 1 & $>0,999$ & $-1,09$ & 6,27 \\
\hline & 2 meses - 3 meses & $-0,11$ & 2,16 & 1 & $>0,999$ & $-4,35$ & 4,12 \\
\hline
\end{tabular}




\subsubsection{Sobrevida}

Ao se ressaltar o caráter paliativo do procedimento de DBE, observouse que o tempo mediano de sobrevida dos pacientes foi de 90 dias, sendo que mais da metade dos pacientes faleceu $(55,2 \%)$ na ocasião do terceiro mês de seguimento.

Tabela 8 - Descrição do tempo de sobrevida dos pacientes

\begin{tabular}{|c|c|c|c|c|c|c|c|c|}
\hline \multirow{2}{*}{$\begin{array}{l}\text { Tempo } \\
\text { médio } \\
\text { estimado }\end{array}$} & \multicolumn{2}{|c|}{$\begin{array}{c}\text { IC (95\%) } \\
\text { Tempo médio }\end{array}$} & \multirow{2}{*}{$\begin{array}{c}\text { Tempo } \\
\text { mediano } \\
\text { estimado }\end{array}$} & \multicolumn{2}{|c|}{$\begin{array}{c}\text { IC (95\%) } \\
\text { Tempo mediano }\end{array}$} & \multirow{2}{*}{ Óbitos } & \multirow{2}{*}{$\mathbf{N}$} & \multirow{2}{*}{$\%$} \\
\hline & Inferior & Superior & & Inferior & Superior & & & \\
\hline 83,76 & 78,49 & 89,03 & 90 & 88,68 & 91,32 & 16 & 29 & 55,2 \\
\hline
\end{tabular}

No Gráfico 2, verifica-se que até 80 dias são poucos os casos de óbitos, entretanto após este período a sobrevida dos pacientes foi bastante curta.

Gráfico 2 - Função de sobrevida de Kaplan-Meier do tempo de sobrevida dos pacientes após a cirurgia

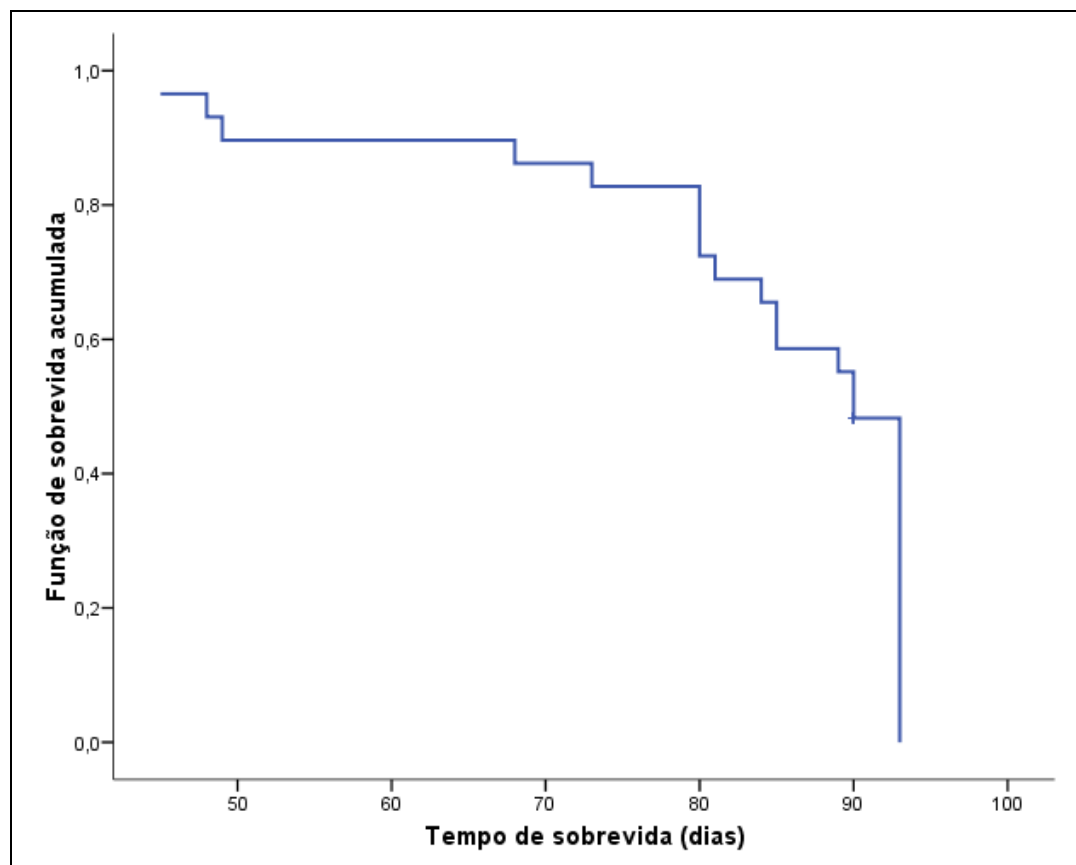




\section{Discussão}


A icterícia de origem obstrutiva é uma apresentação comum em pacientes com doença maligna da via biliar, sendo o primeiro sintoma em até 90\% dos casos (Bergasa et al., 2006). Os pacientes geralmente apresentamse com perda ponderal, dor abdominal e icterícia progressiva. História clínica e exames laboratoriais são essenciais na investigação clínica inicial. O ultrassom convencional desempenha um papel relevante, no sentido de triar a icterícia de padrão obstrutivo, sugerindo o nível de obstrução, além de poder diferenciar doenças benignas de malignas (Saluja et al., 2007).

$\mathrm{Na}$ suspeita de malignidade, estudos radiológicos representados pela ressonância magnética, colangiorressonância e tomografia computadorizada permitem a avaliação adequada na maioria dos casos (Hintze et al., 2001). Estes métodos não invasivos são utilizados para melhor definir a etiologia, localização e estabelecer o estadiamento locorregional. Ao serem avaliadas a extensão da doença, a possibilidade de invasão vascular e as metástases à distância, é possível definir o grau de ressecabilidade do tumor e estabelecer melhores condutas terapêuticas (Andersson et al., 2005).

A obstrução pode ocorrer em qualquer nível da árvore biliar, tendo como sítios mais comuns a região proximal (secundário a colangiocarcinomas, hepatocarcinomas ou lesões metastáticas) e distal (secundário às neoplasias periampulares, como tumores de pâncreas e de 
papila). O correto estadiamento das lesões obstrutivas pela classificação de Bismuth-Corllet pode não apenas determinar o potencial de ressecabilidade das lesões, como também auxiliar adequadamente a escolha sobre a técnica de drenagem a ser realizada (Hii et al., 2004; Chang et al., 1998). Infelizmente, a doença locorregional avançada e a metastática já se mostram evidentes na avaliação inicial ou pré-operatória na maioria dos pacientes.

Nos portadores de doenças malignas avançadas com icterícia de padrão obstrutivo, os principais achados que levam os pacientes a serem submetidos a tratamentos paliativos são: invasão vascular (57\%), metástases hepáticas (24\%) e linfonodos metastáticos à distância (11\%) (Soto et al., 2000). Colangiocarcinoma, tumores de pâncreas e da papila duodenal e a infiltração da via biliar por extensão direta ou compressão extrínseca determinada por metástases linfonodais hilares são as causas mais frequentes de icterícia colestática de etiologia maligna.

No grupo das lesões malignas, o adenocarcinoma pancreático representa a principal causa de icterícia colestática. Lamentavelmente, no momento do diagnóstico, apenas 10\% são restritos ao pâncreas. Associa-se alta taxa de mortalidade, sendo a ressecção cirúrgica com intenção curativa é possível em $20 \%$ dos casos dos tumores da cabeça do pâncreas e somente $5 \%$ dos localizados em corpo e cauda. No curso da doença, a icterícia ocorre em $70 \%$ dos pacientes, sendo a colecistojejunostomia e coledocojejunostomia procedimentos cirúrgicos paliativos seguros (Lillemoe et al., 1996). Em pacientes com risco cirúrgico elevado e prognóstico 
reservado, a passagem de próteses biliares por via percutânea ou endoscópica tem sido cada vez mais recomendada (Speer et al., 1987).

O carcinoma da vesícula biliar é o tumor maligno mais frequente das vias biliares, sendo representado pelo adenocarcinoma em $80 \%$ dos casos (Venturelli et al., 2008; Bergasa et al., 2006). A maioria dos pacientes sobreviventes, a longo prazo, são diagnosticados precocemente após o achado incidental da neoplasia após colecistectomia eletiva. Setenta e cinco por cento daqueles que procuram atendimento médico possuem doença avançada, com extensão da neoplasia para linfonodos, invasão hepática e metástases à distância, o que exclui qualquer tentativa de ressecção curativa (Lake et al., 1993). A sobrevida média é de seis meses. Nos casos em que ocorre invasão direta dos ductos biliares, o tumor é quase sempre irressecável, sendo tratada a icterícia obstrutiva nesses casos com a inserção de próteses, mediante abordagem transhepática ou endoscópica (Speer et al., 1987).

O colangiocarcinoma é o segundo tumor hepático mais prevalente, depois do hepatocarcinoma. Ele pode ser classificado em extra-hepático e intra-hepático, sendo este último subdividido em hilar (tumor de Klatskin) e periférico (Lake et al.,1993). O tratamento curativo, na dependência da localização e extensão do tumor, é cirúrgico, porém somente $15 \%$ a 20\% são ressecáveis (Clary et al., 2004). O tratamento paliativo deve ser considerado se o paciente estiver sem condições clínicas de ser submetido à cirurgia curativa, ou metástases regionais, ou à distância, ou invasão local, caso estejam presentes (De Palma et al., 2003). Os procedimentos cirúrgicos possíveis para descompressão, essencialmente, baseiam-se em derivações intra e extra- 
hepáticas com uma alça intestinal. Para os tumores proximais não ressecáveis, a derivação intra-hepática com uma alça intestinal é o método preferido; para tumores distais irressecáveis, as opções mais utilizadas são: a colecistostomia (quando o duto cístico estiver permeável), a coledocoduodenostomia, a coledocojejunostomia e a hepaticojejunostomia (Suzuki et al., 2001). Pode-se realizar drenagem percutânea ou endoscópica, dependendo do nível e da extensão da lesão (Molnar et al., 1974).

Dentre as lesões malignas periampulares que levam à obstrução da via biliar, o adenocarcinoma ampular possui as maiores taxas de ressecabilidade e melhor prognóstico (Andersen et al., 1989; Leung et al., 1983). Tipicamente, manifesta-se como tumor de pequenas dimensões no momento do diagnóstico, devido ao início precoce dos sintomas, especialmente a icterícia, tendo alta taxa de ressecabilidade (até $90 \%$ dos casos).

A obstrução biliar também pode ser decorrente de extensão tumoral direta, como, por exemplo, a partir do hepatocarcinoma, de neoplasia de vesícula biliar, ou decorrente de compressão extrínseca dos ductos biliares extra-hepáticos por linfonodomegalias. Neoplasias de pâncreas, estômago, vesícula biliar e cólon são causas comuns de linfonodomegalias que podem acarretar obstrução biliar (Soto et al., 2000).

De modo geral, a literatura mostra que apenas $10 \%$ a $20 \%$ dos pacientes são candidatos ao tratamento cirúrgico com intenção curativa. Diante do exposto, para os portadores de neoplasias avançadas da via biliar, o tratamento paliativo impõe-se na maioria dos casos, com o objetivo de aliviar a dor, tratar a colestase e proporcionar melhor qualidade de vida. A 
icterícia de padrão obstrutivo não apenas leva a coloração amarelada da pele e mucosas do paciente, como piora a condição clínica geralmente precária dos portadores de neoplasias avançadas, levando à colangite, ao prurido, às deficiências nutricionais, à perda de peso, insuficiência renal, falência hepática e até mesmo à morte. Portanto, constitui-se em um limitador importante na sobrevida e qualidade de vida do paciente. O alívio da icterícia obstrutiva naqueles com doença maligna irressecável determina aumento da sobrevida (Kida et al., 2011).

Inicialmente, derivações cirúrgicas foram a principal modalidade terapêutica paliativa para a icterícia de padrão obstrutivo. As opções pertinentes consistem em coledocojejunostomia, coledocoduodenostomia, colecistojejunostomia, colecistogastrojejunostomia, colecistostomia, na inserção de drenos em T por laparotomia e nas anastomoses biliodigestivas intra-hepáticas em casos de tumores hilares. Entretanto, as altas taxas de morbimortalidade levaram à busca por métodos não cirúrgicos de drenagem da via biliar.

Dentre as técnicas não cirúrgicas, a drenagem biliar externa percutânea trans-hepática foi a primeira e descrita por Molnar et al. (1974). Consistia da inserção de endoprótese de 7 ou 8 French por via percutânea trans-hepática, sendo realizada, principalmente, em pacientes sem condições cirúrgicas, com a finalidade de aliviar o quadro de icterícia e prolongar a sobrevida. As desvantagens iniciais constatadas incluíam: dor, deslocamento do cateter, escape de bile e fluido ascítico ao redor do sítio de punção, peritonite e hemorragia. 
A CPRE, primeiramente descrita por McCune et al., em 1968, rapidamente passou a ser uma modalidade diagnóstica e terapêutica de grande valor nos casos de icterícia obstrutiva. Atualmente, é o método padrão-ouro amplamente utilizado na paliação de pacientes com neoplasia maligna avançada com comprometimento da via biliar, tendo como possíveis complicações: a colangite, perfuração duodenal, hemorragia, fístula e pancreatite aguda.

Ao se comparar o método padrão CPRE com as técnicas de derivações cirúrgicas, uma meta-análise incluiu três importantes estudos (Andersson et al. 2005, Smith et al. 1994; Shepherd et al. 1988), os quais demonstraram não haver diferenças na taxa de sucesso terapêutico entre as duas modalidades terapêuticas. Estudos recentes comparando o uso de endopróteses e as derivações cirúrgicas na paliação da obstrução biliar maligna têm revelado que as taxas de morbidade, mortalidade e sobrevida não diferem nos dois métodos. Entretanto, a icterícia obstrutiva recorrente, causada pela oclusão da prótese, permanece um desafio. Enquanto em pacientes submetidos a derivações biliodigestivas cirúrgicas, a icterícia obstrutiva recorre em até $30 \%$ dos pacientes; no caso de próteses inseridas endoscopicamente, a taxa de recorrência chega a 50\% em seis meses (Lee et al., 2007).

Diante do exposto, tem sido preconizado que pacientes com expectativa de vida maior que seis meses e aqueles submetidos à cirurgia com intenção curativa e achados intra-abdominais que se revelam com doença avançada devam ser submetidos à drenagem cirúrgica (van den Bosch et al., 1994; Maosheng et al., 2001; Sunpaweravong et al., 2005; Bakkevold et al., 1993). 
Quando comparada à CPRE, a drenagem percutânea é um procedimento alternativo, na medida em que possui taxas de morbidade mais altas identificadas nos estudos (Lee et al., 2007). Além disso, a drenagem percutânea geralmente necessita dreno externo com possibilidade de deslocamento, celulite, dor relacionada ao local de inserção do cateter, colangite recorrente e falha na queda da bilirrubina (Piñol et al., 2002). O potencial efeito na qualidade de vida do paciente é um fator importante e os estudos, em geral, tem registrado que pacientes submetidos à drenagem percutânea não apresentam melhora significativa nos questionários de qualidade de vida ao longo dos períodos avaliados. A técnica de drenagem biliar percutânea certamente deve ser considerada nos casos em que a CPRE falha e que necessitam de descompressão urgente da via biliar, sobretudo em obstruções tumorais proximais (Stanley et al., 1986).

A nova técnica de DBE tem se mostrado um método alternativo de escolha prévia à drenagem percutânea e às derivações cirúrgicas biliodigestivas (derivações cirúrgicas) em situações de falha da CPRE. Alguns aspectos podem ser apresentados acerca da DBE:

- Trata-se de técnica minimamente invasiva, que pode ser realizada na mesma sessão, diminuindo o tempo de internação, os custos e a inconveniência relativa ao paciente.

- Em comparação às alternativas clássicas de drenagem biliar percutânea e cirurgia, a DBE revela-se mais fisiológica por possibilitar drenagem biliar interna imediata e menos invasiva.

- A orientação precisa e segura por ultrassonografia endoscópica e o 
uso do recurso de Doppler colorido otimizam o perfil de segurança da DBE pela avaliação em tempo real de estruturas adjacentes, especialmente vasos sanguíneos.

- O controle preciso da punção proporciona um número maior e mais seguro de acessos ao ducto biliar do que as alternativas clássicas nominadas drenagem biliar percutânea e cirurgia derivativa.

- A DBE não é limitada na ocasião da obesidade ou ascite leve.

Nos relatos publicados referentes aos métodos de drenagem anterógrada e rendez-vous ecoguiado, é difícil particularizar com precisão as taxas de sucesso, pois os autores relatam sucesso de tais procedimentos associado às técnicas de drenagem transmural como um procedimento de resgate em caso de falha das técnicas de rendez-vous e drenagem anterógrada. Em virtude da maior dificuldade técnica da progressão anterógrada do fio-guia na abordagem intra-hepática, a comparação e equivalência dos resultados da abordagem extra e intra-hepática devem ser avaliados em separado. Kim et al. (2010) usaram abordagem ecoguiada tipo rendez-vous em 15 pacientes com obstrução biliar distal neoplásica e falha prévia da CPRE, com a passagem ecoguiada bem-sucedida do fio-guia e, na sequência, drenagem retrógrada por CPRE alcançando sucesso em 12 casos (80\%). Com o acesso ecoguiado pelas técnicas de rendez-vous e anterógrada, em combinação com técnicas transmurais, a taxa de sucesso da drenagem endoscópica foi $92,55 \%$ e a de complicação geral de $4 \%$, incluindo: fístula biliar, pneumoperitônio, dor abdominal e pancreatite pósprocedimento. No presente estudo a complicação ocorreu em 6 (18,75\%) 
pacientes: $1(3,4 \%)$ com dor abdominal imediata, 2 (6,9\%) hemorragia, 1 $(3,4 \%)$ fístula biliar e 1 (3,4\%) migração tardia da prótese biliar.

Até o momento, as maiores casuísticas envolvendo a DBE referem-se às técnicas de hepatogastrostomia e coledocoduodenostomia. Ao serem levados em conta os relatos referentes ao sucesso de colocação de prótese ecoguiada, a taxa de sucesso relatada é de $90 \%$ na coledocoduodenostomia e de $80 \%$ na hapaticogastrostomia. Recentemente, Kahaleh et al. (2006) relataram a maior série de casos publicados acerca de DBE e destacaram taxa de sucesso de $84 \%$ (41/49) e complicações menores em 16\% (8/49). Trinta e cinco pacientes foram submetidos à abordagem intra-hepática, com uma taxa de sucesso de $83 \%$ (29/35). Quatorze deles foram submetidos à abordagem extra-hepática, com sucesso de 86\% (12/14). Em nossa casuística, a técnica de drenagem ecogiada utilizada, a coledocoduodenostomia ocorreu em 17 $(58,62 \%)$ pacientes e a hepatogastrostomia em 6 (20,68\%). Observamos, também, uma taxa de sucesso de 29 (90,6\%).

Ao se comparar a coledocoduodenostomia com a hepatogastrostomia, nota-se que a via biliar extra-hepática oferece um alvo mais evidente e factível para a punção ecoguiada biliar, na medida em que, no bulbo duodenal, o ecoendoscópio encontra-se em uma posição mais estável. Por outro lado, na drenagem da via biliar intra-hepática por hepatogastrostomia, o ecoendoscópio é posicionado em uma posição mais retificada, o que favorece a transmissão da força ao longo do eixo do canal de trabalho do aparelho durante a inserção da prótese. A consistência amolecida do parênquima hepático (exceto em casos com cirrose subjacente) também oferece menos resistência à passagem 
de uma prótese, fato este que não ocorre na parede fibrosa e espessa do ducto biliar comum.

O uso de equipamentos adequados é fundamental para o sucesso deste procedimento desafiador. Deve-se utilizar um ecoendoscópio de arranjo linear com um canal de trabalho de pelo menos $3,2 \mathrm{~mm}$. Recomenda-se o uso de ecoendoscópios com canal terapêutico de grande porte $(3,7$ ou $3,8 \mathrm{~mm})$. A punção do ducto alvo normalmente é realizada com uma agulha de calibre 19 ou 22 gauges. Em geral, a agulha de calibre 19 gauges é preferida porque acomoda o fio-guia de 0,035 polegadas, permitindo melhor controle durante a manipulação cirúrgico-endoscópica da via biliar. Entretanto, quando da utilização de agulha de 22 gauges, é imperativo o uso de fio guia de 0,018 polegadas. Em todos os nossos pacientes utilizamos agulha de 19 gauges, fio guia de 0,035 polegadas e cateter tipo needle-knife para ampliar o trajeto fistuloso bilioentérico.

Vale ressaltar, do ponto de vista clínico, a escolha técnica mais relevante parece ser o tipo de prótese empregada. Em nosso meio, Artifon et al. (2007) publicaram o primeiro caso de utilização de prótese metálica recoberta para a recanalização transmural tipo hepatogastrostomia ecoguiada, em paciente com obstrução maligna da via biliar e com dilatação predominante intra-hepática, evoluindo com a sua melhora clínica em seguimento de três meses. Embora não existam estudos comparando os dois tipos de próteses (plásticas versus metálicas), as metálicas autoexpansíveis (total ou parcialmente recobertas) são justificadas por três razões: 
a) Em expansão plena, efetivamente, selam o trato da punção/dilatação, o que preveniria o vazamento de maneira mais eficaz.

b) O seu diâmetro maior oferece maior patência a longo prazo, o que diminuiria a necessidade de trocas e revisões da prótese.

c) Se ocorrer disfunção por crescimento tumoral para dentro da prótese ou sua obstrução, o manejo é um pouco menos desafiador do que com próteses plásticas, uma vez que uma nova prótese (plástica ou metálica) pode ser facilmente inserida por dentro da prótese metálica ocluída e previamente posicionada.

Em contraste, a troca de uma prótese plástica transmural ocluída geralmente requer substituição por sobre o fio-guia, porque a remoção sem prévia sustentação oferecida pela passagem do fio-guia, envolve o risco de ruptura do trato com passagem subsequente do fio-guia ao peritônio, exigindo, assim, a repetição da DBE para restabelecer o trajeto de recanalização. Essas vantagens presumidas das próteses metálicas devem ser contrabalançadas com o fato de que o custo e a disponibilidade são fatores de limitação relativa de seu uso. 


\subsection{Considerações finais}

O presente estudo demonstra que a DBE é opção segura de acesso alternativo à via biliar em pacientes com icterícia obstrutiva, com insucesso na drenagem por CPRE e precedendo a indicação de drenagem transparietal ou tratamento cirúrgico com intenção paliativa.

Trata-se de procedimento minimamente invasivo, criando-se fistulização não anatômica da via biliar intra ou extra-hepática com o intestino e que abrange a filosofia racional do "one step procedure", permitindo oferecer ao paciente método paliativo eficiente e seguro em um único procedimento.

A escolha do acesso e da via de drenagem dependerá de fatores relacionados ao paciente (dilatação das vias biliares intra-hepáticas, nível da obstrução e cirurgia prévia) e da preferência e experiência do profissional que realizará o procedimento.

A DBE, devido à sua complexidade e grande dificuldade técnica, deve ser realizada apenas em centros terciários, dentro de normatização protocolar "Institucional" e por profissionais com marcada experiência em ecoendoscopia e CPRE. Igualmente, destaca-se por ser ferramenta relevante na drenagem biliar e, em conjunto com a CPRE, apresenta a endoscopia como método de paliação de paciente ictérico com cerca de 90\% de sucesso técnico e ao redor de 100\% de sucesso clínico (alívio da icterícia).

Estudos comparativos da DBE com a derivação cirúrgica e percutânea transhepática são fundamentais para particularizar nuances 
relacionados a detalhes de técnica e replicabilidade clínica em diferentes instituições. A DBE compartilha de modo seguro e efetivo, dentro do contexto de procedimento minimamente invasivo, uma nova ferramenta dentre as já estabelecidas na prática clínica: drenagem transparietal percutânea e cirurgia. 


\section{ConClusões}


A contribuição da DBE à paliação endoscópica da obstrução biliar maligna permitiu as seguintes conclusões:

a) O procedimento é eficaz e seguro, haja vista a evidência satisfatória das taxas de sucessos técnico e clínico.

b) As complicações foram leves e não alteraram o desfecho favorável do procedimento de drenagem biliar.

c) A qualidade de vida foi significativamente melhor após o procedimento (sete, 30, 60 e 90 dias) e permaneceu sustentada até a última avaliação realizada aos três meses. 
8 AnEXos 


\section{Anexo A - Aprovação do Comitê de Ética}

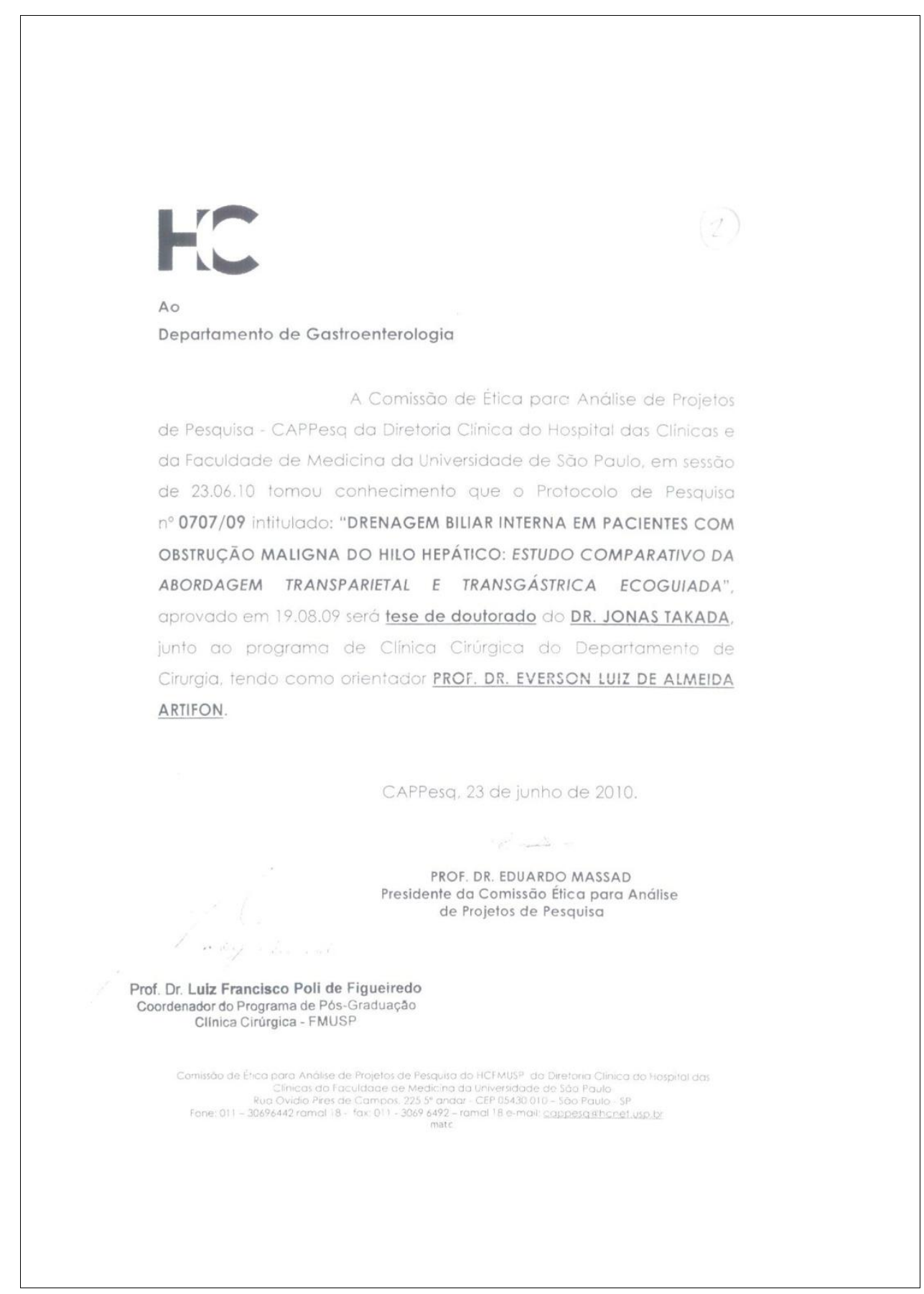




\section{CIÊNCIA}

O Coordenador da Comissão de Ética para Análise de Projetos de Pesquisa - CAPPesq da Diretoria Clínica do Hospital das Clínicas da Faculdade de Medicina da Universidade de São Paulo, em 14/04/201 1. TOMOU CIENCIA do(s) documento(s) abaixo mencionado(s) no Protocolo de Pesquisa no 0707/09, intitulado: "CONTRIBUIÇĀO DA DRENAGEM ECOGUIADA À PALIAÇĀO ENDOSCÓPICA DA OBSTRUÇĀO BILIAR MALIGNA", apresentado pelo Departamento de GASTROENTEROLOGIA.

Carta datada de 31.03 .11 - Inclusão da acadêmica CAROLINA REBELLO DA COSTA como aluna de iniciação científica.

Pesquisador (a) Responsável: DR. EVERSON LUIZ DE ALMEIDA ARTIFON

CAPPesq, 14 de abril de 2011

PROF. DR. EUCLIDES AYRES DE CASTILHO Coordenador

Comissāo de Ética para Análise de Projetos de Pesquisa - CAPPesq

Comissão de Etica para Análise de Projetos de Pesquisa do HCFMUSP da Diretoria Clinica do Hospital das Clinicas da Faculdade de Medicina da Universidade de Săo Paulo Rua Ovidio Pires de Campes. $225.5{ }^{\circ}$ andar - CEP 05403010 - Săo Paulo - SP Fone 01130696442 Fax 01130696492 e-mall cappesq@hcnet usp.br 


\section{Anexo B - Termo de consentimento livre e esclarecido}

Hospital das Clinicas da faculdade de Medicina da Universidade de SAO Paulo- hCFMUSP

I. DADOS DE IDENTIFICAÇĀO DO SUJEITO DA PESQUISA OU RESPONSÁVEL LEGAL

1 NOME DO PACIENTE

DOCUMENTO DE IDENTIDADEN

DATA NASCIMENTO

ENDEREÇO

BAIRRO

CEP

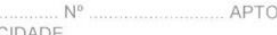

CIDADE

APTO

RESPONSÁVEL LEGAL

DOCUMENTO DE IDENTIDADE

DATA NASCIMENT

ENDEREÇO

CEP

APTO

II - DADOS SOBRE A PESQUISA CIENTIFICA

1. TITULO DO PROTOCOLO DE PESQUISA - Drenagem biliar interna em pacientes com obstrução maligna do hilo hepático: estudo comparativo da abordagem transparietal e transgástrica ecoguiada

2. PESQUISADOR: Dr. Everson Luis Almeida Artifon

CARGO/FUNÇÃO Médico colaborador do Serviço de Endoscopia Gastrointestinal - HCFMUSP

INSCRIÇÃO CONSELHO REGIONAL NN 80944

UNIDADE DO HCFMUSP: Setor de Endoscopia

3 AVALIACÁA DO RISCO DA PESQUISA.

SEMRISCO I RISCOMINIMO X RISCOMEDIO RISCOBAIXOII RISCO

MAMPR

(probabilidade de que o individuo sofra algum dano como consequência imediata ou tardia do estudo)

4. DURAÇÃO DA PESQUISA : 2 anos a partir da aprovação. 
A hepatogastrostomia percutânea e ecoguiada consistem numa comunicação entre a via bilia intrahepática e estômago para drenagem da bile represada por obstrução tumoral à jusante. Está indicada em casos selecionados em que há obstrução da drenagem biliar e que não foi possivel ressecção da neoplasia (câncer) por condição clinica. Os pacientes seräo alocados aleatoriamente para relizar drenagem biliar pelo método ecoendoscópico ou transparietal.

O procedimento é realizado sob sedaçăo consciente (anestesia) sendo praticamente indolor. No grupo realizado por via endoscópica, será através de um aparelho semelhante ao de endoscopia, que encontrará a via biliar intra-hepática dilatada e fará uma comunicação com estômago através de uma prótese, aliviando o figado da obstrução para melhorar suas funções. Nos pacientes do grupo transparieta é feito a drenagem da via biliar intra-hepática através de uma punção com agulha na pele e guiado por radioscopia è realizada passagem de uma prótese, para aliviar o figado da obstrução.

É um procedimento protocolar, fundamentado em dados anatômicos e técnicos relacionados a terapêutica por ecoendoscopia e radiologia intervencionista, realizados por profissionais com experiência em ecoendoscopia terapêtica e radiologia intervencionista.

Como todo procedimento médico há riscos de intercorrências e/ou complicações. Entre as principais intercorrências estão o sangramento, perfuração e infecção, ambos podendo ser de tratamento não cirúrgico e em alguns casos, pode ser necessário a realização de cirurgia. Todas as intercorrências serão tratadas neste hospital sobre a responsabilidade da equipe de endoscopia em conjunto com a área especializada para o tipo de intercorrência.

Sintomas como desconforto abdominal, náuseas e vômitos também podem acontecer, sendo o tratamento com remédios eficazes na grande maioria dos casos.

Agendamento de retornos e consultas periódicas serão realizadas objetivando o constante esclarecimento da evolução e a possibilidade de pequenos ajustes (medicações, dietas, hábitos) visando a melhoria da qualidade de vida.

A equipe encontra-se disponivel, 24 horas, para a orientação, atendimento e condutas, devendo o paciente e/ou familiar entrar em contato com o Dr. Décio S. Couto Jr. (Casa:30677017/cel:84084554) e Dr. Everson Artifon (cel:81753884) ou procurar o Pronto Socorro do Hospital das Clinicas - Sala de Endoscopia $(3069-7175)$. Sevocê tiver alguma consideraçäo ou dúvida sobre a ética da pesquisa, entre em contato com o Comitê de Ética em Pesquisa (CEP) - Rua Ovidio Pires de Campos, 225 - 5 andar - tel: 3069-6442 ramais 16,17, 18 ou 20,Fax: 3069-6442 - email: cappesq@hcnet.usp.br

Você terá acesso, a qualquer tempo, às informações sobre procedimentos, riscos e beneficios relacionados à pesquisa, inclusive para dirimir eventuais dúvidas. Você terá acesso a qualquer momento a todas as informaçōes relacionadas ao estudo, tendo os médicos e responsáveis pela pesquisa a disponibilidade de atender e orientar a respeito de todas as etapas que estão sendo realizadas, assim como de seus resultados.

As informações obtidas serão analisadas em conjunto com outros pacientes, não sendo divulgado a identificação de nenhum paciente.

Sua participação neste estudo é voluntária. A qualquer momento seu consentimento poderá ser retirado. Não haverá qualquer prejuizo para o seu tratamento neste serviço. Caso opte pela não continuidade, esta năo precisa ser justificada.

Todos os dados referentes a você e seu tratamento são confidenciais. Somente o médico e sua equipe sabem que você estará participando deste estudo. Todos os dados coletados serão utilizados somente para pesquisa. Se o estudo for publicado você não será identificado pelo nome 
Não hả despesas pessoais para o participante em qualquer fase do estudo, incluindo consultas $\theta$ exames. Tambèm nāo há compensação financeira relacionada à sua participação. Se exixtir qualquer despesa adicional ela será absorvida pelo orçamento da pesquisa.

A viabilidade de indenizaçăo por eventuais danos à saúde decorrentes da pesquisa não se aplica pois o tratamento não é experimental, já tendo sido realizados estudos prévios e publicados em revistas internacionais; exceto por aquelas legalmente estabelecidas.

Acredito ter sido suficientemente informado a respeito das informações que li ou que foram lidas para mim, descrevendo o estudo" Drenagem biliar interna em pacientes com obstruçäo maligna do hilo hepático: estudo comparativo da abordagem transparietal e transgástrica ecoguiada

Eu discuti com o Dr. Everson Luiz Artifon e Dr. Paulo Sakai sobre a minha decisão em participar nesse estudo. Ficaram claros para mim quais são os propósitos do estudo, os procedimentos a serem realizados, seus desconfortos e riscos, as garantias de confidencialidade e de esclarecimentos permanentes. Ficou claro também que minha participacão é isenta de despesas e que tenho garantra do permanentes ficou claro também que minha participaçăo é isenta de despesas e que tenho garantia do acesso a tratamento hospitalar quando necessánio concordo voluntariamente em participar deste estudo prejuizo ou perda de qualquer beneficio que eu possa ter adquirido, ou no meu atendimento neste Service.

Assinatura do paciente/representante legal Data

Assinatura da testemunha

Data

para casos de pacientes menores de 18 anos, analfabetos, semi-analfabetos ou portadores de deficiẻncia auditiva ou visual.

(Somente para o responsável do projeto)

Declaro que obtive de forma apropriada e voluntária o Consentimento Livre e Esclarecido deste paciente ou representante legal para a participação neste estudo.

Assinatura do responsàvel pelo estudo

Data 


\section{Anexo C - Dados da Casuística}

\begin{tabular}{|c|c|c|c|c|c|c|c|}
\hline Paciente & Nome & Registro & Sexo & Idade & Diagnóstico & Dor & $\begin{array}{c}\text { Perda } \\
\text { Peso (kg) }\end{array}$ \\
\hline 1 & DAVS & 01109025100 & $\mathrm{~F}$ & 46 & Colangioca & Sim & 6 \\
\hline 2 & JGC & $1-10-9022420$ & $\mathrm{~F}$ & 88 & T. pâncreas & Não & 12 \\
\hline 3 & WB & 01109026717 & $M$ & 75 & Metastase & Não & 10 \\
\hline 4 & WJB & 01109027954 & $\mathrm{M}$ & 52 & T. pâncreas & Sim & 3 \\
\hline 5 & MCMC & 01109031871 & $\mathrm{~F}$ & 41 & Colangioca & Sim & 8 \\
\hline 6 & DPA & $2319237 i$ & $\mathrm{M}$ & 64 & Colangioca & Sim & 10 \\
\hline 7 & MAV & $1-10-9035532$ & $\mathrm{~F}$ & 77 & T. pâncreas & Sim & 4 \\
\hline 8 & MSP & $1-10-9055345$ & $\mathrm{~F}$ & 95 & T. pâncreas & Sim & 10 \\
\hline 9 & RAN & $13937440 \mathrm{H}$ & $\mathrm{M}$ & 59 & T. pâncreas & $\mathrm{NaO}$ & 5 \\
\hline 10 & RSC & $1-11-9003110$ & $\mathrm{~F}$ & 75 & Colangioca & $\mathrm{NaO}$ & Não \\
\hline 11 & JM & $1-11-9008466$ & $M$ & 74 & T. pâncreas & Sim & 14 \\
\hline 12 & MSG & $1-11-9010057$ & $\mathrm{~F}$ & 34 & T. pâncreas & $\mathrm{NaO}$ & 8 \\
\hline 13 & $\mathrm{ABP}$ & 1-11-9012384 & $\mathrm{F}$ & 91 & T. pâncreas & Sim & 5 \\
\hline 14 & AFG & $1-11-9010355$ & $\mathrm{M}$ & 73 & T. pâncreas & Sim & 8 \\
\hline 15 & CTM & $1-11-9020139$ & $\mathrm{~F}$ & 85 & T. pâncreas & $\mathrm{NaO}$ & 6 \\
\hline 16 & SNL & $2011860 \mathrm{~K}$ & $\mathrm{M}$ & 34 & T. pâncreas & $\mathrm{NaO}$ & 8 \\
\hline 17 & MJS & $1-11-9033610$ & $\mathrm{~F}$ & 70 & $\mathrm{HCC}$ & Sim & 10 \\
\hline 18 & APT & $13967608 \mathrm{H}$ & $\mathrm{M}$ & 59 & T. pâncreas & Sim & 20 \\
\hline 19 & ATFS & $1-11-9050215$ & $\mathrm{~F}$ & 71 & T. pâncreas & Sim & 3 \\
\hline 20 & MMS & 1-11-9052068 & $\mathrm{F}$ & 86 & T. pâncreas & Sim & 8 \\
\hline 21 & RSSP & $1-11-9063238$ & $\mathrm{~F}$ & 52 & T. pâncreas & Sim & 15 \\
\hline 22 & ARS & $1-11-9067538$ & $\mathrm{M}$ & 65 & T. pâncreas & $\mathrm{NaO}$ & 14 \\
\hline 23 & AFF & $1-11-9067329$ & $M$ & 81 & Colangioca & Não & 10 \\
\hline 24 & MFCS & 1-11-9073932 & $\mathrm{F}$ & 67 & Metastase & Sim & 10 \\
\hline 25 & MCS & $1-11-9075484$ & $\mathrm{~F}$ & 81 & Metastase & $\mathrm{NaO}$ & 10 \\
\hline 26 & $\mathrm{PC}$ & 139976790 & $\mathrm{M}$ & 55 & $\mathrm{HCC}$ & $\mathrm{NaO}$ & 8 \\
\hline 27 & AFP & $1-11-9006853$ & $\mathrm{~F}$ & 56 & Colangioca & Sim & 10 \\
\hline 28 & LFS & $13926145 d$ & $\mathrm{~F}$ & 79 & T. vesicula & Sim & 11 \\
\hline 29 & $\mathrm{RBC}$ & $13914895 j$ & $\mathrm{M}$ & 81 & $\mathrm{HCC}$ & Sim & 8 \\
\hline 30 & AT & $1,20109 E+11$ & $\mathrm{M}$ & 77 & T. pancreas & Sim & 10 \\
\hline 31 & JM & $13928524 \mathrm{~g}$ & $\mathrm{M}$ & 51 & T. pancreas & Sim & 5 \\
\hline 32 & $\mathrm{VF}$ & 1109050202 & $\mathrm{M}$ & 51 & T. pancreas & Sim & 20 \\
\hline
\end{tabular}

$\mathrm{F}=$ Feminino; $\mathrm{M}=$ Masculino; $\mathrm{T}$. pâncreas = Tumor de pâncreas; $\mathrm{HCC}=$ Colangiocarcinoma 


\begin{tabular}{|c|c|c|c|c|c|}
\hline Paciente & Icterícia & Febre & Ascite & Técnica & Cirurgia prévia \\
\hline 1 & Sim & Não & Não & HPG & Sim - Cesárea \\
\hline 2 & Sim & Não & Não & CDT & Sim - Apendicectomia \\
\hline 3 & Sim & Não & Sim & HPJ & Sim - Gastrectomia parcial \\
\hline 4 & Sim & Sim & Sim & CDT & Sim - Apendicectomia \\
\hline 5 & Sim & Não & Não & FALHA & Não \\
\hline 6 & Sim & Não & Sim & HPG & Não \\
\hline 7 & Sim & Não & Não & C. antro & Não \\
\hline 8 & Sim & Não & Não & CDT & Não \\
\hline 9 & Sim & Não & Não & CDT & Sim - Apendicectomia \\
\hline 10 & Sim & Não & Não & CDT & Sim - Colecistectomia e Mastectomia \\
\hline 11 & Sim & Não & Sim & Ant. + PE & Sim - Rafia de úlcera \\
\hline 12 & Sim & Não & Não & Ant. + PE & Não \\
\hline 13 & Sim & Não & Não & CDT & Não \\
\hline 14 & Sim & Não & Sim & CDT & Não \\
\hline 15 & Sim & Não & Não & CDT & Não \\
\hline 16 & Sim & Não & Não & CDT & Não \\
\hline 17 & Sim & Não & Não & HPG & Não \\
\hline 18 & Sim & Não & Não & CDT & Não \\
\hline 19 & Sim & Não & Não & $\mathrm{CDT}+\mathrm{PE}$ & Não \\
\hline 20 & Sim & Não & Não & $\mathrm{CDT}+\mathrm{PE}$ & Não \\
\hline 21 & Sim & Não & Não & C. antro & Não \\
\hline 22 & Sim & Não & Não & CDT & Não \\
\hline 23 & Sim & Não & Não & $\mathrm{HPG}$ & Não \\
\hline 24 & Sim & Não & Não & CDT & Não \\
\hline 25 & Sim & Não & Não & HPG & Não \\
\hline 26 & Sim & Sim & Não & HPG & Não \\
\hline 27 & Sim & Não & Sim & Rendez & Sim - Cesárea \\
\hline 28 & Sim & Não & Não & FALHA & Não \\
\hline 29 & Sim & Não & Não & FALHA & Sim - Gastrectomia parcial \\
\hline 30 & Sim & Não & Não & $\mathrm{CDT}+\mathrm{PE}$ & Não \\
\hline 31 & Sim & Não & Não & CDT & Não \\
\hline 32 & Sim & Não & Não & CDT + PE & Não \\
\hline
\end{tabular}

$\mathrm{HPG}=$ Hepatogastrostomia; HPJ = Hepatojejunostomia; CDT = Coledocoduodenostomia; Ant. $+\mathrm{PE}=$ Drenagem anterógrada + Prótese enteral $; \mathrm{CDT}+\mathrm{PE}=$ Coledocoduodenostomia + Prótese enteral; C. antro $=$ Coledocoantrostomia, Rendez $=$ Rendez-vous. 


\begin{tabular}{|c|c|c|c|c|c|c|}
\hline Paciente & $\begin{array}{c}\text { Diâmetro } \\
\text { prévio da } \\
\text { via biliar } \\
(\mathrm{mm})\end{array}$ & $\begin{array}{l}\text { Invasão } \\
\text { duodenal }\end{array}$ & $\begin{array}{c}\text { Invasão } \\
\text { do eixo } \\
\text { mesentero- } \\
\text { portal }\end{array}$ & $\begin{array}{c}\text { Metástase } \\
\text { hepática }\end{array}$ & $\begin{array}{c}\text { Classificação } \\
\text { Bismuth }\end{array}$ & $\begin{array}{c}\text { Tamanho } \\
\text { da lesão } \\
(\mathrm{mm})\end{array}$ \\
\hline 1 & 10 & Não & Sim & Não & II & $27 \times 32$ \\
\hline 2 & 22 & Não & Sim & Não & 1 & $35 \times 41$ \\
\hline 3 & 15 & Não & Não & Sim & II & $21 \times 38$ \\
\hline 4 & 20 & Sim & Sim & Não & 1 & $45 \times 61$ \\
\hline 5 & FALHA & Não & Sim & Não & IIIA & $27 \times 36$ \\
\hline 6 & 15 & Não & Sim & Não & II & $41 \times 47$ \\
\hline 7 & 22 & Sim & Sim & Não & 1 & $51 \times 59$ \\
\hline 8 & 25 & Não & Sim & Não & I & $53 \times 55$ \\
\hline 9 & 24 & Sim & Não & Sim & I & $46 \times 58$ \\
\hline 10 & 20 & Não & Sim & Não & IIIA & $39 \times 43$ \\
\hline 11 & 24 & Sim & Sim & Não & 1 & $27 \times 35$ \\
\hline 12 & 22 & Sim & Não & Sim & I & $42 \times 44$ \\
\hline 13 & 26 & Não & Sim & Não & 1 & $25 \times 29$ \\
\hline 14 & 28 & Não & Sim & Não & I & $23 \times 27$ \\
\hline 15 & 20 & Não & Sim & Não & 1 & $29 \times 38$ \\
\hline 16 & 30 & Sim & Não & Sim & $\mathrm{I}$ & $26 \times 34$ \\
\hline 17 & 18 & Não & Sim & Não & IIIA & $47 \times 59$ \\
\hline 18 & 24 & Não & Sim & Não & 1 & $35 \times 46$ \\
\hline 19 & 22 & Sim & Sim & Não & I & $25 \times 31$ \\
\hline 20 & 20 & Sim & Sim & Não & 1 & $29 \times 41$ \\
\hline 21 & 26 & Não & Não & Sim & I & $27 \times 34$ \\
\hline 22 & 24 & Não & Sim & Não & 1 & $61 \times 52$ \\
\hline 23 & 20 & Não & Sim & Não & II & $37 \times 41$ \\
\hline 24 & 20 & Não & Sim & Não & IIIB & $35 \times 49$ \\
\hline 25 & 18 & Não & Sim & Não & IIIA & $22 \times 35$ \\
\hline 26 & 15 & Não & Não & Sim & IIIA & $41 \times 43$ \\
\hline 27 & 16 & Não & Sim & Não & IIIA & $28 \times 34$ \\
\hline 28 & FALHA & Não & Sim & Não & II & $34 \times 30$ \\
\hline 29 & FALHA & Não & Sim & Não & IV & $35 \times 32$ \\
\hline 30 & 22 & Sim & Sim & Não & I & $29 \times 38$ \\
\hline 31 & 20 & Não & Sim & Não & 1 & $41 \times 37$ \\
\hline 32 & 30 & Sim & Sim & Não & I & $33 \times 31$ \\
\hline
\end{tabular}




\begin{tabular}{|c|c|c|c|c|c|c|c|}
\hline Paciente & $\begin{array}{c}\text { Índice } \\
\text { Karnofsky }\end{array}$ & $\begin{array}{c}\text { SF-36 } \\
\text { (before) }\end{array}$ & $\begin{array}{l}\text { Pré } \\
\text { BT }\end{array}$ & $\begin{array}{l}\text { Pré } \\
\text { gGT }\end{array}$ & $\begin{array}{c}\text { Pré } \\
\text { FA }\end{array}$ & $\begin{array}{c}\text { Pré } \\
\text { Leuco }\end{array}$ & $\begin{array}{c}\text { Tempo } \\
\text { (minutos) }\end{array}$ \\
\hline 1 & 40 & 59 & 13,5 & 540 & 350 & 6600 & 45 \\
\hline 2 & 60 & 63 & 15,5 & 610 & 430 & 10000 & 50 \\
\hline 3 & 50 & 55 & 27,12 & 1671,4 & 575 & 5200 & 47 \\
\hline 4 & 50 & 61 & 8,4 & 410 & 345 & 14500 & 62 \\
\hline 5 & 30 & FALHA & 9.8 & 222 & 49 & 10900 & 48 \\
\hline 6 & 40 & 51 & 22,8 & 1100 & 880 & 5500 & 38 \\
\hline 7 & 40 & 50 & 10,7 & 738 & 362 & 7700 & 40 \\
\hline 8 & 50 & 60 & 15,5 & 486 & 233 & 1960 & 17 \\
\hline 9 & 50 & 62 & 16,93 & 545 & 330 & 15740 & 48 \\
\hline 10 & 40 & 60 & 17,7 & 1429 & 461 & 7200 & 75 \\
\hline 11 & 60 & 60 & 16,82 & 1322 & 923 & 8600 & 93 \\
\hline 12 & 50 & 63 & 11,67 & 1400 & 928 & 9800 & 33 \\
\hline 13 & 50 & 52 & 14,59 & 479 & 263 & 5000 & 26 \\
\hline 14 & 40 & 56 & 16,27 & 868 & 611 & 6700 & 54 \\
\hline 15 & 50 & 60 & 3,54 & 1400 & 887 & 6500 & 72 \\
\hline 16 & 60 & 62 & 18,46 & 1281 & 743 & 7530 & 40 \\
\hline 17 & 50 & 64 & 11,2 & 994 & 538 & 19900 & 56 \\
\hline 18 & 60 & 54 & 7,85 & 658 & 389 & 5510 & 38 \\
\hline 19 & 50 & 58 & 14,2 & 944 & 506 & 5500 & 44 \\
\hline 20 & 60 & 57 & 8,2 & 464 & 478 & 5600 & 38 \\
\hline 21 & 40 & 53 & 19,2 & 473 & 312 & 18700 & 25 \\
\hline 22 & 50 & 60 & 6,9 & 487 & 378 & 7000 & 45 \\
\hline 23 & 40 & 50 & 4,4 & 1189 & 784 & 6900 & 45 \\
\hline 24 & 60 & 62 & 11,24 & 656 & 411 & 11530 & 60 \\
\hline 25 & 50 & 58 & 13,5 & 292 & 642 & 10700 & 35 \\
\hline 26 & 50 & 54 & 9,76 & 1362 & 340 & 24910 & 30 \\
\hline 27 & 40 & 42 & 18,86 & 672 & 498 & 7860 & 42 \\
\hline 28 & 30 & FALHA & FALHA & FALHA & FALHA & FALHA & 37 \\
\hline 29 & 20 & FALHA & FALHA & FALHA & FALHA & FALHA & 44 \\
\hline 30 & 50 & 48 & 25 & 865 & 473 & 13200 & 50 \\
\hline 31 & 40 & 60 & 11,12 & 1380 & 366 & 6.010 & 66 \\
\hline 32 & 50 & 58 & 17,6 & 442 & 662 & 7.900 & 60 \\
\hline
\end{tabular}

Pré BT = Pré bilirrubina total; Pré gGT = Pré gama-glutamil transferase; Pré FA = Pré Fosfatase alcalina; Pré Leuco $=$ Pré Leucócitos 


\begin{tabular}{|c|c|c|c|}
\hline Paciente & Prótese & Tamanho & Complicações imediatas \\
\hline 1 & Metálica & Biliar $60 \times 10 \mathrm{~mm}$ & Não \\
\hline 2 & Metálica & Biliar $60 \times 10 \mathrm{~mm}$ & Não \\
\hline 3 & Metálica & Biliar $80 \times 10 \mathrm{~mm}$ & Não \\
\hline 4 & Metálica & Biliar $60 \times 10 \mathrm{~mm}$ & Sim - Bacteremia \\
\hline 5 & FALHA & FALHA & FALHA \\
\hline 6 & Metálica & Biliar 60x10 mm & Não \\
\hline 7 & Metálica & $\begin{array}{l}\text { Biliar } 80 \times 10 \mathrm{~mm}+\text { duodenal } \\
\text { 100x25 mm }\end{array}$ & Não \\
\hline 8 & Metálica & Biliar $60 \times 10 \mathrm{~mm}$ & Sim - Hemorragia \\
\hline 9 & Metálica & Biliar $60 \times 10 \mathrm{~mm}$ & Não \\
\hline 10 & Metálica & Biliar $80 \times 10 \mathrm{~mm}$ & Não \\
\hline 11 & Metálica & $\begin{array}{l}\text { Biliar } 60 \times 10 \mathrm{~mm}+\text { duodenal } \\
90 \times 22 \mathrm{~mm}\end{array}$ & Não \\
\hline 12 & Metálica & $\begin{array}{l}\text { Biliar } 60 \times 10 \mathrm{~mm}+\text { duodenal } \\
90 \times 22 \mathrm{~mm}\end{array}$ & Não \\
\hline 13 & Metálica & Biliar $60 \times 10 \mathrm{~mm}$ & Não \\
\hline 14 & Metálica & Biliar $60 \times 10 \mathrm{~mm}$ & Não \\
\hline 15 & Metálica & Biliar 60x10 mm & Não \\
\hline 16 & Metálica & Biliar $60 \times 10 \mathrm{~mm}$ & Não \\
\hline 17 & Metálica & Biliar 60x8 mm & $\begin{array}{l}\text { Sim. Tentativa de hepatogastro com } \\
\text { liberação da prótese submucosa. } \\
\text { Paciente encaminhada para } \\
\text { cirurgia. Realizada "dissecção" da } \\
\text { prótese deixando-a intra gástrica }\end{array}$ \\
\hline 18 & Metálica & Biliar 80x10mm & Não \\
\hline 19 & Metálica & $\begin{array}{l}\text { Biliar } 80 \times 10 \mathrm{~mm}+\text { duodenal } \\
90 \times 22 \mathrm{~mm}\end{array}$ & Não \\
\hline 20 & Metálica & $\begin{array}{l}\text { Biliar } 60 \times 10 \mathrm{~mm}+\text { duodenal } \\
90 \times 22 \mathrm{~mm}\end{array}$ & Não \\
\hline 21 & Metálica & Biliar 60x8mm & Não \\
\hline 22 & Metálica & Biliar 60x10mm & Não \\
\hline 23 & Metálica & Biliar 80x10mm & Não \\
\hline 24 & Metálica & Biliar 80x10mm & Não \\
\hline 25 & Metálica & Biliar 60x10mm & Não \\
\hline 26 & Metálica & Biliar 80x10mm & Sim - Hemorragia \\
\hline 27 & Metálica & Biliar 60X10mm & Não \\
\hline 28 & FALHA & FALHA & FALHA \\
\hline 29 & FALHA & FALHA & FALHA \\
\hline 30 & Metálica & $\begin{array}{l}\text { Biliar } 60 \times 10 \mathrm{~mm}+\text { duodenal } \\
90 \times 22 \mathrm{~mm}\end{array}$ & Não \\
\hline 31 & Metálica & Biliar 60X10mm & Sim - Bilioma \\
\hline 32 & Metálica & $\begin{array}{l}\text { Biliar } 60 \times 10 \mathrm{~mm}+\text { duodenal } \\
90 \times 22 \mathrm{~mm}\end{array}$ & Não \\
\hline
\end{tabular}




\begin{tabular}{|c|c|c|c|c|c|}
\hline \multirow{2}{*}{ Paciente } & \multicolumn{5}{|c|}{7 dias } \\
\hline & BT & gGT & FA & Leuco & SF-36 \\
\hline 1 & 2.2. & 110 & 88 & 5800 & 75 \\
\hline 2 & 3.0 & 118 & 75 & 6700 & 79 \\
\hline 3 & 2.5 & 76 & 92 & 7500 & 76 \\
\hline 4 & 3.7 & 110 & 112 & 8800 & 72 \\
\hline 5 & FALHA & FALHA & FALHA & FALHA & FALHA \\
\hline 6 & 2.9 & 120 & 98 & $\mathrm{nl}$ & 65 \\
\hline 7 & 3.4 & 169 & 98 & $\mathrm{nl}$ & 70 \\
\hline 8 & 2.8 & 123 & 80 & $\mathrm{nl}$ & 75 \\
\hline 9 & 3.8 & 176 & 130 & $\mathrm{nl}$ & 73 \\
\hline 10 & 5.4 & 207 & 158 & $\mathrm{nl}$ & 77 \\
\hline 11 & 3.2 & 128 & 102 & $\mathrm{nl}$ & 80 \\
\hline 12 & 4.1 & 165 & 96 & $\mathrm{nl}$ & 76 \\
\hline 13 & 2.85 & 116 & 83 & $\mathrm{nl}$ & 67 \\
\hline 14 & 6.0 & 203 & 176 & $\mathrm{nl}$ & 70 \\
\hline 15 & 2.9 & 132 & 89 & $\mathrm{nl}$ & 74 \\
\hline 16 & 2.75 & 109 & 78 & $\mathrm{nl}$ & 77 \\
\hline 17 & 2.85 & 97 & 81 & $\mathrm{nl}$ & 76 \\
\hline 18 & 5.1 & 209 & 187 & $\mathrm{nl}$ & 76 \\
\hline 19 & 3.4 & 154 & 106 & $\mathrm{nl}$ & 74 \\
\hline 20 & 2.95 & 147 & 109 & $\mathrm{nl}$ & 78 \\
\hline 21 & 5.6 & 317 & 254 & $\mathrm{nl}$ & 70 \\
\hline 22 & 2.7 & 210 & 123 & $\mathrm{nl}$ & 78 \\
\hline 23 & 3.6 & 153 & 113 & $\mathrm{nl}$ & 72 \\
\hline 24 & 4.7 & 193 & 124 & $\mathrm{nl}$ & 75 \\
\hline 25 & 3.1 & 160 & 112 & $\mathrm{nl}$ & 73 \\
\hline 26 & 4.4 & 402 & 138 & $\mathrm{nl}$ & 67 \\
\hline 27 & 9.8 & 321 & 345 & $\mathrm{nl}$ & 70 \\
\hline 28 & FALHA & FALHA & FALHA & FALHA & FALHA \\
\hline 29 & FALHA & FALHA & FALHA & FALHA & FALHA \\
\hline 30 & 15.7 & 527 & 345 & 13.400 & 60 \\
\hline 31 & 5.5 & 567 & 198 & $\mathrm{nl}$ & 66 \\
\hline 32 & 2.5 & $\mathrm{nl}$ & $\mathrm{nl}$ & $\mathrm{nl}$ & 69 \\
\hline
\end{tabular}

$\mathrm{BT}=$ Bilirrubina total; gGT = Gama-glutamil-transferase; FA = Fosfatase alcalina; Leuco = Leucócitos; $\mathrm{nl}=$ Normal 


\begin{tabular}{|c|c|c|c|c|c|}
\hline \multirow{2}{*}{ Paciente } & \multicolumn{5}{|c|}{1 mês } \\
\hline & BT & gGT & FA & Leuco & SF-36 \\
\hline 1 & 2.0 & 117 & 90 & 6700 & 78 \\
\hline 2 & 2.5 & 105 & 86 & 7700 & 77 \\
\hline 3 & 2.1 & 75 & 81 & 7100 & 74 \\
\hline 4 & 2.3 & 88 & 93 & 8300 & 74 \\
\hline 5 & FALHA & FALHA & FALHA & FALHA & FALHA \\
\hline 6 & 45 dias & Óbito & Óbito & Óbito & Óbito \\
\hline 7 & 2.1 & 97 & 76 & $\mathrm{nl}$ & 68 \\
\hline 8 & 2.05 & $\mathrm{nl}$ & $\mathrm{nl}$ & $\mathrm{nl}$ & 76 \\
\hline 9 & 2.0 & $\mathrm{nl}$ & $\mathrm{nl}$ & $\mathrm{nl}$ & 72 \\
\hline 10 & 3.1 & 116 & 102 & $\mathrm{nl}$ & 75 \\
\hline 11 & 2.7 & 123 & $\mathrm{nl}$ & $\mathrm{nl}$ & 76 \\
\hline 12 & 2.8 & 115 & 78 & $\mathrm{nl}$ & 72 \\
\hline 13 & 0.85 & $\mathrm{nl}$ & $\mathrm{nl}$ & $\mathrm{nl}$ & 65 \\
\hline 14 & 2.8 & 121 & 97 & $\mathrm{nl}$ & 72 \\
\hline 15 & 1.5 & $\mathrm{nl}$ & $\mathrm{nl}$ & $\mathrm{nl}$ & 74 \\
\hline 16 & 0.95 & $\mathrm{nl}$ & $\mathrm{nl}$ & $\mathrm{nl}$ & 76 \\
\hline 17 & 1.85 & $\mathrm{nl}$ & $\mathrm{nl}$ & $\mathrm{nl}$ & 78 \\
\hline 18 & 2.8 & $\mathrm{nl}$ & 97 & $\mathrm{nl}$ & 75 \\
\hline 19 & 2.6 & 103 & 92 & $\mathrm{nl}$ & 76 \\
\hline 20 & 1.5 & $\mathrm{nl}$ & $\mathrm{nl}$ & $\mathrm{nl}$ & 70 \\
\hline 21 & 40 dias & Óbito & Óbito & Óbito & Óbito \\
\hline 22 & 1.8 & $\mathrm{nl}$ & $\mathrm{nl}$ & $\mathrm{nl}$ & 76 \\
\hline 23 & 38 dias & Óbito & Óbito & Óbito & Óbito \\
\hline 24 & 2.1 & $\mathrm{nl}$ & $\mathrm{nl}$ & $\mathrm{nl}$ & 75 \\
\hline 25 & 1.8 & $\mathrm{nl}$ & $\mathrm{nl}$ & $\mathrm{nl}$ & 70 \\
\hline 26 & 2.1 & $\mathrm{nl}$ & $\mathrm{nl}$ & $\mathrm{nl}$ & 67 \\
\hline 27 & 3.5 & $\mathrm{nl}$ & $\mathrm{nl}$ & $\mathrm{nl}$ & 73 \\
\hline 28 & FALHA & FALHA & FALHA & FALHA & FALHA \\
\hline 29 & FALHA & FALHA & FALHA & FALHA & FALHA \\
\hline 30 & 5.5 & 533 & 298 & $\mathrm{nl}$ & 58 \\
\hline 31 & 2.2 & 434 & $\mathrm{nl}$ & $\mathrm{nl}$ & 68 \\
\hline 32 & 2.1 & $\mathrm{nl}$ & $\mathrm{nl}$ & $\mathrm{nl}$ & 58 \\
\hline
\end{tabular}

BT = Bilirrubina total; gGT = Gama-glutamil-transferase; FA = Fosfatase alcalina; Leuco = Leucócitos; $\mathrm{nl}=$ Normal 


\begin{tabular}{|c|c|c|c|c|c|}
\hline & \multicolumn{5}{|c|}{2 meses } \\
\hline & BT & gGT & FA & Leuco & SF-36 \\
\hline 1 & 2.3 & 98 & 95 & 5.900 & 58 \\
\hline 2 & 2.5 & 90 & 86 & 6800 & 76 \\
\hline 3 & 2.0 & 77 & 85 & 7800 & 72 \\
\hline 4 & 2.2 & 88 & 90 & 7300 & 69 \\
\hline 5 & FALHA & FALHA & FALHA & FALHA & FALHA \\
\hline 6 & Óbito & Óbito & Óbito & Óbito & Óbito \\
\hline 7 & 75 dias & Óbito & Óbito & Óbito & Óbito \\
\hline 8 & 0.8 & $\mathrm{nl}$ & $\mathrm{nl}$ & $\mathrm{nl}$ & 55 \\
\hline 9 & 1.5 & $\mathrm{nl}$ & $\mathrm{nl}$ & $\mathrm{nl}$ & 68 \\
\hline 10 & 70 dias & Óbito & Óbito & Óbito & Óbito \\
\hline 11 & 2.15 & $\mathrm{nl}$ & $\mathrm{nl}$ & $\mathrm{nl}$ & 72 \\
\hline 12 & 1.4 & $\mathrm{nl}$ & $\mathrm{nl}$ & $\mathrm{nl}$ & 60 \\
\hline 13 & 80 dias & Óbito & Óbito & Óbito & Óbito \\
\hline 14 & 0.8 & $\mathrm{nl}$ & $\mathrm{nl}$ & $\mathrm{nl}$ & 59 \\
\hline 15 & 1.1 & $\mathrm{nl}$ & $\mathrm{nl}$ & $\mathrm{nl}$ & 70 \\
\hline 16 & 1.5 & $\mathrm{nl}$ & $\mathrm{nl}$ & $\mathrm{nl}$ & 62 \\
\hline 17 & 1.8 & $\mathrm{nl}$ & $\mathrm{nl}$ & $\mathrm{nl}$ & 70 \\
\hline 18 & 1.95 & $\mathrm{nl}$ & 91 & $\mathrm{nl}$ & 66 \\
\hline 19 & 2.3 & $\mathrm{nl}$ & $\mathrm{nl}$ & $\mathrm{nl}$ & 71 \\
\hline 20 & 1.5 & $\mathrm{nl}$ & $\mathrm{nl}$ & $\mathrm{nl}$ & 68 \\
\hline 21 & Óbito & Óbito & Óbito & Óbito & Óbito \\
\hline 22 & 1.7 & $\mathrm{nl}$ & $\mathrm{nl}$ & $\mathrm{nl}$ & 70 \\
\hline 23 & Óbito & Óbito & Óbito & Óbito & Óbito \\
\hline 24 & $\mathrm{nl}$ & $\mathrm{nl}$ & $\mathrm{nl}$ & $\mathrm{nl}$ & 73 \\
\hline 25 & 83 dias & Óbito & Óbito & Óbito & Óbito \\
\hline 26 & 1.8 & $\mathrm{nl}$ & $\mathrm{nl}$ & $\mathrm{nl}$ & 67 \\
\hline 27 & 2.2 & $\mathrm{nl}$ & $\mathrm{nl}$ & $\mathrm{nl}$ & 70 \\
\hline 28 & FALHA & FALHA & FALHA & FALHA & FALHA \\
\hline 29 & FALHA & FALHA & FALHA & FALHA & FALHA \\
\hline 30 & 1.7 & 169 & $\mathrm{nl}$ & $\mathrm{nl}$ & 62 \\
\hline 31 & 1.8 & $\mathrm{nl}$ & $\mathrm{nl}$ & $\mathrm{nl}$ & 69 \\
\hline 32 & 1.8 & $\mathrm{nl}$ & $\mathrm{nl}$ & $\mathrm{nl}$ & 56 \\
\hline
\end{tabular}

$\mathrm{BT}=$ Bilirrubina total; gGT = Gama-glutamil-transferase; FA = Fosfatase alcalina; Leuco = Leucócitos; $\mathrm{nl}=$ Normal 


\begin{tabular}{|c|c|c|c|c|c|}
\hline & \multicolumn{5}{|c|}{3 meses } \\
\cline { 2 - 6 } & BT & gGT & FA & Leuco & SF-36 \\
\hline 1 & 85 dias & ÓBITO & ÓBITO & ÓBITO & ÓBITO \\
\hline 2 & 2.5 & 88 & 100 & 6800 & 60 \\
\hline 3 & 2.4 & 87 & 90 & 5800 & 65 \\
\hline 4 & 2.2 & 80 & 95 & 6600 & 58 \\
\hline 5 & FALHA & FALHA & FALHA & FALHA & FALHA \\
\hline 6 & Óbito & Óbito & Óbito & Óbito & Óbito \\
\hline 7 & Óbito & Óbito & Óbito & Óbito & Óbito \\
\hline 8 & 82 dias & Óbito & Óbito & Óbito & Óbito \\
\hline 9 & 80 dias & Óbito & Óbito & Óbito & Óbito \\
\hline 10 & Óbito & Óbito & Óbito & Óbito & Óbito \\
\hline 11 & 1.9 & nl & $\mathrm{nl}$ & $\mathrm{nl}$ & 68 \\
\hline 12 & 0.7 & $\mathrm{nl}$ & $\mathrm{nl}$ & $\mathrm{nl}$ & 55 \\
\hline 13 & Óbito & Óbito & Óbito & Óbito & Óbito \\
\hline 14 & 90 dias & Óbito & Óbito & Óbito & Óbito \\
\hline 15 & 1.3 & $\mathrm{nl}$ & $\mathrm{nl}$ & $\mathrm{nl}$ & 59 \\
\hline 16 & 80 dias & Óbito & Óbito & Óbito & Óbito \\
\hline 17 & 1.3 & $\mathrm{nl}$ & $\mathrm{nl}$ & $\mathrm{nl}$ & 54 \\
\hline 18 & 85 dias & Óbito & Óbito & ÓBITO & Óbito \\
\hline 19 & 1.95 & $\mathrm{nl}$ & $\mathrm{nl}$ & $\mathrm{nl}$ & 66 \\
\hline 20 & 93 dias & Óbito & Óbito & Óbito & Óbito \\
\hline 21 & Óbito & Óbito & Óbito & Óbito & Óbito \\
\hline 22 & 1.8 & $\mathrm{nl}$ & $\mathrm{nl}$ & $\mathrm{nl}$ & $\mathrm{nl}$ \\
\hline 23 & Óbito & Óbito & Óbito & Óbito & Óbito \\
\hline 24 & 90 dias & Óbito & Óbito & Óbito & Óbito \\
\hline 25 & Óbito & Óbito & Óbito & Óbito & Óbito \\
\hline 26 & 2.1 & $\mathrm{nl}$ & $\mathrm{nl}$ & $\mathrm{nl}$ & 66 \\
\hline 27 & 2.0 & $\mathrm{nl}$ & $\mathrm{nl}$ & $\mathrm{nl}$ & 67 \\
\hline 28 & FALHA & FALHA & FALHA & FALHA & FALHA \\
\hline 29 & FALHA & FALHA & FALHA & FALHA & FALHA \\
\hline 30 & 1.8 & $\mathrm{nl}$ & $\mathrm{nl}$ & $\mathrm{nl}$ & $\mathrm{nl}$ \\
\hline 31 & 1.9 & $\mathrm{nl}$ & $\mathrm{nl}$ & $\mathrm{nl}$ & $\mathrm{nl}$ \\
\hline 32 & 80 dias & Óbito & Óbito & Óbito & Óbito \\
\hline
\end{tabular}

$\mathrm{BT}=$ Bilirrubina total; gGT = Gama-glutamil-transferase; FA = Fosfatase alcalina; Leuco = Leucócitos; $\mathrm{nl}=$ Normal 


\section{Anexo D - Protocolo}

\section{PROTOCOLO}

\section{Identificação}

Nome:

Registro:

Sexo:

Idade:

\section{Dados clínicos (Pré tratamento)}

Dor (detalhar)

Perda de peso:

Exame físico geral/abdominal:

( ) Icterícia:

( ) Febre:

( ) Ascite

( ) Cirurgia abdominal prévia

( ) Massa palpável

( ) Outros:

\section{Dados laboratorais (Pré tratamento)}

\begin{tabular}{|l|l|}
\hline HB: & GGT: \\
\hline HT: & BT: \\
\hline Leucócitos: & BD: \\
\hline Bastões: & Plaquetas: \\
\hline TGO/AST: & TAP/RNI: \\
\hline TGP/ALT: & Creatinina: \\
\hline FA: & Outros: \\
\hline
\end{tabular}

\section{Imagem}

( ) USG ( ) TC ( ) RNM ( ) CRNM ( ) OUTRO

Ascite: ( ) sim ( ) não

Nível da obstrução (distância da confluência dos hepáticos):

Descritivo da imagem: 


\section{Hipoteses diagnósticas:}

( ) Colangio CA

( ) CA cabeça de pâncreas

( ) CA vesícula biliar

( ) CA papila

( ) Outro:

\section{Classificação de Bismuth-Corlete}

( ) I - tumores localizados abaixo da confluência

( ) II - tumores confinados à confluência

( ) Illa - tumores que afetam a bifurcação, com extensão para o ducto direito.

( ) lllb - tumores que afetam a bifurcação, com extensão para o ducto esquerdo.

( ) IV - tumores com extensão para ambos os ductos.

\section{CPRE:}

Tipo de prótese: ( ) METÁLICA ( ) PLÁSTICA

Tempo de procedimento:

Tipo de sedação:

Tempo da passagem de prótese:

No. de próteses:

Tipo da prótese:

Dilatação balonada:

- Diâmetro:

- Tamanho:

- Quantas vezes:

Aspecto da bile: $\square$ pus $\square$ verde $\square$ amarela $\square$ branca $\square$ outro:

Esvaziamento do contraste após 20' de posicionar a prótese (metálica/plática)
$\square$ Ruim
$\square$ Bom
口 Ótimo

\section{CPTH:}

Tipo de prótese: ( ) METÁLICA ( ) PLÁSTICA

Tempo de procedimento:

Tipo de sedação:

Tempo da passagem de prótese:

No. de próteses:

Tipo da prótese:

Dilatação balonada: 
- Diâmetro:

- Tamanho:

- Quantas vezes:

Aspecto da bile: $\square$ pus $\square$ verde $\square$ amarela $\square$ branca $\square$ outro:

Passagem da prótese:

( ) BILATERAL - ( ) EXTERNO ( ) INTERNO-EXTERNO

( ) UNILATERAL - ( ) EXTERNO ( ) INTERNO-EXTERNO

\section{Complicações imediatas:}

( ) Hemobilia

( ) Hemoperitôneo

( ) Coleperitôneo

( ) Obstrução da prótese

( ) Outros:

\section{Seguimento:}

\section{1 semana:}

Dados Clínicos:

Laboratoriais

\begin{tabular}{|l|l|}
\hline HB: & GGT: \\
\hline HT: & BT: \\
\hline Leucócitos: & BD: \\
\hline Bastões: & Plaquetas: \\
\hline TGO/AST: & TAP/RNI: \\
\hline TGP/ALT: & Creatinina: \\
\hline FA: & Outros: \\
\hline
\end{tabular}

Imagem:

Complicações:

Impressões do examinador: 
30 dias:

Dados Clínicos:

Laboratoriais

\begin{tabular}{|l|l|}
\hline HB: & GGT: \\
\hline HT: & BT: \\
\hline Leucócitos: & BD: \\
\hline Bastões: & Plaquetas: \\
\hline TGO/AST: & TAP/RNI: \\
\hline TGP/ALT: & Creatinina: \\
\hline FA: & Outros: \\
\hline
\end{tabular}

Imagem:

Complicações:

Impressões do examinador:

60 dias:

Dados Clínicos:

Laboratoriais

\begin{tabular}{|l|l|}
\hline HB: & GGT: \\
\hline HT: & BT: \\
\hline Leucócitos: & BD: \\
\hline Bastões: & Plaquetas: \\
\hline TGO/AST: & TAP/RNI: \\
\hline TGP/ALT: & Creatinina: \\
\hline FA: & Outros: \\
\hline
\end{tabular}

Imagem: 
Complicações:

Impressões do examinador:

\section{0 dias:}

Dados Clínicos:

Laboratoriais

\begin{tabular}{|l|l|}
\hline HB: & GGT: \\
\hline HT: & BT: \\
\hline Leucócitos: & BD: \\
\hline Bastões: & Plaquetas: \\
\hline TGO/AST: & TAP/RNI: \\
\hline TGP/ALT: & Creatinina: \\
\hline FA: & Outros: \\
\hline
\end{tabular}

Imagem:

Complicações:

Impressões do examinador:

120 dias:

Dados Clínicos: 


Laboratoriais
\begin{tabular}{|l|l|}
\hline HB: & GGT: \\
\hline HT: & BT: \\
\hline Leucócitos: & BD: \\
\hline Bastões: & Plaquetas: \\
\hline TGO/AST: & TAP/RNI: \\
\hline TGP/ALT: & Creatinina: \\
\hline FA: & Outros: \\
\hline
\end{tabular}

Imagem:

Complicações:

Impressões do examinador:

dias:

Dados Clínicos:

Laboratoriais

\begin{tabular}{|l|l|}
\hline HB: & GGT: \\
\hline HT: & BT: \\
\hline Leucócitos: & BD: \\
\hline Bastões: & Plaquetas: \\
\hline TGO/AST: & TAP/RNI: \\
\hline TGP/ALT: & Creatinina: \\
\hline FA: & Outros: \\
\hline
\end{tabular}

Imagem:

Complicações:

Impressões do examinador: 


\section{Anexo E - SF-36}

\section{SF - 36 PESQUISA EM SAÚDE SCORE}

Instruções: Esta pesquisa questiona você sobre sua saúde. Estas informações nos manterão informados de como você se sente e quão bem você é capaz de fazer suas atividades de vida diária. Responda cada questão marcando a resposta como indicado. Caso você esteja inseguro em como responder, por favor, tente responder o melhor que puder.

1 - Em geral você diria que sua saúde é:

(Circule uma)

\begin{tabular}{|c|}
\hline Muito Boa \\
\hline Boa $\ldots \ldots \ldots . . . .$. \\
\hline (n) 4 \\
\hline
\end{tabular}

2 - Comparada há 1 ano atrás, como você classificaria sua saúde em geral, agora?

(Circule uma)

Muito melhor agora do que há um ano atrás ........................ 1

Um pouco melhor agora do que há um ano atrás ................... 2

Quase a mesma de um ano atrás ........................................... 3

Um pouco pior agora do que há um ano atrás ....................... 4

Muito pior agora do que há um ano atrás ............................. 5 
3 - Os seguintes itens são sobre atividades que você poderia fazer atualmente durante um dia comum. Devido a sua saúde, você tem dificuldade para fazer essas atividades? Neste caso, quanto?

(circule um número em cada linha)

\begin{tabular}{|l|c|c|c|}
\hline \multicolumn{1}{|c|}{ Atividades } & $\begin{array}{c}\text { Sim } \\
\text { dificulta } \\
\text { muito }\end{array}$ & $\begin{array}{c}\text { Sim } \\
\text { dificulta } \\
\text { um pouco }\end{array}$ & $\begin{array}{c}\text { Não. Não } \\
\text { dificulta de } \\
\text { modo } \\
\text { algum }\end{array}$ \\
\hline $\begin{array}{l}\text { a - Atividades vigorosas, que exigem muito } \\
\text { esforço, tais como: correr, levantar objetos } \\
\text { pesados, participar em esportes árduos. }\end{array}$ & 1 & 2 & 3 \\
\hline $\begin{array}{l}\text { b - Atividades moderadas, tais como: mover } \\
\text { uma mesa, passar aspirador de pó, jogar bola, } \\
\text { varrer a casa. }\end{array}$ & 1 & 2 & 3 \\
\hline c - Levantar ou carregar mantimentos & 1 & 2 & 3 \\
\hline d - Subir vários lances de escada & 1 & 2 & 3 \\
\hline e - Subir um lance de escada & 1 & 2 & 3 \\
\hline f - Curvar-se, ajoelhar-se ou dobrar-se & 1 & 2 & 3 \\
\hline g - Andar mais de 1 quilômetro & 1 & 2 & 3 \\
\hline h - Andar vários quarteirões & 1 & 2 & 3 \\
\hline i - Andar um quarteirão & 1 & 2 & 3 \\
\hline j - Tomar banho ou vestir-se & 2 & 3 \\
\hline
\end{tabular}

4 - Durante as últimas 4 semanas, você teve algum dos seguintes problemas com o seu trabalho ou com alguma atividade diária regular, como consequência de sua saúde física?

(circule um número em cada linha)

\begin{tabular}{|l|c|c|}
\hline & Sim & Não \\
\hline $\begin{array}{l}\text { a - Você diminuiu a quantidade de tempo que se dedicava ao seu } \\
\text { trabalho ou a outras atividades? }\end{array}$ & 1 & 2 \\
\hline b - Realizou menos tarefas do que você gostaria? & 1 & 2 \\
\hline c - Esteve limitado no seu trabalho ou em outras atividades? & 1 & 2 \\
\hline $\begin{array}{l}\text { d - Teve dificuldade de fazer seu trabalho ou outras atividades? } \\
\text { (necessitou de um esforço extra?) }\end{array}$ & 1 & 2 \\
\hline
\end{tabular}


5 - Durante as últimas 4 semanas, você teve algum dos seguintes problemas com o seu trabalho ou outra atividade regular diária,como consequência de algum problema emocional (como sentir-se deprimido ou ansioso)?

(circule um número em cada linha)

\begin{tabular}{|l|c|c|}
\hline $\begin{array}{l}\text { a - Você diminuiu a quantidade de tempo que se dedicava ao seu } \\
\text { trabalho ou a outras atividades? }\end{array}$ & 1 & 2 \\
\hline b - Realizou menos tarefas do que você gostaria? & 1 & 2 \\
\hline $\begin{array}{l}\text { C - Não trabalhou ou não fez qualquer das atividades com tanto } \\
\text { cuidado como geralmente faz? }\end{array}$ & 1 & 2 \\
\hline
\end{tabular}

6 - Durante as últimas 4 semanas, de que maneira sua saúde física ou problemas emocionais interferiram nas suas atividades sociais normais, em relação a família, vizinhos, amigos ou em grupo?

(Circule uma)

De forma nenhuma................................................................... 1

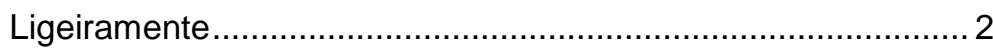

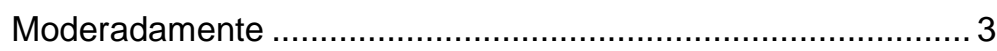

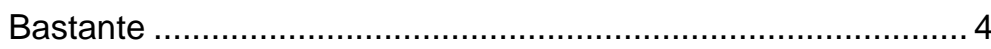

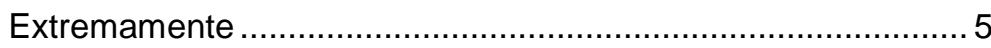

7 - Quanta dor no corpo você teve durante as últimas 4 semanas?

(Circule uma)

Nenhuma

8 - Durante as últimas 4 semanas, quanto a dor interferiu com o seu trabalho normal (incluindo tanto o trabalho, fora de casa e dentro de casa)?

(Circule uma)

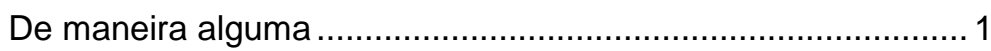

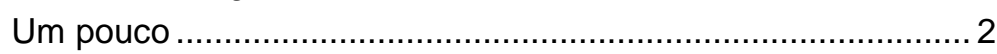

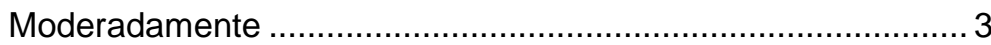

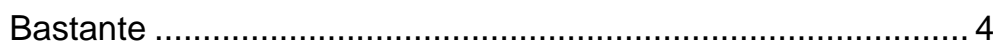

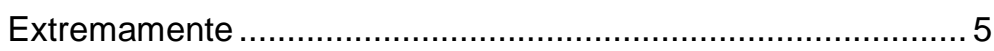


9 - Estas questões são sobre como você se sente e como tudo tem acontecido com você durante as últimas 4 semanas. Para cada questão, por favor dê uma resposta que mais se aproxime da maneira como você se sente. Em relação as últimas 4 semanas.

(Circule um número para cada linha)

\begin{tabular}{|l|c|c|c|c|c|c|}
\hline & $\begin{array}{c}\text { Todo } \\
\text { tempo }\end{array}$ & $\begin{array}{c}\text { A maior } \\
\text { parte do } \\
\text { tempo }\end{array}$ & $\begin{array}{c}\text { Uma boa } \\
\text { parte do } \\
\text { tempo }\end{array}$ & $\begin{array}{c}\text { Alguma } \\
\text { parte do } \\
\text { tempo }\end{array}$ & $\begin{array}{c}\text { Uma } \\
\text { pequena } \\
\text { parte do } \\
\text { tempo }\end{array}$ & Nunca \\
\hline $\begin{array}{l}\text { a - Quanto tempo você tem } \\
\text { se sentido cheio de vigor, } \\
\text { cheio de vontade, cheio de } \\
\text { força? }\end{array}$ & 1 & 2 & 3 & 4 & 5 & 6 \\
\hline $\begin{array}{l}\text { b - Quanto tempo você tem } \\
\text { se sentido uma pessoa } \\
\text { muito nervosa? }\end{array}$ & 1 & 2 & 3 & 4 & 5 & 6 \\
\hline $\begin{array}{l}\text { c - Quanto tempo você tem } \\
\text { se sentido tão deprimido } \\
\text { que nada pode animá-lo? }\end{array}$ & 1 & 2 & 3 & 4 & 5 & 6 \\
\hline $\begin{array}{l}\text { d - Quanto tempo você tem } \\
\text { se sentido calmo ou } \\
\text { tranquilo? }\end{array}$ & 1 & 2 & 3 & 4 & 5 & 6 \\
\hline $\begin{array}{l}\text { e- Quanto tempo você tem } \\
\text { se sentido com muita } \\
\text { energia? }\end{array}$ & 1 & 2 & 3 & 4 & 5 & 6 \\
\hline $\begin{array}{l}\text { f - Quanto tempo você tem } \\
\text { se sentido desanimado e } \\
\text { abatido? }\end{array}$ & 1 & 2 & 3 & 4 & 5 & 6 \\
\hline $\begin{array}{l}\text { g- Quanto tempo você tem } \\
\text { se sentido esgotado? }\end{array}$ & 1 & 2 & 3 & 4 & 5 & 6 \\
\hline $\begin{array}{l}\text { h - Quanto tempo você tem } \\
\text { se sentido uma pessoa } \\
\text { feliz? }\end{array}$ & 1 & 2 & 3 & 4 & 5 & 6 \\
\hline $\begin{array}{l}\text { I- Quanto tempo você tem } \\
\text { se sentido cansado? }\end{array}$ & 1 & 2 & 3 & 4 & 5 & 6 \\
\hline
\end{tabular}

10 - Durante as últimas 4 semanas, quanto do seu tempo a sua saúde física ou problemas emocionais interferiram com as suas atividades sociais (como visitar amigos, parentes, etc.)?

(Circule uma)

Todo o tempo 1

A maior parte do tempo ......................................................... 2

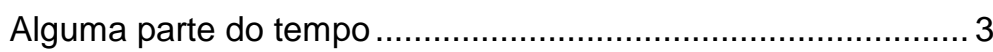

Uma pequena parte do tempo .................................................... 4

Nenhuma parte do tempo....................................................... 5 
11 - O quanto verdadeiro ou falso é cada uma das afirmações

(Circule um número me cada linha)

\begin{tabular}{|l|c|c|c|c|c|}
\hline & $\begin{array}{c}\text { Definitivam } \\
\text { ente } \\
\text { verdadeiro }\end{array}$ & $\begin{array}{c}\text { A maioria } \\
\text { das vezes } \\
\text { verdadeira }\end{array}$ & $\begin{array}{c}\text { Não } \\
\text { sei }\end{array}$ & $\begin{array}{c}\text { A maioria } \\
\text { das vezes } \\
\text { falsa }\end{array}$ & $\begin{array}{c}\text { Definitiva } \\
\text {-mente } \\
\text { falsa }\end{array}$ \\
\hline $\begin{array}{l}\text { a - Eu costumo adoecer um } \\
\text { pouco mais facilmente que } \\
\text { as outras pessoas }\end{array}$ & 1 & 2 & 3 & 4 & 5 \\
\hline $\begin{array}{l}\text { b - Eu sou tão saudável } \\
\text { quanto qualquer pessoa que } \\
\text { eu conheço. }\end{array}$ & 1 & 2 & 3 & 4 & 5 \\
\hline $\begin{array}{l}\text { c - Eu acho que a minha } \\
\text { saúde vai piorar }\end{array}$ & 1 & 2 & 3 & 4 & 5 \\
\hline d- Minha saúde é excelente & 1 & 2 & 3 & 4 & 5 \\
\hline
\end{tabular}




\section{Anexo F - Avaliação da qualidade de vida}

\begin{tabular}{|c|c|c|c|c|c|c|c|c|c|c|}
\hline \multirow[b]{2}{*}{ Paciente } & \multicolumn{5}{|c|}{ Questão 1} & \multicolumn{5}{|c|}{ Questão 2} \\
\hline & Pré & $\begin{array}{c}7 \\
\text { dias }\end{array}$ & $\begin{array}{c}1 \\
\text { mês }\end{array}$ & $\begin{array}{c}2 \\
\text { meses }\end{array}$ & $\begin{array}{c}3 \\
\text { meses }\end{array}$ & Pré & $\begin{array}{c}7 \\
\text { dias }\end{array}$ & $\begin{array}{c}1 \\
\text { mês }\end{array}$ & $\begin{array}{c}2 \\
\text { meses }\end{array}$ & $\begin{array}{c}3 \\
\text { meses }\end{array}$ \\
\hline 1 & 4 & 4 & 3 & 4 & Óbito & 4 & 3 & 4 & 4 & Óbito \\
\hline 2 & 4 & 3 & 3 & 3 & 4 & 4 & 4 & 3 & 3 & 4 \\
\hline 3 & 5 & 4 & 4 & 4 & 4 & 4 & 3 & 3 & 3 & 4 \\
\hline 4 & 4 & 4 & 4 & 4 & 4 & 4 & 4 & 3 & 3 & 3 \\
\hline 5 & FALHA & FALHA & FALHA & FALHA & FALHA & FALHA & FALHA & FALHA & FALHA & FALHA \\
\hline 6 & 5 & 4 & 5 & Óbito & Óbito & 4 & 4 & 5 & Óbito & Óbito \\
\hline 7 & 4 & 4 & 3 & 4 & Óbito & 3 & 3 & 3 & 5 & Óbito \\
\hline 8 & 4 & 4 & 4 & 4 & Óbito & 4 & 3 & 3 & 4 & Óbito \\
\hline 9 & 5 & 3 & 3 & 4 & Óbito & 3 & 3 & 3 & 3 & Óbito \\
\hline 10 & 4 & 3 & 4 & 4 & Óbito & 4 & 3 & 3 & 4 & Óbito \\
\hline 11 & 5 & 4 & 3 & 3 & 3 & 4 & 3 & 3 & 3 & 3 \\
\hline 12 & 5 & 4 & 3 & 3 & 4 & 3 & 3 & 3 & 3 & 3 \\
\hline 13 & 4 & 4 & 3 & 5 & Óbito & 4 & 4 & 3 & 4 & Óbito \\
\hline 14 & 4 & 4 & 3 & 5 & Óbito & 4 & 4 & 4 & 4 & Óbito \\
\hline 15 & 5 & 4 & 3 & 3 & 3 & 3 & 3 & 3 & 3 & 3 \\
\hline 16 & 5 & 4 & 3 & 4 & Óbito & 4 & 4 & 3 & 4 & Óbito \\
\hline 17 & 5 & 3 & 3 & 4 & 3 & 5 & 4 & 4 & 4 & 4 \\
\hline 18 & 4 & 4 & 4 & 5 & Óbito & 4 & 3 & 3 & 4 & Óbito \\
\hline 19 & 4 & 3 & 3 & 4 & 3 & 4 & 4 & 3 & 3 & 4 \\
\hline 20 & 5 & 4 & 3 & 4 & Óbito & 5 & 4 & 4 & 4 & Óbito \\
\hline 21 & 5 & 5 & 4 & Óbito & Óbito & 4 & 4 & 4 & Óbito & Óbito \\
\hline 22 & 5 & 4 & 4 & 4 & 4 & 4 & 3 & 3 & 3 & 3 \\
\hline 23 & 5 & 5 & 5 & Óbito & Óbito & 5 & 4 & 4 & Óbito & Óbito \\
\hline 24 & 4 & 4 & 4 & 5 & Óbito & 5 & 4 & 4 & 4 & Óbito \\
\hline 25 & 5 & 4 & 4 & 5 & Óbito & 4 & 3 & 3 & 4 & Óbito \\
\hline 26 & 5 & 4 & 4 & 4 & 3 & 4 & 4 & 3 & 3 & 3 \\
\hline 27 & 4 & 3 & 3 & 3 & 3 & 4 & 3 & 3 & 3 & 3 \\
\hline 28 & FALHA & FALHA & FALHA & FALHA & FALHA & FALHA & FALHA & FALHA & FALHA & FALHA \\
\hline 29 & FALHA & FALHA & FALHA & FALHA & FALHA & FALHA & FALHA & FALHA & FALHA & FALHA \\
\hline 30 & 5 & 3 & 3 & 3 & 3 & 4 & 4 & 4 & 3 & 3 \\
\hline 31 & 4 & 3 & 3 & 3 & 4 & 3 & 3 & 3 & 3 & 3 \\
\hline 32 & 4 & 3 & 4 & 4 & Óbito & 4 & 4 & 3 & 4 & Óbito \\
\hline
\end{tabular}




\begin{tabular}{|c|c|c|c|c|c|c|c|c|c|c|}
\hline \multirow[b]{2}{*}{ Paciente } & \multicolumn{5}{|c|}{ Questão 3} & \multicolumn{5}{|c|}{ Questão 4} \\
\hline & Pré & $\begin{array}{c}7 \\
\text { dias }\end{array}$ & $\begin{array}{c}1 \\
\text { mês }\end{array}$ & $\begin{array}{c}2 \\
\text { meses }\end{array}$ & $\begin{array}{c}3 \\
\text { meses }\end{array}$ & Pré & $\begin{array}{c}7 \\
\text { dias }\end{array}$ & $\begin{array}{c}1 \\
\text { mês }\end{array}$ & $\begin{array}{c}2 \\
\text { meses }\end{array}$ & $\begin{array}{c}3 \\
\text { meses }\end{array}$ \\
\hline 1 & 15 & 16 & 18 & 15 & Óbito & 4 & 4 & 5 & 4 & Óbito \\
\hline 2 & 14 & 15 & 20 & 20 & 20 & 4 & 5 & 4 & 6 & 5 \\
\hline 3 & 16 & 18 & 18 & 20 & 22 & 4 & 4 & 4 & 5 & 6 \\
\hline 4 & 17 & 17 & 20 & 21 & 22 & 5 & 5 & 6 & 5 & 5 \\
\hline 5 & FALHA & FALHA & FALHA & FALHA & FALHA & FALHA & FALHA & FALHA & FALHA & FALHA \\
\hline 6 & 10 & 10 & 10 & Óbito & Óbito & 5 & 5 & 4 & Óbito & Óbito \\
\hline 7 & 16 & 15 & 18 & 18 & Óbito & 4 & 4 & 6 & 6 & Óbito \\
\hline 8 & 18 & 22 & 20 & 18 & Óbito & 4 & 5 & 5 & 4 & Óbito \\
\hline 9 & 15 & 21 & 21 & 20 & Óbito & 4 & 5 & 6 & 5 & Óbito \\
\hline 10 & 17 & 16 & 17 & 18 & Óbito & 4 & 4 & 5 & 5 & Óbito \\
\hline 11 & 16 & 18 & 20 & 20 & 22 & 5 & 6 & 6 & 6 & 7 \\
\hline 12 & 14 & 15 & 20 & 22 & 24 & 4 & 6 & 6 & 6 & 5 \\
\hline 13 & 13 & 16 & 17 & 17 & Óbito & 4 & 4 & 4 & 4 & Óbito \\
\hline 14 & 16 & 16 & 18 & 18 & Óbito & 4 & 5 & 5 & 5 & Óbito \\
\hline 15 & 15 & 15 & 14 & 18 & 19 & 4 & 6 & 6 & 5 & 6 \\
\hline 16 & 17 & 21 & 22 & 20 & Óbito & 4 & 4 & 6 & 5 & Óbito \\
\hline 17 & 15 & 17 & 17 & 24 & 20 & 4 & 6 & 6 & 6 & 6 \\
\hline 18 & 14 & 13 & 17 & 22 & Óbito & 4 & 5 & 5 & 5 & Óbito \\
\hline 19 & 14 & 14 & 23 & 21 & 21 & 5 & 5 & 5 & 5 & 6 \\
\hline 20 & 16 & 17 & 18 & 16 & Óbito & 4 & 5 & 5 & 6 & Óbito \\
\hline 21 & 18 & 20 & 21 & Óbito & Óbito & 4 & 6 & 4 & Óbito & Óbito \\
\hline 22 & 17 & 22 & 23 & 24 & 20 & 4 & 4 & 5 & 5 & 6 \\
\hline 23 & 15 & 20 & 20 & Óbito & Óbito & 4 & 5 & 5 & Óbito & Óbito \\
\hline 24 & 15 & 16 & 24 & 20 & Óbito & 4 & 5 & 5 & 5 & Óbito \\
\hline 25 & 16 & 22 & 20 & 18 & Óbito & 5 & 5 & 5 & 5 & Óbito \\
\hline 26 & 16 & 22 & 22 & 24 & 21 & 4 & 5 & 5 & 6 & 4 \\
\hline 27 & 14 & 16 & 19 & 20 & 21 & 4 & 5 & 5 & 5 & 4 \\
\hline 28 & FALHA & FALHA & FALHA & FALHA & FALHA & FALHA & FALHA & FALHA & FALHA & FALHA \\
\hline 29 & FALHA & FALHA & FALHA & FALHA & FALHA & FALHA & FALHA & FALHA & FALHA & FALHA \\
\hline 30 & 17 & 22 & 22 & 21 & 22 & 4 & 5 & 5 & 5 & 6 \\
\hline 31 & 18 & 16 & 20 & 22 & 23 & 4 & 4 & 6 & 6 & 6 \\
\hline 32 & 13 & 15 & 18 & 18 & Óbito & 4 & 4 & 5 & 5 & Óbito \\
\hline
\end{tabular}




\begin{tabular}{|c|c|c|c|c|c|c|c|c|c|c|}
\hline \multirow[b]{2}{*}{ Paciente } & \multicolumn{5}{|c|}{ Questão 5} & \multicolumn{5}{|c|}{ Questão 6} \\
\hline & Pré & $\begin{array}{c}7 \\
\text { dias }\end{array}$ & $\begin{array}{c}1 \\
\text { mês }\end{array}$ & $\begin{array}{c}2 \\
\text { meses }\end{array}$ & $\begin{array}{c}3 \\
\text { meses }\end{array}$ & Pré & $\begin{array}{c}7 \\
\text { dias }\end{array}$ & $\begin{array}{c}1 \\
\text { mês }\end{array}$ & $\begin{array}{c}2 \\
\text { meses }\end{array}$ & $\begin{array}{c}3 \\
\text { meses }\end{array}$ \\
\hline 1 & 3 & 3 & 4 & 3 & Óbito & 5 & 5 & 4 & 5 & Óbito \\
\hline 2 & 3 & 5 & 5 & 5 & 4 & 5 & 4 & 4 & 4 & 4 \\
\hline 3 & 3 & 4 & 4 & 4 & 3 & 5 & 5 & 4 & 5 & 4 \\
\hline 4 & 3 & 4 & 5 & 5 & 4 & 4 & 4 & 3 & 3 & 3 \\
\hline 5 & FALHA & FALHA & FALHA & FALHA & FALHA & FALHA & FALHA & FALHA & FALHA & FALHA \\
\hline 6 & 4 & 3 & 3 & Óbito & Óbito & 4 & 3 & 4 & Óbito & Óbito \\
\hline 7 & 3 & 4 & 4 & 3 & Óbito & 5 & 4 & 3 & 4 & Óbito \\
\hline 8 & 3 & 5 & 5 & 4 & Óbito & 5 & 4 & 4 & 4 & Óbito \\
\hline 9 & 3 & 4 & 5 & 4 & Óbito & 5 & 5 & 4 & 4 & Óbito \\
\hline 10 & 3 & 4 & 4 & 4 & Óbito & 5 & 4 & 4 & 4 & Óbito \\
\hline 11 & 4 & 5 & 5 & 5 & 5 & 5 & 4 & 3 & 4 & 3 \\
\hline 12 & 4 & 4 & 6 & 6 & 5 & 4 & 4 & 3 & 3 & 3 \\
\hline 13 & 3 & 4 & 4 & 4 & Óbito & 4 & 3 & 4 & 4 & Óbito \\
\hline 14 & 3 & 4 & 5 & 4 & Óbito & 4 & 4 & 3 & 4 & Óbito \\
\hline 15 & 4 & 4 & 4 & 4 & 4 & 5 & 3 & 3 & 3 & 3 \\
\hline 16 & 3 & 4 & 3 & 4 & Óbito & 4 & 4 & 3 & 4 & Óbito \\
\hline 17 & 4 & 3 & 4 & 4 & 4 & 5 & 4 & 3 & 4 & 4 \\
\hline 18 & 3 & 5 & 5 & 4 & Óbito & 5 & 5 & 4 & 4 & Óbito \\
\hline 19 & 4 & 5 & 5 & 5 & 5 & 5 & 4 & 3 & 4 & 3 \\
\hline 20 & 3 & 4 & 5 & 4 & Óbito & 5 & 4 & 3 & 4 & Óbito \\
\hline 21 & 3 & 4 & 4 & Óbito & Óbito & 4 & 4 & 4 & Óbito & Óbito \\
\hline 22 & 4 & 4 & 4 & 5 & 4 & 5 & 3 & 3 & 3 & 3 \\
\hline 23 & 3 & 4 & 4 & Óbito & Óbito & 5 & 3 & 4 & Óbito & Óbito \\
\hline 24 & 4 & 4 & 5 & 3 & Óbito & 5 & 4 & 4 & 4 & Óbito \\
\hline 25 & 3 & 4 & 4 & 4 & Óbito & 5 & 4 & 3 & 4 & Óbito \\
\hline 26 & 3 & 4 & 4 & 6 & 4 & 5 & 5 & 4 & 4 & 3 \\
\hline 27 & 4 & 4 & 4 & 5 & 5 & 4 & 4 & 3 & 4 & 4 \\
\hline 28 & FALHA & FALHA & FALHA & FALHA & FALHA & FALHA & FALHA & FALHA & FALHA & FALHA \\
\hline 29 & FALHA & FALHA & FALHA & FALHA & FALHA & FALHA & FALHA & FALHA & FALHA & FALHA \\
\hline 30 & 3 & 4 & 4 & 5 & 5 & 4 & 4 & 3 & 3 & 4 \\
\hline 31 & 3 & 4 & 5 & 5 & 4 & 5 & 3 & 3 & 3 & 3 \\
\hline 32 & 3 & 5 & 5 & 4 & Óbito & 5 & 4 & 3 & 4 & Óbito \\
\hline
\end{tabular}




\begin{tabular}{|c|c|c|c|c|c|c|c|c|c|c|}
\hline \multirow[b]{2}{*}{ Paciente } & \multicolumn{5}{|c|}{ Questão 7} & \multicolumn{5}{|c|}{ Questão 8} \\
\hline & Pré & $\begin{array}{c}7 \\
\text { dias }\end{array}$ & $\begin{array}{c}1 \\
\text { mês }\end{array}$ & $\begin{array}{c}2 \\
\text { meses }\end{array}$ & $\begin{array}{c}3 \\
\text { meses }\end{array}$ & Pré & $\begin{array}{c}7 \\
\text { dias }\end{array}$ & $\begin{array}{c}1 \\
\text { mês }\end{array}$ & $\begin{array}{c}2 \\
\text { meses }\end{array}$ & $\begin{array}{c}3 \\
\text { meses }\end{array}$ \\
\hline 1 & 4 & 3 & 2 & 2 & Óbito & 4 & 3 & 3 & 3 & Óbito \\
\hline 2 & 1 & 1 & 2 & 1 & 1 & 1 & 1 & 1 & 2 & 1 \\
\hline 3 & 1 & 1 & 1 & 1 & 2 & 1 & 1 & 1 & 1 & 1 \\
\hline 4 & 3 & 1 & 1 & 2 & 1 & 3 & 2 & 2 & 1 & 2 \\
\hline 5 & FALHA & FALHA & FALHA & FALHA & FALHA & FALHA & FALHA & FALHA & FALHA & FALHA \\
\hline 6 & 5 & 3 & 3 & Óbito & Óbito & 4 & 3 & 3 & Óbito & Óbito \\
\hline 7 & 4 & 3 & 4 & 4 & Óbito & 3 & 3 & 2 & 2 & Óbito \\
\hline 8 & 4 & 3 & 3 & 3 & Óbito & 3 & 3 & 3 & 2 & Óbito \\
\hline 9 & 5 & 3 & 3 & 4 & Óbito & 4 & 3 & 3 & 3 & Óbito \\
\hline 10 & 1 & 1 & 2 & 4 & Óbito & 1 & 1 & 1 & 3 & Óbito \\
\hline 11 & 5 & 3 & 2 & 2 & 2 & 4 & 2 & 2 & 2 & 3 \\
\hline 12 & 1 & 1 & 1 & 2 & 1 & 1 & 1 & 1 & 1 & 3 \\
\hline 13 & 4 & 2 & 2 & 2 & Óbito & 4 & 2 & 3 & 2 & Óbito \\
\hline 14 & 4 & 2 & 2 & 3 & Óbito & 3 & 2 & 2 & 2 & Óbito \\
\hline 15 & 1 & 1 & 1 & 2 & 2 & 1 & 1 & 1 & 2 & 1 \\
\hline 16 & 1 & 1 & 1 & 2 & Óbito & 1 & 1 & 1 & 2 & Óbito \\
\hline 17 & 5 & 2 & 2 & 3 & 2 & 4 & 3 & 2 & 2 & 2 \\
\hline 18 & 4 & 2 & 2 & 3 & Óbito & 5 & 3 & 3 & 4 & Óbito \\
\hline 19 & 4 & 2 & 2 & 2 & 2 & 3 & 2 & 2 & 2 & 2 \\
\hline 20 & 5 & 2 & 2 & 3 & Óbito & 4 & 2 & 2 & 5 & Óbito \\
\hline 21 & 5 & 3 & 3 & Óbito & Óbito & 3 & 2 & 2 & Óbito & Óbito \\
\hline 22 & 1 & 1 & 1 & 3 & 2 & 1 & 1 & 1 & 1 & 2 \\
\hline 23 & 1 & 1 & 2 & Óbito & Óbito & 1 & 1 & 2 & Óbito & Óbito \\
\hline 24 & 4 & 2 & 2 & 2 & Óbito & 3 & 1 & 1 & 1 & Óbito \\
\hline 25 & 5 & 3 & 2 & 3 & Óbito & 3 & 3 & 1 & 2 & Óbito \\
\hline 26 & 5 & 3 & 2 & 3 & 2 & 4 & 2 & 1 & 1 & 1 \\
\hline 27 & 4 & 2 & 2 & 3 & 2 & 3 & 2 & 2 & 2 & 2 \\
\hline 28 & FALHA & FALHA & FALHA & FALHA & FALHA & FALHA & FALHA & FALHA & FALHA & FALHA \\
\hline 29 & FALHA & FALHA & FALHA & FALHA & FALHA & FALHA & FALHA & FALHA & FALHA & FALHA \\
\hline 30 & 5 & 2 & 2 & 3 & 3 & 4 & 2 & 3 & 1 & 1 \\
\hline 31 & 4 & 2 & 1 & 2 & 3 & 3 & 1 & 2 & 1 & 2 \\
\hline 32 & 4 & 3 & 1 & 2 & Óbito & 3 & 1 & 3 & 2 & Óbito \\
\hline
\end{tabular}




\begin{tabular}{|c|c|c|c|c|c|c|c|c|c|c|}
\hline \multirow[b]{2}{*}{ Paciente } & \multicolumn{5}{|c|}{ Questão 9} & \multicolumn{5}{|c|}{ Questão 10} \\
\hline & Pré & $\begin{array}{c}7 \\
\text { dias }\end{array}$ & $\begin{array}{c}1 \\
\text { mês }\end{array}$ & $\begin{array}{c}2 \\
\text { meses }\end{array}$ & $\begin{array}{c}3 \\
\text { meses }\end{array}$ & Pré & $\begin{array}{c}7 \\
\text { dias }\end{array}$ & $\begin{array}{c}1 \\
\text { mês }\end{array}$ & $\begin{array}{c}2 \\
\text { meses }\end{array}$ & $\begin{array}{c}3 \\
\text { meses }\end{array}$ \\
\hline 1 & 28 & 24 & 25 & 28 & Óbito & 2 & 3 & 3 & 3 & Óbito \\
\hline 2 & 27 & 26 & 24 & 27 & 28 & 4 & 4 & 4 & 4 & 4 \\
\hline 3 & 27 & 28 & 26 & 26 & 26 & 4 & 4 & 5 & 4 & 4 \\
\hline 4 & 24 & 25 & 27 & 27 & 24 & 2 & 3 & 3 & 3 & 2 \\
\hline 5 & FALHA & FALHA & FALHA & FALHA & FALHA & FALHA & FALHA & FALHA & FALHA & FALHA \\
\hline 6 & 29 & 30 & 29 & Óbito & Óbito & 2 & 3 & 3 & Óbito & Óbito \\
\hline 7 & 25 & 26 & 29 & 25 & Óbito & 3 & 3 & 4 & 2 & Óbito \\
\hline 8 & 29 & 25 & 26 & 28 & Óbito & 2 & 3 & 3 & 2 & Óbito \\
\hline 9 & 27 & 29 & 30 & 33 & Óbito & 1 & 3 & 3 & 3 & Óbito \\
\hline 10 & 27 & 28 & 36 & 32 & Óbito & 4 & 4 & 4 & 3 & Óbito \\
\hline 11 & 29 & 31 & 28 & 28 & 30 & 3 & 4 & 4 & 3 & 4 \\
\hline 12 & 27 & 27 & 36 & 32 & 33 & 5 & 5 & 5 & 5 & 4 \\
\hline 13 & 25 & 26 & 33 & 29 & Óbito & 3 & 4 & 5 & 4 & Óbito \\
\hline 14 & 30 & 34 & 34 & 30 & Óbito & 2 & 4 & 4 & 4 & Óbito \\
\hline 15 & 27 & 28 & 30 & 25 & 28 & 4 & 4 & 4 & 4 & 3 \\
\hline 16 & 28 & 30 & 26 & 22 & Óbito & 4 & 4 & 4 & 4 & Óbito \\
\hline 17 & 30 & 33 & 28 & 29 & 26 & 3 & 3 & 4 & 3 & 4 \\
\hline 18 & 27 & 29 & 28 & 24 & Óbito & 2 & 3 & 3 & 3 & Óbito \\
\hline 19 & 33 & 30 & 28 & 29 & 30 & 2 & 3 & 4 & 4 & 2 \\
\hline 20 & 30 & 32 & 34 & 35 & Óbito & 2 & 3 & 3 & 3 & Óbito \\
\hline 21 & 33 & 29 & 28 & Óbito & Óbito & 3 & 4 & 4 & Óbito & Óbito \\
\hline 22 & 26 & 25 & 27 & 26 & 32 & 5 & 5 & 5 & 5 & 5 \\
\hline 23 & 28 & 25 & 30 & Óbito & Óbito & 4 & 4 & 4 & Óbito & Óbito \\
\hline 24 & 28 & 27 & 29 & 27 & Óbito & 3 & 4 & 4 & 3 & Óbito \\
\hline 25 & 33 & 29 & 30 & 32 & Óbito & 2 & 3 & 4 & 3 & Óbito \\
\hline 26 & 34 & 33 & 28 & 27 & 26 & 2 & 4 & 4 & 3 & 4 \\
\hline 27 & 33 & 28 & 28 & 26 & 22 & 3 & 3 & 3 & 2 & 4 \\
\hline 28 & FALHA & FALHA & FALHA & FALHA & FALHA & FALHA & FALHA & FALHA & FALHA & FALHA \\
\hline 29 & FALHA & FALHA & FALHA & FALHA & FALHA & FALHA & FALHA & FALHA & FALHA & FALHA \\
\hline 30 & 27 & 29 & 33 & 30 & 29 & 3 & 4 & 4 & 3 & 4 \\
\hline 31 & 33 & 29 & 25 & 28 & 22 & 2 & 4 & 3 & 4 & 3 \\
\hline 32 & 32 & 28 & 33 & 27 & Óbito & 3 & 3 & 3 & 2 & Óbito \\
\hline
\end{tabular}




\begin{tabular}{|c|c|c|c|c|c|}
\hline \multirow[b]{2}{*}{ Paciente } & \multicolumn{5}{|c|}{ Questão 11} \\
\hline & Pré & $\begin{array}{c}7 \\
\text { dias }\end{array}$ & $\begin{array}{c}1 \\
\text { mês }\end{array}$ & $\begin{array}{c}2 \\
\text { meses }\end{array}$ & $\begin{array}{c}3 \\
\text { meses }\end{array}$ \\
\hline 1 & 16 & 16 & 12 & 12 & Óbito \\
\hline 2 & 14 & 15 & 12 & 12 & 12 \\
\hline 3 & 16 & 17 & 15 & 16 & 14 \\
\hline 4 & 14 & 15 & 12 & 10 & 12 \\
\hline 5 & FALHA & FALHA & FALHA & FALHA & FALHA \\
\hline 6 & 16 & 10 & 8 & Óbito & Óbito \\
\hline 7 & 18 & 14 & 14 & 12 & Óbito \\
\hline 8 & 16 & 15 & 16 & 15 & Óbito \\
\hline 9 & 17 & 13 & 15 & 13 & Óbito \\
\hline 10 & 17 & 14 & 15 & 18 & Óbito \\
\hline 11 & 18 & 12 & 14 & 13 & 13 \\
\hline 12 & 14 & 16 & 11 & 13 & 13 \\
\hline 13 & 18 & 15 & 15 & 14 & Óbito \\
\hline 14 & 16 & 16 & 17 & 12 & Óbito \\
\hline 15 & 15 & 14 & 11 & 12 & 11 \\
\hline 16 & 16 & 15 & 14 & 12 & Óbito \\
\hline 17 & 12 & 14 & 9 & 12 & 10 \\
\hline 18 & 15 & 13 & 13 & 12 & Óbito \\
\hline 19 & 16 & 14 & 15 & 10 & 12 \\
\hline 20 & 14 & 14 & 12 & 15 & Óbito \\
\hline 21 & 16 & 14 & 13 & Óbito & Óbito \\
\hline 22 & 13 & 11 & 10 & 9 & 9 \\
\hline 23 & 15 & 11 & 12 & Óbito & Óbito \\
\hline 24 & 16 & 14 & 13 & 11 & Óbito \\
\hline 25 & 16 & 10 & 13 & 14 & Óbito \\
\hline 26 & 14 & 12 & 10 & 10 & 12 \\
\hline 27 & 14 & 12 & 10 & 12 & 13 \\
\hline 28 & FALHA & FALHA & FALHA & FALHA & FALHA \\
\hline 29 & FALHA & FALHA & FALHA & FALHA & FALHA \\
\hline 30 & 14 & 12 & 10 & 11 & 13 \\
\hline 31 & 12 & 14 & 12 & 11 & 2 \\
\hline 32 & 14 & 11 & 17 & 12 & Óbito \\
\hline
\end{tabular}




\section{REFERÊNCIAS}


Aabakken L, Bretthauer M, Line PD. Double-balloon enteroscopy for endoscopic retrograde cholangiography in patients with a Roux-en-Y anastomosis. Endoscopy. 2007; 39(12):1068-71.

Andersen JR, Sørensen SM, Kruse A, Rokkjaer M, Matzen P. Randomised trial of endoscopic endoprosthesis versus operative bypass in malignant obstructive jaundice. Gut. 1989; 30(8):1132-5.

Andersson M, Kostic S, Johansson M, Lundell L, Asztély M, Hellström M. MRI combined with MR cholangiopancreatography versus helical CT in the evaluation of patients with suspected periampullary tumors: a prospective comparative study. Acta Radiol. 2005; 46(1):16-27.

Ang TL, Teo EK, Fock KM. Eus-guided transduodenal biliary drainage in unresectable pancreatic cancer with obstructive jaundice. JOP. 2007; 8(4):438-443.

Artifon EL, Ferreira FC, Sakai P. Endoscopic ultrasound-guided biliary drainage. Korean J Radiol. 2012b; 13(Suppl 1):S74-82.

Artifon ELA, Chaves DM, Ishioka S, Souza TF, Matuguma SE, Sakai P. Echoguided hepatico-gastrostomy: a case report. Clinics. 2007; 62:799-802. 
Artifon ELA, Ferreira FC, Otoch JP. Endoscopic ultrasound-guided choledochoduodenostomy for relieving malignant distal biliary obstruction. Rev Gastroenterol Mex. 2012a; 77(1):31-7.

Artifon ELA, Okawa L, Takada J, Gupta K, Moura EG, Sakai P. EUS-guided choledochoantrostomy: an alternative for biliary drainage in unresectable pancreatic cancer with duodenal invasion. Gastrointest Endosc. 2011a; 73(6):1317-20.

Artifon ELA, Safatle-Ribeiro AV, Ferreira FC, Poli-de-Figueiredo L, Rasslan S, Carnevale F, Otoch JP, Sakai P, Kahaleh M. EUS-guided antegrade transhepatic placement of a self-expandable metal stent in hepatico-jejunal anastomosis. JOP. 2011b; 9;12(6):610-3.

Artifon ELA, Takada J, Okawa L, Moura EG, Sakai P. EUS-guided choledochoduodenostomy for biliary drainage in unresectable pancreatic cancer: a case series. JOP. 2010; 11(6):597-600.

Bakkevold KE, Kambestad B. Morbidity and mortality after radical and palliative pancreatic cancer surgery. Risk factors influencing the short-term results. Ann Surg. 1993; 217(4):356-68

Bergasa NV. Medical palliation of the jaundiced patient with pruritus. Gastroenterol Clin North Am. 2006; 35(1):113-23.

Bories E, Pesenti C, Caillol F, Lopes C, Giovannini M. Transgastric endoscopic ultrasonography-guided biliary drainage: results of a pilot study. Endoscopy. 2007; 39(4):287-91 
Boring CC, Squires TS, Tong T, Montgomery S. Cancer statistics 1994. CA Cancer J Clin. 1994; 44(1):7-26.

Brauer BC, Chen YK, Fukami N, Shah RJ. Single-operator EUS-guided cholangiopancreatography for difficult pancreaticobiliary access (with video). Gastrointest Endosc. 2009; 70(3):471-9.

Burmester E, Niehaus J, Leineweber T, Huetteroth T. EUS-cholangiodrainage of the bile duct: Report of 4 cases. Gastrointest Endosc. 2003; 57(2):246-251.

Calvo MM, Bujanda L, Heras I, Cabriada JL, Bernal A, Orive V, Miguelez J. The rendezvous technique for the treatment of choledocholithiasis. Gastrointest Endosc. 2001; 54(4):511-3.

Carr-Locke DL. Overview of the role of ERCP in the management of diseases of the biliary tract and the pancreas. Gastrointest Endosc. 2002; 56(6 Suppl):S157-60.

Chang WH, Kortan P, Haber GB. Outcome in patients with bifurcation tumors who undergo unilateral versus bilateral hepatic duct drainage. Gastrointest Endosc. 1998; 47(5):354-62.

Choudari CP, Sherman S, Fogel EL, Phillips S, Kochell A, Flueckiger J, Lehman GA. Success of ERCP at a referral center after a previously unsuccessful attempt. Gastrointest Endosc. 2000; 52(4):478-83. 
Chu YC, Yang CC, Yeh YH, Chen CH, Yueh SK. Double-balloon enteroscopy application in biliary tract disease-its therapeutic and diagnostic functions. Gastrointest Endosc. 2008; 68(3):585-91.

Clary B, Jarnigan W, Pitt H, Gores G, Busuttil R, Pappas T. Hilar cholangiocarcinoma. J Gastrointest Surg. 2004; 8(3):298-302.

De Palma GD, Galloro G, Romano G, Sottile R, Puzziello A, Persico F, Masone S, Labianca O, Persico G. Long-term follow-up after endoscopic biliary stent placement for bile duct strictures from laparoscopic cholecystectomy. Hepatogastroenterology. 2003; 50(53):1229-31.

Ferrucci JT Jr., Mueller PR, Harbin WP. Percutaneous transhepatic biliary drainage: technique, results, and applications. Radiology. 1980; 135(1):1-13.

Fogel EL, Sherman S, Devereaux BM, Lehman GA. Therapeutic biliary endoscopy. Endoscopy. 2001; 33(1):31-8.

Giovannini M, Moutardier V, Pesenti C, Bories E, Lelong B, Delpero JR. Endoscopic ultrasound-guided bilioduodenal anastomosis: A new technique for biliary drainage. Endoscopy. 2001; 33(10):898-900.

Gupta K, Mallery S, Hunter D, Freeman ML. Endoscopic ultrasound and percutaneous access for endoscopic biliary and pancreatic drainage after initially failed ERCP. Rev Gastroenterol Disord. 2007; 7(1):22-37. 
Harbin WP, Mueller PR, Ferrucci JT Jr. Transhepatic cholangiography: complications and use patterns of the fine-needle technique: a multiinstitutional survey. Radiology. 1980; 135(1):15-22.

Hatfield ARW. Palliation of malignant obstructive jaundice - surgery or stent? Gut. 1990; 31(12):1339-40.

Hii MW, Gibson RN. Role of radiology in the treatment of malignant hilar biliary strictures 1: review of the literature. Australas Radiol. 2004; 48(1):3-13.

Hintze RE, Abou-Rebyeh H, Adler A, Veltzke-Schlieker W, Felix R, Wiedenmann B. Magnetic resonance cholangiopancreatography-guided unilateral endoscopic stent placement for Klatskin tumors. Gastrointest Endosc. 2001; 53(1):40-6.

Huibregtse K KM. Endoscopic retrograde cholangiopancreatography, endoscopic sphincterotomy and endoscopic biliary and pancreatic drainage. In: T Y, e Textbook of gastroenterology. Philadelphia: J.B. Lippincott, 1995: 2590-617.

Kahaleh M, Hernandez AJ, Tokar J, Adams RB, Shami VM, Yeaton P. Interventional EUS guided cholangiography: evaluation of a technique in evolution. Gastrointest Endosc. 2006; 64(1):52-9.

Kida M, Miyazawa S, Iwai T, Ikeda H, Takezawa M, Kikuchi H, Watanabe M, Imaizumi $\mathrm{H}$, Koizumi W. Endoscopic management of malignant biliary obstruction by means of covered metallic stents: primary stent placement vs. re-intervention. Endoscopy. 2011; 43(12):1039-44. 
Kim YS, Gupta K, Mallery S, Li R, Kinney T, Freeman ML. Endoscopic ultrasound rendezvous for bile duct access using a transduodenal approach: cumulative experience at a single center. A case series. Endoscopy. 2010; 42(6):496-502.

Kirkwood BR, Sterne JAC. Essential medical statistics. 2. ed. Massachusetts: Blackwell Science. 2006. 502p.

Kleinbaum DG. Survival analysis: a self-learning text. 1. ed. New York: Springer. 1996. 324p.

Kumar S, Sherman S, Hawes RH, Lehman GA. Success and yield of second attempt ERCP. Gastrointest Endosc. 1995; 41(5):445-7.

Lake JR. Benign and malignant neoplasms of the gallbladder, bile ducts and ampulla. In: Sleisinger MH, Fordtran JS (Eds). Gastrointestinal disease. 5. ed. v. 2. Philadelphia: WB Saunders. 1993. p. 1891-902.

Lee SH, Park JK, Yoon WJ, Lee JK, Ryu JK, Yoon YB, Kim YT. Optimal biliary drainage for inoperable Klatskin's tumor based on Bismuth type. World J Gastroenterol. 2007; 13(29):3948-55.

Leung JW, Emery R, Cotton PB, Russell RC, Vallon AG, Mason RR. Management of malignant obstructive jaundice at The Middlesex Hospital. $\mathrm{Br}$ J Surg. 1983; 70(10):584-6.

Lillemoe KD, Cameron JL, Yeo CJ, Sohn TA, Nakeeb A, Sauter PK, Hruban $\mathrm{RH}$, Abrams RA, Pitt HA. Pancreaticoduodenectomy. Does it have a role in the palliation of pancreatic cancer? Ann Surg. 1996; 223(6):718-25. 
Lobo DN, Balfour TW, Iftikhar SY. Periampullary diverticula: consequences of failed ERCP. Ann R Coll Surg Engl. 1998; 80(5):326-31.

Mallery S, Matlock J, Freeman ML. EUS-guided rendezvous drainage of obstructed biliary and pancreatic ducts: report of 6 cases. Gastrointest Endosc. 2004; 59(1):100-7.

Maosheng D, Ohtsuka T, Ohuchida J, Inoue K, Yokohata K, Yamaguchi K, Chijiiwa K, Tanaka M. Surgical bypass versus metallic stent for unresectable pancreatic cancer. J Hepatobiliary Pancreat Surg. 2001; 8(4):367-73.

Maranki J HA, Arlan B, Jaffan AA, Angle JF, Shami VM, Kahaleh M. Interventional EUS-Guided Cholangiography (IEUC): Long Term Experience of an Emerging Alternative to Percutaneous Transhepatic Cholangiography (PTC) with Video. Endoscopy. 2009; 41(6):532-8.

Martin DF. Combined percutaneous and endoscopic procedures for bile duct obstruction. Gut. 1994; 35(8):1011-2.

McCullagh, P, Nelder, JA. Generalized linear models. 2. ed.: New York: Chapman and Hall. 1989. 511p.

McCune WS, Shorb PE, Moscovitz H. Endoscopic cannulation of the ampulla of vater: a preliminary report. Ann Surg. 1968; 167(5):752-756.

Molnar W, Stockum AE. Relief of obstructive jaundice through percutaneous transhepatic catheter--a new therapeutic method. Am J Roentgenol Radium Ther Nucl Med. 1974; 122(2):356-67. 
Neter J, Kutner MH, Nachtsheim CJ, Wasserman W. Applied linear statistical models. 4. ed. Ilinois: Richard D. Irwing. 1996. 1408p.

Nguyen-Tang T, Binmoeller KF, Sanchez-Yague A, Shah JN. Endoscopic ultrasound (EUS)-guided transhepatic anterograde self expandable metal stent (SEMS) placement across malignant biliary obstruction. Endoscopy. 2010; 42(3):232-36.

Park DH, Koo JE, Oh J, Lee YH, Moon SH, Lee SS, Seo DW, Lee SK, Kim MH. EUS-guided biliary drainage with one-step placement of a fully covered metal stent for malignant biliary obstruction: A prospective feasibility study. Am J Gastroenterol. 2009; 104(9):2168-74.

Perez-Miranda M, de la Serna C, Diez-Redondo P, Vila JJ. Endosonographyguided cholangiopancreatography as a salvage drainage procedure for obstructed biliary and pancreatic ducts. World J Gastrointest Endosc. 2010; 2(6):212-22.

Piñol V, Castells A, Bordas JM, Real MI, Llach J, Montañà X, Feu F, Navarro S. Percutaneous self-expanding metal stents versus endoscopic polyethylene endoprostheses for treating malignant biliary obstruction: randomized clinical trial. Radiology. 2002; 225(1):27-34.

Puspok A, Lomoschitz F, Dejaco C, Hejna M, Sautner T, Gangl A. Endoscopic ultrasound guided therapy of benign and malignant biliary obstruction: A case series. Am J Gastroenterol. 2005; 100(8):1743-1747. 
Saluja SS, Sharma R, Pal S, Sahni P, Chattopadhyay TK. Differentiation between benign and malignant hilar obstructions using laboratory and radiological investigations: a prospective study. HPB (Oxford). 2007; 9(5):373-82.

Schöfl R. Diagnostic endoscopic retrograde cholangiopancreatography. Endoscopy. 2001; 33(2):147-57.

Shepherd HA, Royle G, Ross AP, Diba A, Arthur M, Colin-Jones D. Endoscopic biliary endoprosthesis in the palliation of malignant obstruction of the distal common bile duct: a randomized trial. $\mathrm{Br} J$ Surg. 1988; 75(12):1166-8.

Smith AC, Dowsett JF, Russell RC, Hatfield AR, Cotton PB. Randomised trial of endoscopic stenting versus surgical bypass in malignant low bileduct obstruction. Lancet. 1994; 344(8938):1655-60.

Soto JA, Alvarez O, Lopera JE, Múnera F, Restrepo JC, Correa G. Biliary obstruction: findings at MR cholangiography and crosssectional MR imaging. Radiographics. 2000; 20:353-66.

Speer AG, Cotton PB, Russell RC, Mason RR, Hatfield AR, Leung JW, MacRae KD, Houghton J, Lennon CA.Randomised trial of endoscopic versus percutaneous stent insertion in malignant obstructive jaundice. Lancet. 1987; $11 ; 2(8550): 57-62$.

Stanley J, Gobien RP, Cunningham J, Andriole J. Biliary decompression: an institutional comparison of percutaneous and endoscopic methods. Radiology. 1986; 158(1):195-7. 
Sunpaweravong S, Ovartlarnporn B, Khow-ean U, Soontrapornchai $\mathrm{P}$, Charoonratana V. Endoscopic stenting versus surgical bypass in advanced malignant distal bile duct obstruction: cost-effectiveness analysis. Asian $J$ Surg. 2005; 28(4):262-5.

Suzuki S, Kurachi K, Yokoi Y, Tsuchiya Y, Okamoto K, Okumura T, Inaba K, Konno H, Nakamura S. Intrahepatic cholangiojejunostomy for unresectable malignant biliary tumors with obstructive jaundice. $J$ Hepatobiliary Pancreat Surg. 2001; 8(2):124-9.

Tarantino I, Barresi L, Repici A, Traina M. EUS-guided biliary drainage: A case series. Endoscopy. 2008; 40(4): 336-9.

Trede M. Treatment of pancreatic carcinoma: the surgeon's dilemma. $\mathrm{Br} \mathrm{J}$ Surg. $1987 ; 74(2): 79-80$.

van den Bosch RP, van der Schelling GP, Klinkenbijl JH, Mulder PG, van Blankenstein M, Jeekel J. Guidelines for the application of surgery and endoprostheses in the palliation of obstructive jaundice in advanced cancer of the pancreas. Ann Surg. 1994; 219(1):18-24.

Venturelli MF, Cárcamo IC, Born GM, Venegas OL, Bertrán VM, Venturelli LA, Felmer EO. Cáncer vesicular en colecistectomías: Análisis de sobrevida y factores pronósticos. Rev Chil Cir. 2008; 60(4): 277-81.

Vila JJ, Artifon EL, Otoch JP. Post-endoscopic retrograde cholangiopancreatography complications: How can they be avoided? World $J$ Gastrointest Endosc. 2012; 4(6):241-246. 
Wiersema, M. J., Sandusky D, Carr R, Wiersema LM, Erdel WC, Frederick PK. Endosonography-guided cholangiopancreatography. Gastrointest Endosc. 1996; 43(2 Pt 1):102-6.

Wilson JA, Hoffman B, Hawes $\mathrm{RH}$, Romagnuolo J. EUS in patients with surgically altered upper GI anatomy. Gastrointest Endosc. 2010; 72(5):94753.

Wright BE, Cass OW, Freeman ML. ERCP in patients with long-limb Rouxen-Y gastrojejunostomy and intact papilla. Gastrointest Endosc. 2002. 